\title{
THE EMERGENCE OF A NEW NORDIC FOOD CULTURE
}

Final report from the program New Nordic Food II, 2010-2014

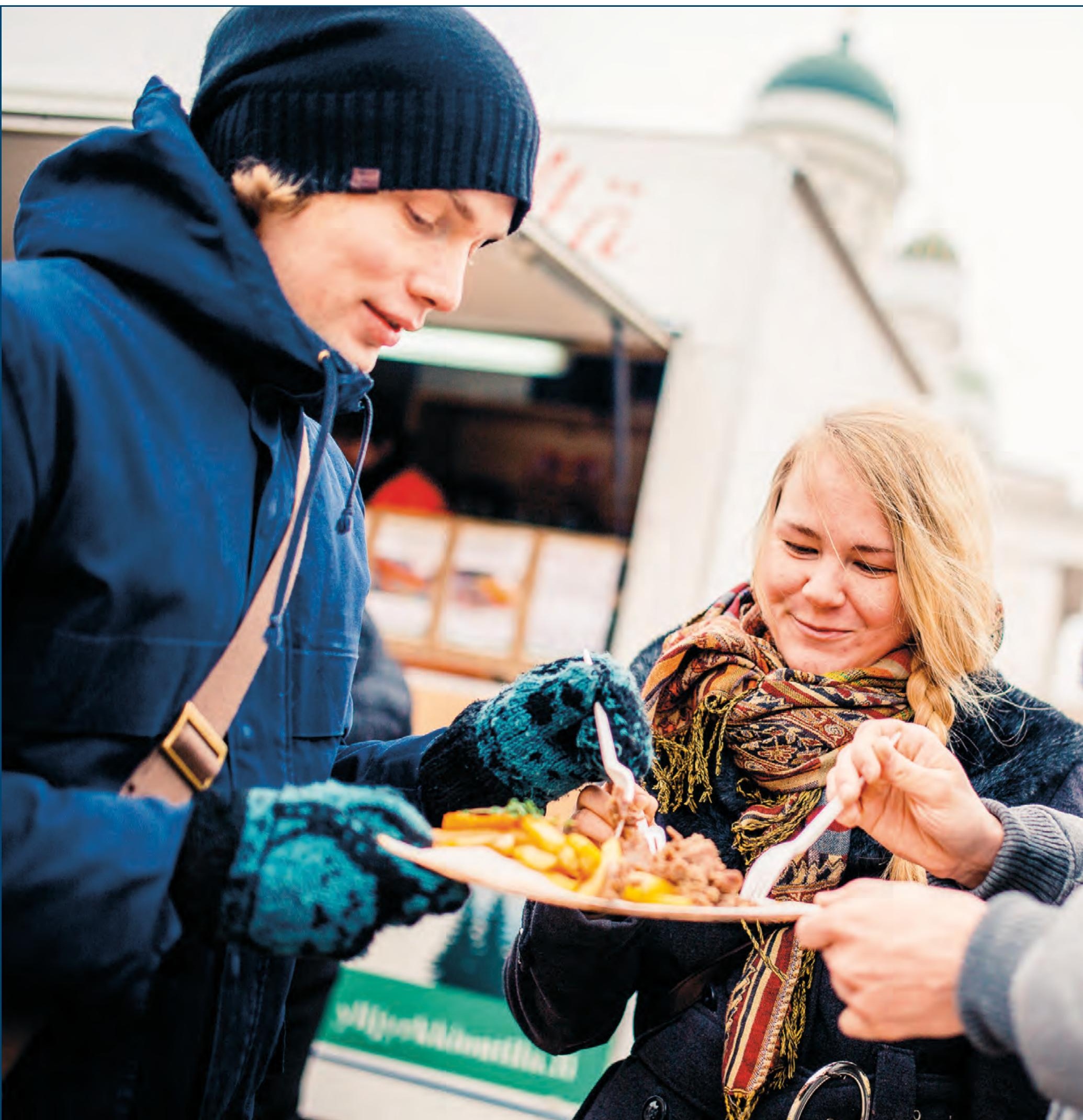




\section{THE EMERGENCE OF A NEW NORDIC FOOD CULTURE \\ FINAL REPORT FROM THE PROGRAM NEW NORDIC FOOD II, 2010-2014}

ISBN 978-92-893-4154-7 (PRINT)

ISBN 978-92-893-4155-4 (PDF)

HTTP://DX.DOI.ORG/10.6027/ANP2015-723

ANP 2015:723

C NORDIC COUNCIL OF MINISTERS 2015

LAYOUT: LOUISE M. JEPPESEN - WWW.KEEPYOURDARLINGS.COM

COVER PHOTO: STREAT HELSINKI - JUSSI HELLSTEN

PRINT: ROSENDAHLS SCHULTZ GRAFISK

COPIES: 200

TYPEFACE: META

PRINTED IN DENMARK

This publication has been published with financial support by the Nordic Council of Ministers. However, the contents of this publication do not necessarily reflect the views, policies or recommendations of the Nordic Council of Ministers.

www.norden.org/nordpub

\section{Nordic co-operation}

Nordic co-operation is one of the world's most extensive forms of regional collaboration, involving Denmark, Finland, Iceland, Norway, Sweden, and the Faroe Islands, Greenland, and Åland.

Nordic co-operation has firm traditions in politics, the economy, and culture. It plays an import-ant role in European and international collaboration, and aims at creating a strong Nordic community in a strong Europe.

Nordic co-operation seeks to safeguard Nordic and regional interests and principles in the global community. Common Nordic values help the region solidify its position as one of the world's most innovative and competitive.

Nordic Council of Ministers

Ved Stranden 18

DK-1061 Copenhagen K

Phone (+45) 33960200

www.norden.org 


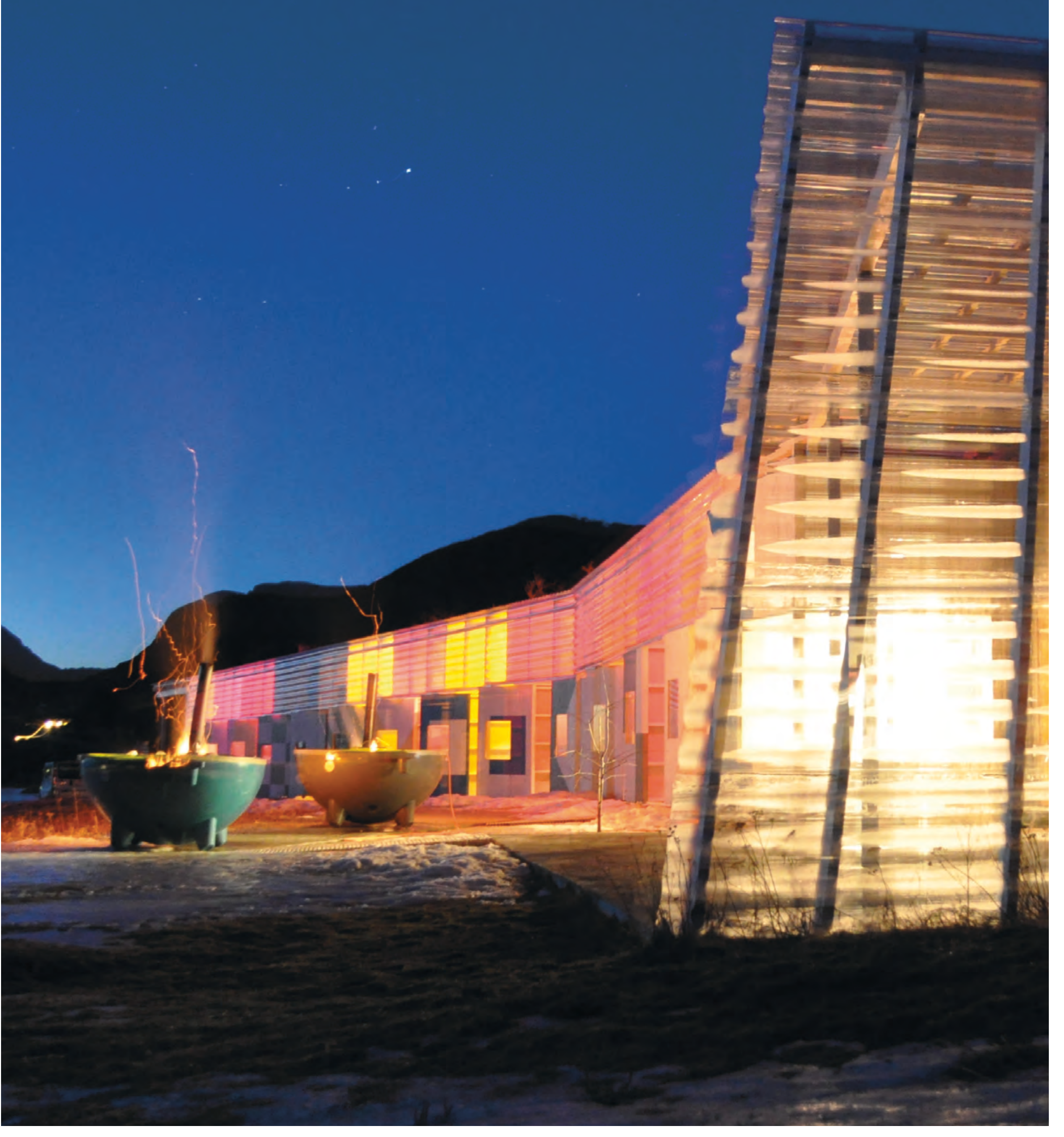




\section{CONTENT}

IN RETROSPECT AND LOOKING FORWARD WITH NEW NORDIC FOOD

NORDIC FOOD IS A MOVEMENT FOR THE FUTURE

NEW NORDIC FOOD 2010-2014 - A GREAT SUCCESS

NEW NORDIC FOOD II COMMUNICATION

NEW NORDIC FOOD II COMMUNICATION 2010-2014

NEW NORDIC FOOD II - IN THE WORLD

\#NORDICFOOD2024 - NORDIC FOOD FOR THE FUTURE

FOOD \& CREATIVE INDUSTRIES

INTERNATIONAL FOOD DESIGN EXPERIENCE, DUNEDIN, JULY 2014

JA JA JA FESTIVAL LONDON, NOVEMBER 2014

NORDIC PLAYLIST RADIO BAR ICELANDIC AIRWAVES, REYKJAVIK NOVEMBER 2014

NORDIC FOOD DIPLOMACY

NORDIC FOOD DIPLOMACY AND CREATING A WEB-BASED TOOL KIT

THE NORDIC COUNTRIES AS A SUSTAINABLE GASTRONOMIC REGION

STREAT HELSINKI, HELSINKI, MARCH 2014

NORTH NORDIC FOOD FESTIVAL IN NEW YORK, SEPTEMBER 2014

SCANDINAVIAN LIGHT \& DESIGN, VIENNA, NOVEMBER 2014

FOOD CULTURE AND YOUNG TALENTS

CHILDREN AND FOOD IN THE NORDIC REGION

CHILDREN AND FOOD IN THE NORDIC REGION, 2014

PUBLIC MEALS AS A FUTURE WELFARE SOLUTION

NEW NORDIC FOOD FOR MANY - IN NORDIC HIGHER EDUCATION

SME IN THE BIO-ECONOMY

ICELANDIC CHAMPIONSHIP WITH NORDIC PARTICIPANTS 2014

SEAWEED - THE UNIQUE FOOD OF THE NORTH

EVENT OVERVIEW - NEW NORDIC FOOD II

MIDWAY EVALUATION OF NNF II 


\section{IN RETROSPECT AND LOOKING FORWARD WITH NEW NORDIC FOOD}

New Nordic Food (NNF), based on the New Nordic Kitchen Manifest, has strived in the last eight
years to raise the profile of the Nordic cuisine and the meal experience both in the Nordic Region and internationally. Since the signing of the kitchen manifest, New Nordic Food has evolved into a Nordic social movement. Today, the challenge lies in taking that movement to a new level, so that the Nordic Region can become one of the most outstanding and innovative food regions in the world.

During the last mandate period 20102014, New Nordic Food II (NNF II) was assigned the task of managing various projects to highlight the possibilities that exist in the new Nordic cuisine. The Nordic Council of Ministers' globalisation initiative Culture and Creativity has also permeated the work of NNF II, amongst other things through the project KreaNord. This report presents the results of all the projects carried out over the last five years.
The activities in the programme have attracted considerable attention and this has generated a process of change within the food sector. It promotes regional products while using them in new ways. Within the scope of meals served in public institutions, there has been a successful launch of a discussion on how to improve both the nutritional status and the taste. Work with the Food \& Children project has increased the level of knowledge in food education. The Nordic Region as a

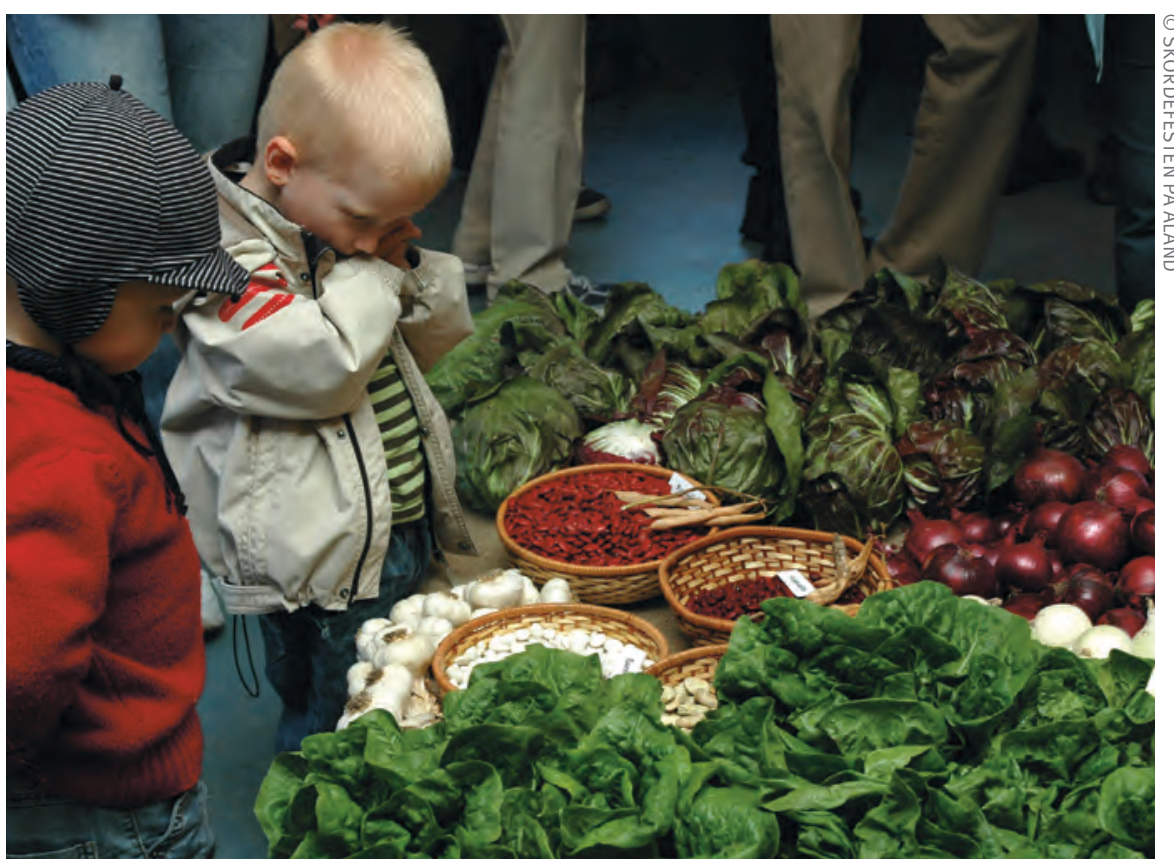

gastronomic region has attracted attention. Even internationally, Nordic food has drawn attention in a creative way. A good example is Street Food, which NNF II raised to a new level by making Nordic fast food from local raw material.

It is also interesting to read the interviews that New Nordic Food has done with some of the chefs, where they reflect over how much has happened since they signed the Nordic Kitchen Manifest, see page 66.

One of the reasons for this success is that the steering group entrusted the working groups and project managers to interpret their respective assignments in their own way, rather than having a controlling approach. This meant that the work has developed with great inspiration and creativity. This way of working, giving this freedom, also requires proving support and inspiration from the steering group. This is a balancing act that can always be improved. In future programmes we hope that the work to maintain creativity and inspiration will continue and that co-operation with the secretariat will intensify. How then can we move on? Can the Nordic Region continue to attract the same attention in the world; in the domestic kitchen, in restaurants and in the public kitchen? Can Nordic food emerge in completely new contexts? 


\section{"We must adapt our agriculture to other parameters, such as making the world's best, most interesting and healthy food. We will never be able to produce the world's cheapest food, which is probably not very interesting anyway."}

MATTIAS DAHLGREN

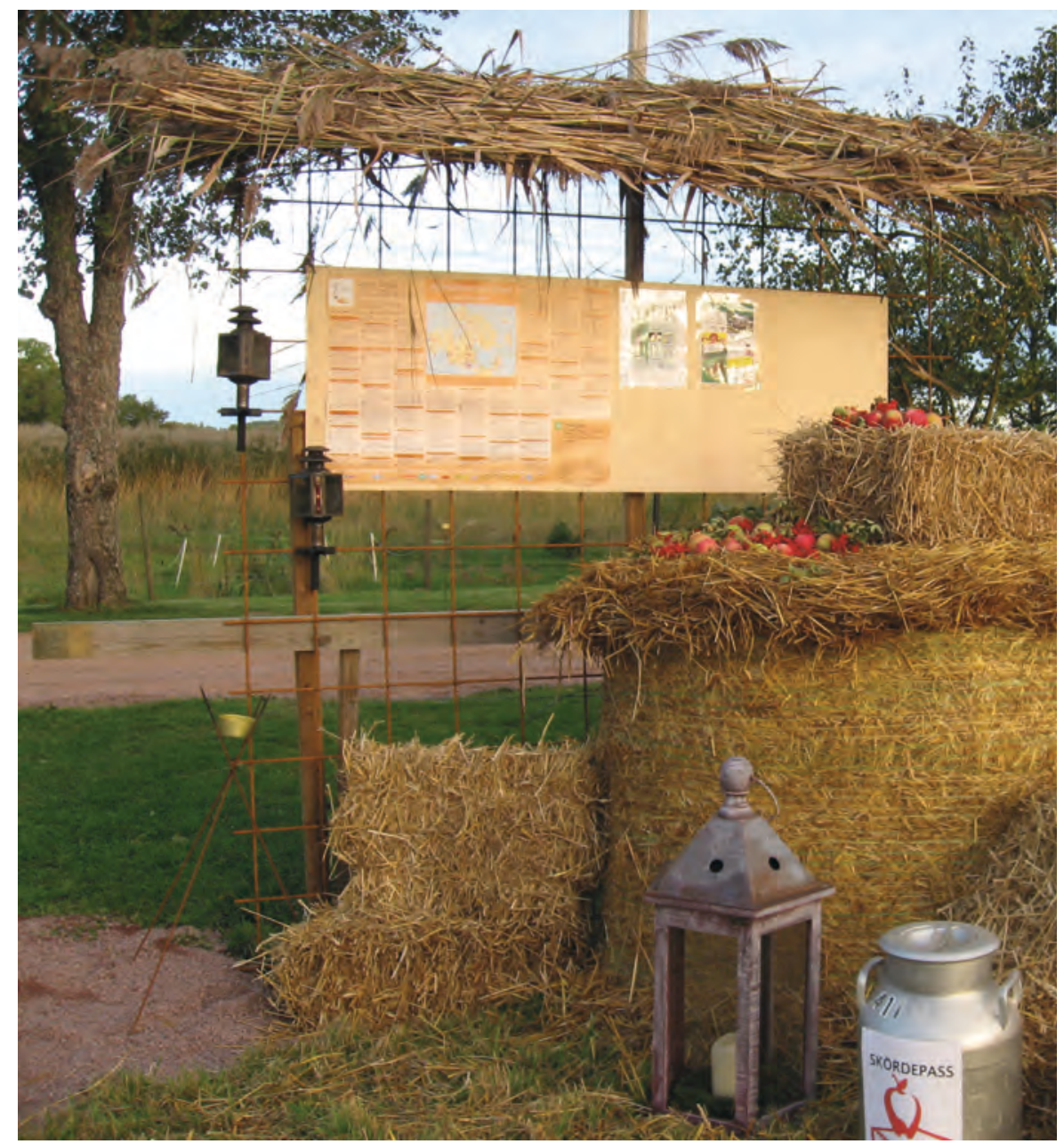

We have come a long way with the change process. And there is still a synergistic effect in the Nordic countries working together to achieve greater impact, both internationally and to get inspiration from each other to develop nationally.

Common meeting places still need to be created in the Nordic countries to be able to share our experiences and to find new joint collaborations. In NNF we have seen that one of the most important assignments has been "connecting people", which has resulted in new partnerships. It is when people meet that networks are created - IRL (In Real Life). Going forward, it is also very important that we do more to involve young people in this co-operation to give them access to these meeting places.

The core values in New Nordic Food; purity, freshness, simplicity and ethics, are aimed at bringing out the pure original flavours. We have no reason to hide the original flavours with strong spices or other condiments. There is nowhere else in the world on the same latitude as the Nordic countries where there is the same warmth and favourable climate for growing plants. Thanks to the many hours of sunshine during the growing season we have ingredients full of flavour and rich in nutrients. This makes us unique in the world!

If we add to that that the Nordic Region is the northernmost destination which is most accessible by air transport, we have the conditions to become an exciting and accessible food destination.

In food production we can also become better at sustainable food production and getting even more flavour from products from the area in which they are produced; terroir. To quote Mattias Dahlgren; "We must adapt our agriculture to other parameters, such as making the world's best, most interesting and healthy food. We will never be able to produce the world's cheapest food, which is probably not very interesting anyway."

Can we link more dimensions in the future so we can have well-being in the whole body? Can good and healthy food be combined with movement and the mind aimed at young people? - New Nordic Lifestyle! 


\section{NORDIC FOOD IS A MOVEMENT FOR THE FUTURE}

New Nordic Food is making its way in the Nordic countries. It has functioned as a catalyst for a small revolution in how we perceive our food, how we eat, our food traditions and our use of resources. This is still not very visible in all countries, as the signals and symptoms are appearing many places at the same time, and not all of this has the label New Nordic Food attached. As it happens, this has in fact been part of the strategy to maintain enthusiasm. New Nordic Food is a grassroots movement, not a dogmatic clan, therefore, the characteristics are different than expected. In New Nordic Food, we observe the social entrepreneurs. Their rhetoric varies, so it is not obvious that they are on the same theme, and they are not necessarily interested in being associated either with the movement or with each other. The differences are so great that it will be necessary to illustrate through a few examples, in order to show the breadth and the range of initiatives.

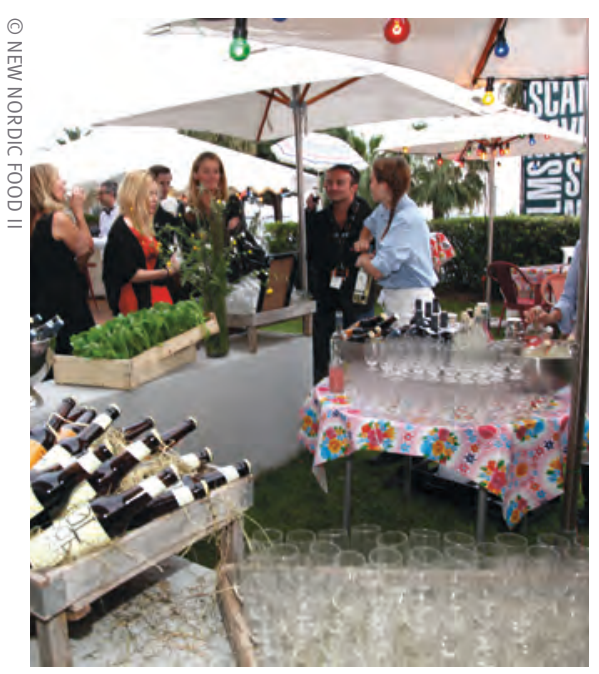

We all know Claus Meyer and his role as a mentor and founding father in establishing the ideas behind New Nordic Food. In recent years, his main interest has taken his philosophy to other regions of the world. The ideology of a positive food culture and its importance for humans in establishing good food habits is central for all positive change. This induces a proper prevention strategy for future health problems, improved regional economy and environmentally friendly food production, still founded on the ideas from New Nordic Food.

In Iceland, Baldvin Jónsson has contributed to increased exports of agricultural produce from Iceland to the US. This has opened a new export sector for the Icelandic agricultural sector over and above seafood.

In Åland, the whole community contributes to the annual Skördefesten, a three-day harvest festival in late September. This is the biggest harvest festival in both Sweden and Finland and has a substantial impact on local food production, on the menus of restaurants and on Åland's self-esteem. The pride in local food has left its mark on food served to tourists, and the island can now serve as a model for the rest of the Nordic countries when it comes to food and tourism.

In Sweden, Bodil Cornell has created her own universe for traditional and new crafts in food production in rural Jämtland. Her national centre Eldrimner is a treasure chest for artistan food and the competitions organised for craft foods, called Særimner (like the pig cooked for the gods), brings local food producers from all Nordic countries together to celebrate the sprouting richness of Nordic food culture. In Norse mythology, the cauldron Eldrimner cooks food for the gods, an appropriate image for her enthusiasm for local food production, food traditions and food quality.

In Finland, the visionary food artist Antto Melasniemi has "explored the edible" through unexpected pop-up stunts in art concepts like the Solar Kitchen Restaurant, only open when the sun was shining. He collaborates with designers to create the ultimate Finnish experience and he illustrates how food-art can be a holistic experience when perception utilises all our senses in a visit to a restaurant concept outside the expected and comfortable space.

\section{At the cooking school in Narsaq in} Greenland, Inunnguaq Hegelund won the annual chefs' competition in 2010, using local Greenlandic raw materials. The competition, called Kalaallit Nunaanni igasunut unammisitsineq, has been a driver for the introduction of local raw materials and dishes in restaurants and for tourists. Slowly we are seeing the pride in local food penetrate Greenlandic gastronomy. The awarded restaurant Ulo at Hotel Arctic in Illulisat, run by Jeppe Ejvind Nielsen, is an amazing achievement worth a trip to Greenland in itself. In the short summer season, the chefs spend more time outside gathering, fishing, hunting and picking edible plants than in the kitchen. The food is Greenland on your plate and it whispers to you like an iceberg does; as the Greenlandic proverb goes. 


\section{"New Nordic Food is making its way in the Nordic countries. It has functioned as a catalyst for a small revolution in how we perceive our food, how we eat, our food traditions and our use of resources."}

In Norway, there is no way around Andreas Viestad. He raised the flag for Nordic cuisine long before the manifesto was written. His TV series with more than 70 programmes on Scandinavian Cooking has been shown in all corners of the globe, and has been shown daily on TV stations in the USA for the last 15 years. The very positive image of Nordic food this has created in American minds cannot be underestimated. Today, Andreas is focusing on educating the coming generation through his food culture centre at Gjeitmyra in central Oslo. Here he relates sustainability to food culture, wellbeing and health, vital issues for maintaining the Nordic welfare model.

In the Faroe Islands, you were served Argentinian beef and pizza when you arrived as a tourist in 2006. A meeting with the ambassadors of the New Nordic Food programme in 2009, initiated by Leif Sørensen, a co-signer of the manifesto, has led to an emerging awareness of the importance of food in tourism. Today, Leif has started a partnership with El Celler in Girona and provided inspiration for some of the best Nordic restaurants in Tórshavn, like Koks and Áarstova. Collaboration with the local marine research institute Havstovan has reintroduced seaweed into Nordic gastronomy. Rebuilding the networks for harvesting and farming of seaweed has been another strong focus of New Nordic Food.

René Redzepi has now had the status as chef of the world's best restaurant NOMA for four out of the last five years, so it is time for him to rephrase New Nordic Food as his sole focus. In this effort, he seeks

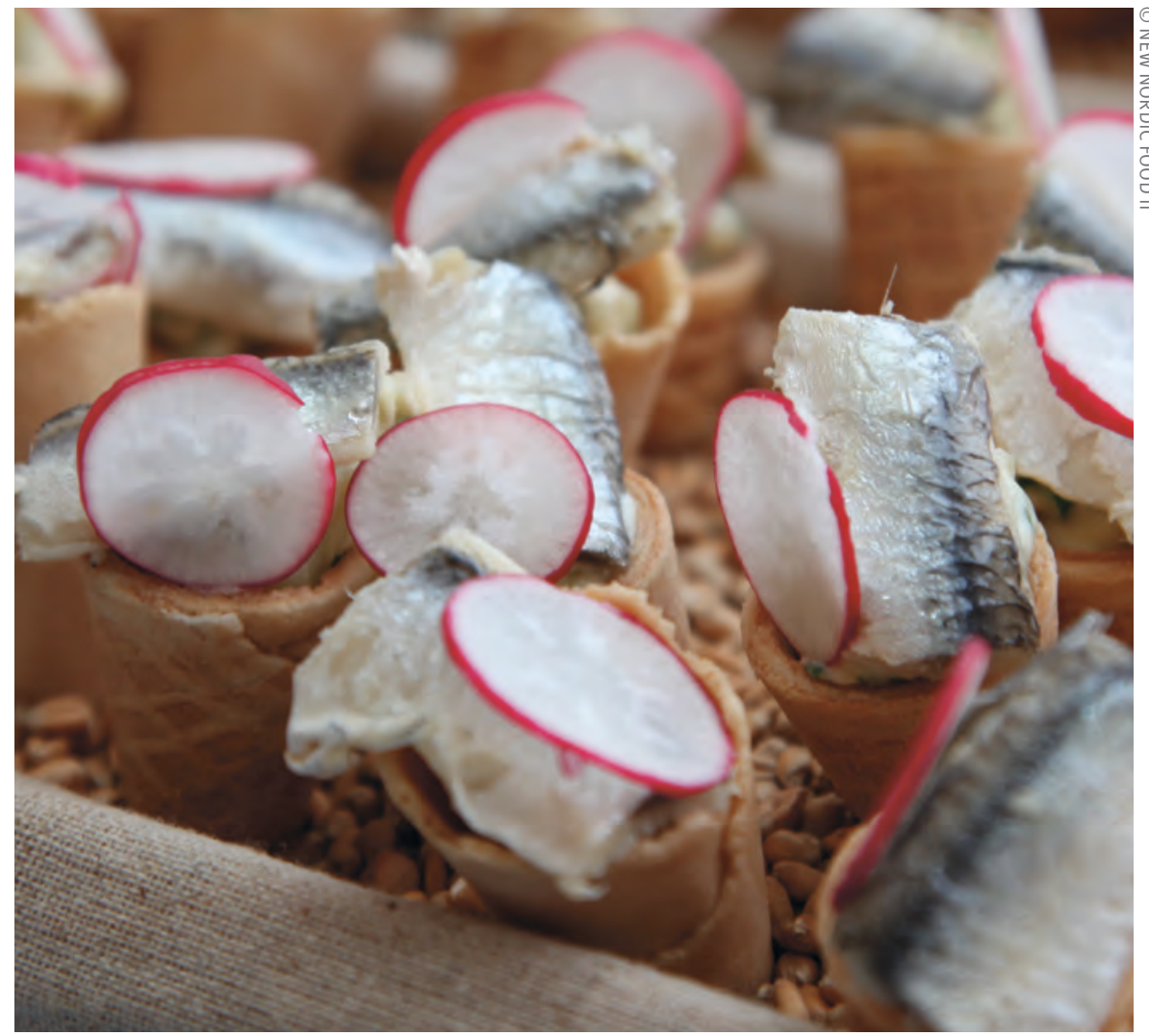

collaboration with other uncompromising partners in Japan, a cuisine with a philosophy very close to the Nordic. When he took NOMA to Tokyo in 2015, this provided a mutual fertilisation of the Nordic avant-garde with the best practitioners of the Japanese cuisine. In many ways, these worlds are very close, especially in ideology. René was one of the founders of the Nordic cuisine manifesto, and the Japanese, like us, are very engaged in the perceived attributes of food and the interaction of raw materials with production methods and the environment. Both cuisines have a keen interest in using of all parts of a raw material with the positive aspects this has for the environment, and they focus on health for society and their guests. These are only a few examples of how New Nordic Food and Japanese cuisine meet in a common ideology, but there are more links.

In many ways, this is a short list of examples, which at the same time proves that New Nordic Food and the ideology in the kitchen manifesto have been successful. Enthusiastic movements succeed where dogmas fail, because they maintain a degree of freedom, the liberty to think new and to be able to take developments 


\section{"The complete value chain for food is already the biggest value-creating sector in all Nordic countries, and with an increasing turnover, the number of employees will help to secure a strong contribution to the welfare of the countries."}

to a completely different level. Where a dogmatic movement keeps the dog on a leash, creative and enthusiastic movements provide creativity and opportunities to social entrepreneurs. This has been one of the basic ideas of New Nordic Food the greater the participation, the greater the creativity, and thus more plurality in the expressive content.

Activities performed by the New Nordic Food programme are not to be confused with the grassroots movement itself, but are based on the same philosophical foundation. The programme has had a clear idea not to be a pop star in the show, but to be the invisible puppeteer providing the stage for the main characters. The pop stars are the social entrepreneurs, the agents of change, and they need the limelight to succeed. The public wants the real thing in order to join in with the ideas, so this is important. This implies that the programme has not been a goal in itself, but the role has been to support and encourage projects and ideas that needed a touch of energy to get going at a faster rate.

It was clear quite early on that the Nordic gastronomic stars did not need much support to provide their international fame. The Nordic countries now have a series of international celebrities among chefs that outnumber our most famous sport stars, and with a much wider audience. The fact is that the Council of Ministers' programme, New Nordic Food, has long benefited from the help and support of the star chefs, not the other way around. They have let the other actors of the food chain climb onto their

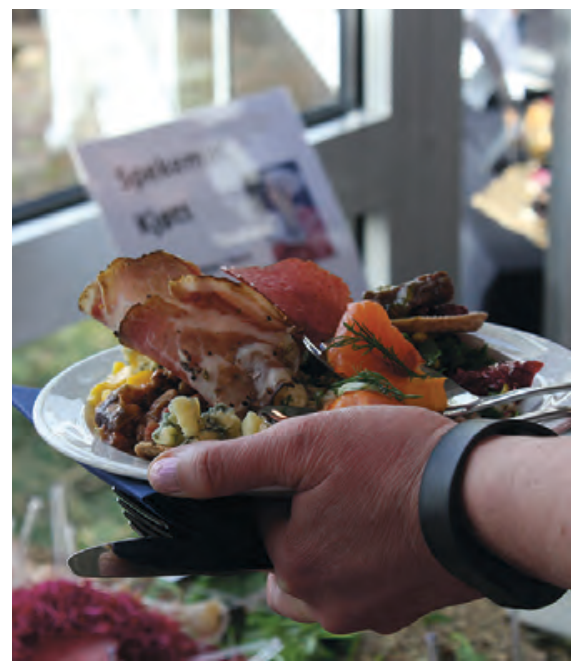

has often been supplemented by other sources to provide the desired effect. One example of a small investment is the support given at the Eurovision Song Contest in Malmö in 2013, where food vendors and restaurants collaborated on a concept to provide a Nordic signature on all food served at the venue. A concept experienced by all the international visitors as well as the thousands of journalists. The idea at this event, as at many others, was to tie food to a bigger idea, to make a synergistic, stronger and more visible concept for the public.

In Shanghai, during the Nordic Design and Fashion week in 2014, the Chinese public was exposed to sustainability in food and materials. The message came through clearly, when participants met sustainability not only in fabrics, but also as a strengthening message in meals and cooking classes. The idea is strong therefore the media is attracted, so the coverage of such events is good.

In the later phase of the programme, it became imperative to provide a sustainable continuation of activities and networks where political ambitions are still not fulfilled. There still is a long way to go before we live as we learn, especially when it comes to food served to the public, in institutional meals in hospitals, to the elderly and in schools. Even when two big hospitals in Copenhagen have shown that good food makes less waste, improved job satisfaction and quicker recovery among patients, it still remains to get this to spread far and wide. It is still difficult to explain that investment in food comes back several-fold through wellbe- 
ing, reduced absence among staff and in improved working conditions. Still, slowly we are seeing movements in the right direction. The same reasoning relates to school meals, food for the elderly and food used in entertainment by our authorities.

If innovation is measured in value created, there is no doubt that New Nordic Food has been a success, but it is impossible to provide numbers. The value creation has happened in so many sectors of society and under so many budget posts that it is not possible to calculate the impact. The effect on restaurant visits is maybe the obvious, but also the most visible result. The rest will remain for a while as a list of unproven claims: school food creating jobs in Denmark and Norway is moving; food tourism is growing rapidly in all Nordic countries; craft production of local food is rocketing in all Nordic countries, and has become an symbol of pride and self-esteem; and the turnover of high quality foods of Nordic origin is becoming a sign of good taste.

The complete value chain for food is already the biggest value-creating sector in all Nordic countries, and with an increasing turnover, the number of employees will help to secure a strong contribution to the welfare of the countries. The consequence is that we need to see our food sector and our food culture as a major innovation force, worth maintaining in order to afford the future of the Nordic welfare model.

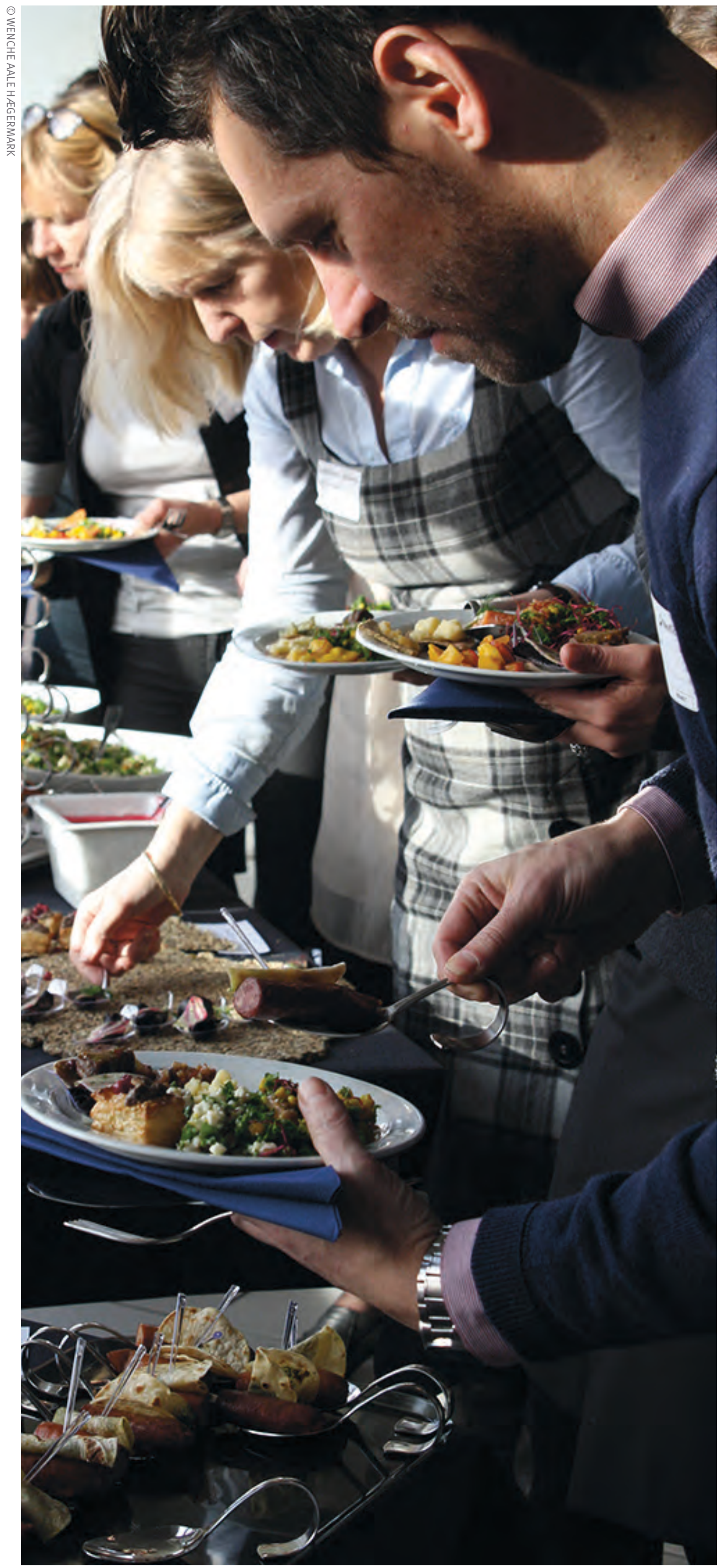




\section{NEW NORDIC FOOD 2010-2014 - A GREAT SUCCESS}

\section{“... in EK-FJLS (Executive) all agreed that the New Nordic Food concept was important for Nordic co-operation and that it is one of the greatest Nordic successes in recent times."}

From the meeting documents of the Committee of Senior Officials at the Nordic Council of Ministers on 22 January 2014.

The above quote talks about the developments that have taken place in Nordic food in the last decade. It also tells us about the politicians' commitment to this development which was clearly shown in the New Nordic Food programme. The programme has been an outright success but it is important to emphasise that this success rests on many shoulders. New Nordic Food, as a movement, a concept and as a programme in the Council of Ministers is the result of: good geographic conditions, a clear vision, excellent Nordic co-operation as well as the enthusiastic work of many players. It has often been emphasised that the "Nordic food phenomenon" is a popular movement (bottom up) and not governed by any strategic (political) decisions. This is true, but the role of politicians has been important through strong political and financial support. The New Nordic Food programme has been an important instrument for politicians to show their Nordic intentions.

\section{BACKGROUND}

In the 20th century, Nordic food production underwent profound changes. After the war, cheap food ruled both consumers and producers and many small food producers closed down because of a slowing economy, outdated facilities or buy outs from larger and more competitive players. There was a radical structural shift towards more concentrated industrial food production. This transformation was particularly evident in the Nordic Region. The result was large-scale industrial processed food, which felt unfamiliar to more and more people.

A more widespread reaction came in the early 2000s, when interest for organic and locally produced food became stronger and a broad range of local products began to emerge across the Nordic Region. These became important jigsaw pieces for regional programmes for rural development, entrepreneurship and for the growing stream of tourists, where gastronomy became more and more in demand.

The essence of this expanding movement was expressed very clearly in 2004 when the visionary Claus Meyer gathered together twelve Nordic chefs who formulated the characteristics of Nordic food. The result was the Nordic Kitchen Manifest (page 66), which received political support the following year when the Nordic ministers for agriculture and fisheries drew up the Århus Declaration (page 67). Here the politicians showed that they were keenly aware of the growing movement around food and stated that this had strong links to important political issues such as health, rural development, export, tourism and the general growth of the experience industry.

\section{THE NEW NORDIC FOOD PROGRAMME}

As a result of the Århus Declaration, the Nordic Council of Ministers started the New Nordic Food Programme in 2007, with the aim of drawing attention to the area and acting as a link between the national food programmes which were beginning to appear in the Nordic Region. In this context it is important to emphasise that the Nordic countries have a long collaboration in food, but this has mostly been around health, safe and nourishing food. It was therefore stressed that the New Nordic Food programme should build on this very fruitful co-operation, but emphasise the taste and the experience sides of the Nordic food culture. To illustrate these different aspects of Nordic food, one can compare them to a pyramid. Here the base is made up of safe and nutritious products with a positive effect on public health, but the tip is made up of tasty and experience-rich meals, where the social and cultural aspects are also included.

During the first period of the New Nordic Food programme, 2007-2009, there was focus on about 30 different projects that clearly indicated two things. Partly the commitment of the politicians in the New Nordic Food sector, and partly that the New Nordic Food movement included all aspects of food and food culture, from 
“... in EK-FJLS (Executive) all agreed that the New Nordic Food concept was important for Nordic co-operation and that it is one of the greatest Nordic successes in recent times."

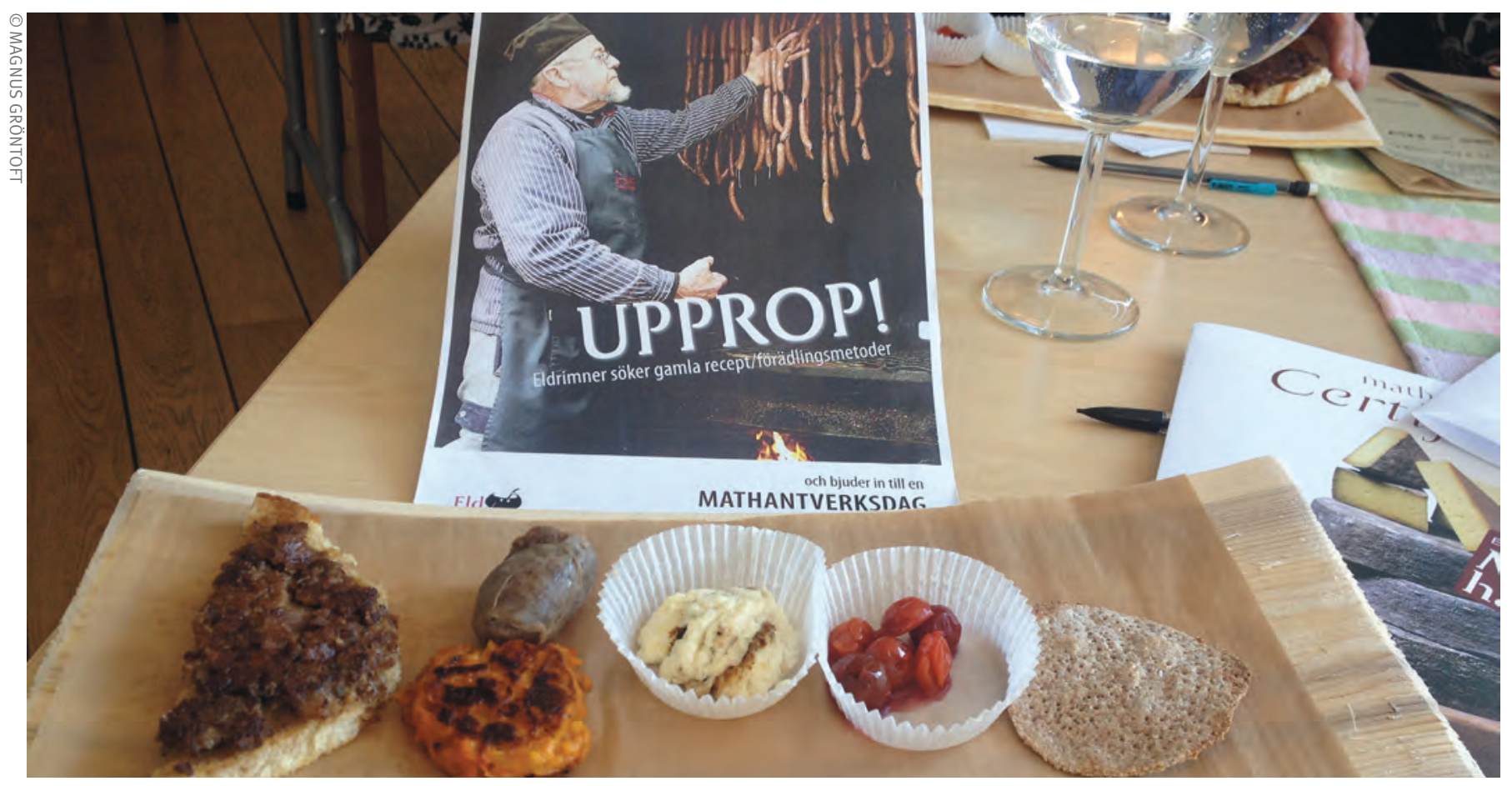

UPPROP FROM ELDRIMNER

slaughter and Nordic malt production to linguistic development and tourism. The work during the first period took place in close co-operation with Nordic Innovation, which announced its own focus area around New Nordic Food.

The second period of the New Nordic Food programme lasted five years and was concluded in 2014. Here the work was more focused as by then different national ventures had now started up and contributed to the growing awareness around food and food culture. During the second period, certain areas were therefore prioritised. These were: Food \& Children, SME, "Seaweed and Kelp", Food for Many (incl. public procurement), and Food \& Health. In the latter case, the health aspect did not consist primarily of the nutritional content, but rather that good taste and an experience-rich meal makes healthy food more attractive. In addition, these areas also included Nordic Food Diplomacy, and food and the creative industries, where groundbreaking work was done. This work has made a considerable contribution to Nordic food culture, slowly beginning to establish itself amongst other "highbrow cultures".

\section{AN EXPANSIVE FUTURE}

During the eight years that the programme has been active, the view of Nordic food and food culture underwent a radical change. Nordic food has now received major international recognition based on fantastic raw materials, excellent skills, rich entrepreneurship and cross-border co-operation between different sectors of society. The meal sector has become a valued partner through its experiences of working with all five senses. Here, co-operation with the cultural and creative industries in KreaNord has been very fruitful and yielded many high-profile Nordic and international events.

The Nordic premises are still good with superior raw materials and excellent skills, but this needs to be combined with continued expansive ventures if Nordic food is to continue to attract a great deal of attention. Important areas are better education, increased co-operation within the Region and with other sectors, export, 


\section{"Nordic food today is not just a dietary intake to survive and be able to work. Food has to a much greater extent moved towards the centre in a great number of sectors of society, ranging from health and well-being to tourism and experiences."

and developing the food sectors' experiences with all five senses. This is something that will be an important driving force, even within traditional industry, when technically perfect products can be produced even in countries which were previously considered underdeveloped. Competition is getting tougher and if the Nordic Region is going to be able to develop its prosperity, Nordic products and services must evolve in line with the demands placed by new generations. The food sectors' knowledge and experience can play a significiant role in the development of Nordic welfare.

Clearly this can be seen in health care, where good, nourishing food can often replace medicine. But there are also many different industries which need to co-operate if the Region is to retain its lead and its prosperity. There are many who see the need for increased co-operation between the different industries, which cover both traditional industry and the cultural and creative industries, which also include the food and meal sector.

\section{METHODOLOGY}

The fact that New Nordic Food has been successful in carrying out such comprehensive work, as presented in this final report, is due to a thorough work methodology. Nordic food today is not just a dietary intake to survive and be able to work. Food has to a much greater extent moved towards the centre in a great number of sectors of society, ranging from health and well-being to tourism and experiences. This requires the ability to integrate different groups that normally work far apart. Here there are great opportunities for the meal as the uniting factor, and this has also been the starting point in the events held over the years. With a strategy where cross-border networks and cross-sectoral co-operation have been the tools, food and the meal have attracted attention and very often been taken as the starting point in a long series of creative collaborations.

\section{EVALUATION}

Distancing oneself a little bit, one must nevertheless ask what the New Nordic Food programme has done to contribute to the revolution that the Nordic food culture has undergone in the last ten years. Primarily, it has been about the Nordic politicians clear standpoints for New Nordic Food in the Århus Declaration and before that when the Council of Ministers acted as host when the Nordic Kitchen Manifest was drawn up. This was starting points of the major Nordic national ventures, for example, SRE in Finland and Culinary Nation in Sweden. Here the New Nordic Food programme has had a contact and communicative purpose. Although major funding has been distributed at national level one must not underestimate the importance of the added value that the contacts between the five small countries has had. Nordic co-operation is important here. It is particularly important in such a relatively new area as New Nordic Food, where everyone has the same opportunities and are all at the same stage of development. To assess a programme such as New
Nordic Food, whose main task was to communicate is therefore not simple, as it takes place against a background of many other media voices. However, the mid-term evaluation which was done in 2012-2013 rated the programme highly, see page 64 . The reason is partly due to the fact that the Nordic contacts are not obvious and that the initiative is praised for bringing together people with the same interests in the Region. Other factors that should be highlighted are the importance of distributing funds and individual resources reasonably fairly across the whole Nordic Region. This creates active contact centres that are important for spreading the development. The programme has also, through its committed project managers, successfully developed areas in the Nordic food sector which have been completely new, for example, Nordic competitions in artisan food, fruitful co-operation with other creative industries, Nordic Food Diplomacy, Seaweed and Kelp, etc. This has created positive enterprising thinking throughout the whole programme.

\section{ACTIVITIES}

On the following pages there is an account of the programme New Nordic Food II's Nordic and international activities during the whole period between 2011-2014. It should be noted that these activities are just the top of the communicative work. Key elements of this work are the outward communication via newsletters, websites, FaceBook, YouTube, Twitter as well as a large number of consultative dialogues which were carried out by all involved during the entire period of the New Nordic Food programme. 


\title{
NEW NORDIC FOOD II COMMUNICATION
}

\author{
The highlights of New Nordic Food Il's communication activities include an active website and \\ a strong social media presence, with an enhanced news flow and a range of very successful inter- \\ national projects. The programme closed in 2014 with \#NORDICFOOD2024, a series of six work- \\ shops on key topics for the future of the Nordic kitchen. The New Nordic Kitchen Manifesto under- \\ pinned all communication activities and consolidated the gastronomic Nordic Region.
}

\section{SPREADING THE WORD ABOUT NORDIC CUISINE}

New Nordic Food II was defined as a communication programme under the Nordic Council of Ministers. Its activities were aimed at spreading knowledge about the Nordic cuisine ideology and developing the skills of those involved with Nordic food. Efforts were directed towards decision makers, cooking professionals, project managers within development and communication about food and food culture in the Nordic region, and the general public. The aim was to inspire innovative food initiatives in all relevant sectors.

The role was to maintain, develop and expand communication about Nordic food, which was done through projects ranging from Nordic Diet to Nordic Food Diplomacy. New Nordic Food II has become a very solid player when it comes to organizing food projects and events in the Nordic Region, as well as internationally. The communication was designed to support the project managers in promoting events, conferences and workshops towards their target groups, and present the Nordic values through the projects.
Networking was an essential part of New Nordic Food II. Conferences were held in Helsinki in 2011 and Oslo in 2012, as the main focal points in the first half of the period. The conferences were meeting places for those who work with development and communication, concerning food and food culture in the Nordic region.

During 2013-2014, the focus was in organizing events under the Swedish and Icelandic presidency of the Nordic Council of Ministers, as well as international events with Nordic partners in Europe, USA and Asia.

\section{STRONGER COMMUNICATION PROFILE INTERNATIONALLY}

New Nordic Food II's visual identity and communication was adapted in order to strengthen the international profile. New Nordic Food has become a valued element of the region's branding and this represents great potential. The international pilot projects have created new ways of promoting the Nordic food message to new target groups around the world.

New Nordic Food II's website offers in-depth information in the Scandinavian languages and English (and some in Japanese and Russian), about the programme and its events, and distributes news about Nordic food activities. An electronic newsletter has been sent out in a Scandinavian and an English version. In addition, a website for Nordic Food Diplomacy was launched. The site introduces a thorough tool kit for those using New Nordic Food in entertainment, Nordic diplomacy and branding.

This is complemented by continuous activity on social media. Efforts included a very active and steadily growing Facebook community, a blog with contributions from New Nordic Food II and specially invited guest writers, as well as tweets around larger events and pilot projects. Video documentation has also become an important communication element.

New Nordic Food has created a strong network of Nordic and international food journalists and bloggers. This is supported by communication co-operation with Nordic Council of Ministers, national food actors and the media. For international food writers and media companies, New Nordic Food serves also as an introductory partner to Nordic food culture and its actors. Several scientific articles and 


\section{"For international food writers and media companies, New Nordic Food serves also as an introductory partner to Nordic food culture and its actors. Several scientific articles and reports have also been published about the New Nordic Food movement and Nordic Cuisine."}

reports have also been published about the New Nordic Food movement and Nordic Cuisine.

\section{\#NORDICFOOD2024 CONCLUDES THE PROGRAMME ACTIVITIES}

At the end of 2014, \#NORDICFOOD2024, a series of six vision workshops, covering a wide range of fields from tourism and public meals to bioeconomy, was arranged. Leading players were invited from across the Nordic region to discuss visions for the future food culture.

The communication was supported by video documentation and a series of articles highlighting the Nordic Kitchen Manifesto, including interviews with six of the Nordic chefs that signed the manifesto in 2004, see page 66 .

\section{CONCLUDING DISCUSSION}

In 2015 the New Nordic Food programme will continue under the auspices of the Nordic Council of Ministers, but in a downscaled version with a smaller budget. But there is still need to stay focused on continuous communication about activities and networks both in the Nordic Region and internationally. It would therefor be recommended to allocated resources for a communications officer in order to maintain an active news flow in existing news channels and networks. The great interest for Nordic food culture amongst international players and the media could then be met through multi-language communication.

\section{MORE INFO}

Half way report 2010-2012: New Nordic Food II - A popular movement continues, http://newnordicfood.org/about-nnf-ii/new-nordic-food-ii-half-way-report/

New Nordic Food II Report 2013:

http://nynordiskmad.org/fileadmin/webmasterfiles/Billeder/NNM-

Årsrapport-2013_final.pdf

New Nordic Food II Communication Report 2014:

http://nynordiskmad.org/fileadmin/webmasterfiles/Billeder/Kommunikationreport2014.pdf

\section{\#NORDICFOOD2024}

- Workshops and concluding articles: http://newnordicfood.org/projects/nordicfood2024/

- Articles with six chefs who signed the Nordic Kitchen Manifesto: http://nynordiskmad.org/om-nnm-ii/koeksmanifestet/

- Essays on the future of New Nordic Food: http://nordicway.org/nnf/\#essays

Green Growth web magazine: Special edition on New Nordic Food, March 2015 http://nordicway.org/nnf/

\section{COMMUNICATION CHANNELS}

http://nordicway.org/nnf/

www.nynordiskmad.org

www.nfd.nynordiskmad.org

www.nynordiskmad.blogspot.com www.youtube.com/nynordiskmat www.facebook.com/nynordiskmad www.twitter.com/nynordiskmat 


\section{NEW NORDIC FOOD}

\section{COMMUNICATION 2010-2014}

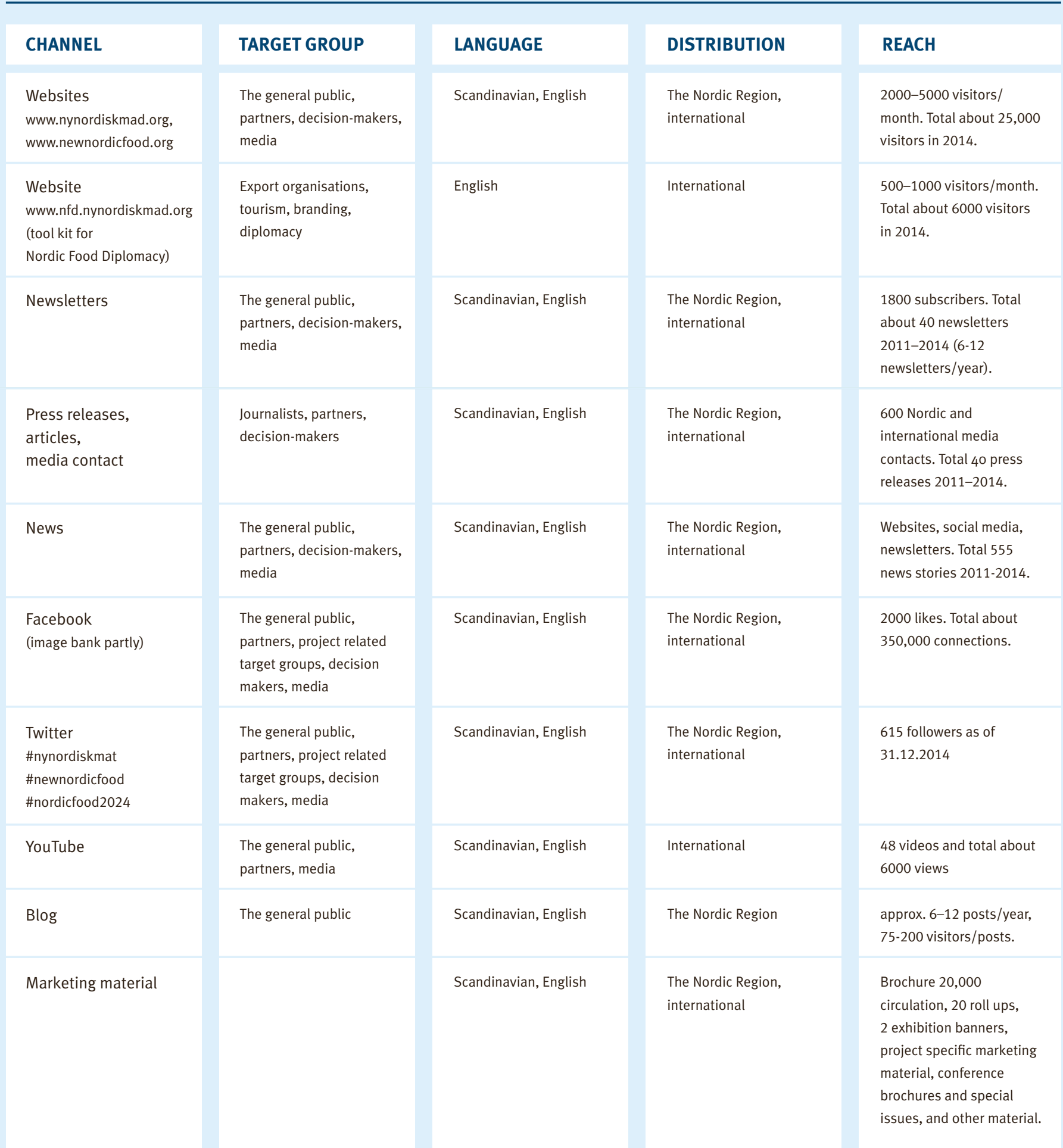




\section{NEW NORDIC FOOD II - IN THE WORLD}

SEE ALSO WWW.NEWNORDICFOOD.ORG, FACEBOOK AND TWITTER

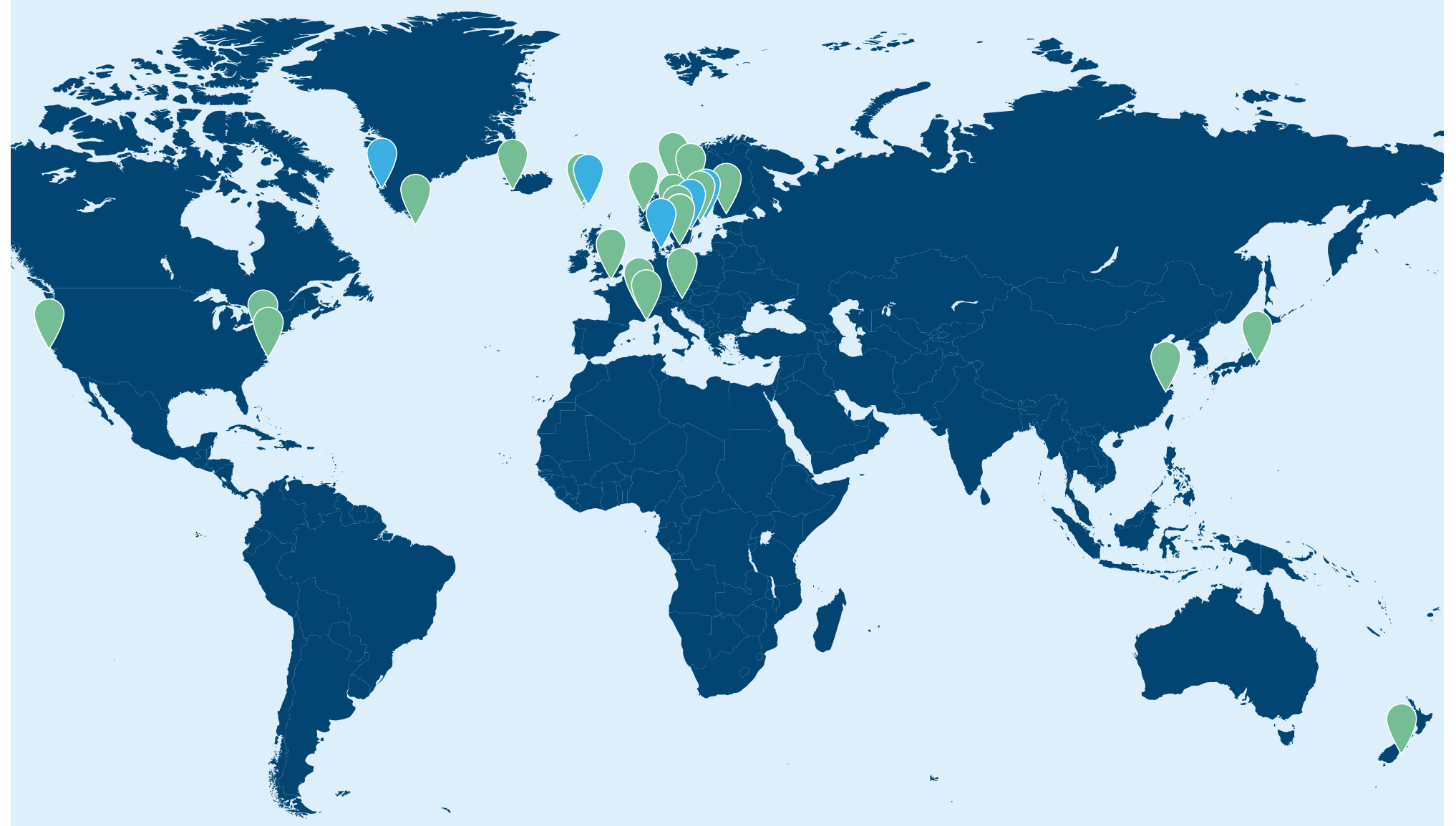

ACTIVITIES 2010-2014

- see all events on page 60-62
GREEN PIN

PUBLIC EVENTS

BLUE PIN

MEETINGS WITHIN NNF II 


\title{
\#NORDICF0OD2024 - NORDIC FOOD FOR THE FUTURE
}

RESULTS AND CONTRIBUTIONS - SEE HTTP://NORDICWAY.ORG/NNF/ AND HTTP://NYNORDISKMAD.ORG

\author{
In a series of six workshops, \#NORDICFOOD2024 focused on the ways in which Nordic Food \\ should develop during the coming years. How far can we go to realise the visions of Nordic \\ cuisine in selected areas in the future? New Nordic Food II invited leading actors from across \\ the region to discuss the future vision of Nordic food, as well as the necessary actions to \\ promote this vision.
}

\section{THE WORLD IS RAPIDLY CHANGING and tomorrow's food culture is shaped today. We are facing global challenges, such as climate change, malnutrition, inadequate resources, and growing inequality between people and cultures and between producers and consumers.}

But the Nordic region is in many ways in a position to become one of the best and most transparent food producing areas in the world. The basis for this lies in the Nordic social model and in our common Nordic values, but is also expressed in something as specific as the Nordic Cuisine Manifesto from 2004.

The Nordic Cuisine Manifesto was conceived and formulated in a Nordic cooperation and summarized in ten points on purity, season, ethics, health, sustainability and quality.

\section{The six \#NORDICFOOD2024 vision} workshops were based on the Nordic Cuisine Manifesto's tenth point:

"To cooperate with representatives of consumers, other cooking craftsmen, agriculture, fishing, food, retail and wholesale industry, researchers, teachers, politicians and authorities on this joint project to the benefit and advantage of all in the Nordic countries."
The following themes were selected, and the result can be seen at

http://nordicway.org/nnf/

\section{INTRODUCTION TO THE WORKSHOPS}

\#NORDICFOOD2024 started with an open seminar in Stockholm. Six invited guests, among them the new rural minister in Sweden, gave their view on the future for the Nordic Food.

\section{BIOECONOMY AND INNOVATION FOR A SUSTAINABLE FOOD CHAIN}

After a highly successful decade for the New Nordic Food movement, it is now time to discuss visions of what Nordic food should be capable of towards 2024. The second in a series of this six vision workshops took place on Iceand and adressed the bioeconomy's role for a sustainable Nordic food chain.

\section{THE NORDIC REGION AS A SUSTAINABLE GASTRONOMIC REGION}

Food tourism has become an important component in the five Nordic countries' tourism strategies. A vision workshop held at Copenhagen Street Food, explored the future of Nordic food as an element of the region's tourism and lifestyle. The potential is vast, as there are 120 million potential food visitors in Europe alone.

\section{PUBLIC MEALS AS}

\section{A FUTURE WELFARE SOLUTION}

More than six million public meals are served in the Nordic region every day, and each of these meals should incite a healthy and sustainable food culture. This was the main conclusion when experts from the region gathered to discuss the public meal's role in the transition towards more sustainable Nordic societies. The fourth \#NORDICFOOD2024 workshop was held at Copenhagen House of Food in December.

\section{FROM NICHE TO CRITICAL MASS}

Developing Nordic food products from niche to critical mass calls for refinement, close relations between producers and consumers, and storytelling based on genuine respect for craft and quality raw materials. \#NORDICFOOD2024 discussed the visions for commercialisation of Nordic food at Livsmedelsakademin in Malmö.

\section{STAGING NORDIC TABLE 2024}

Staging Nordic Table 2024 was a closing statement from the Food \& Creative Industries project, and at the same time, the beginning of a new platform for interplay between creators, investors, and agenda setters. The most powerful way to vision \#NORDICFOOD2024 is to find out what the important players of the present wish to emphasize, and to create a disclosure that illustrates where Nordic food is heading. 

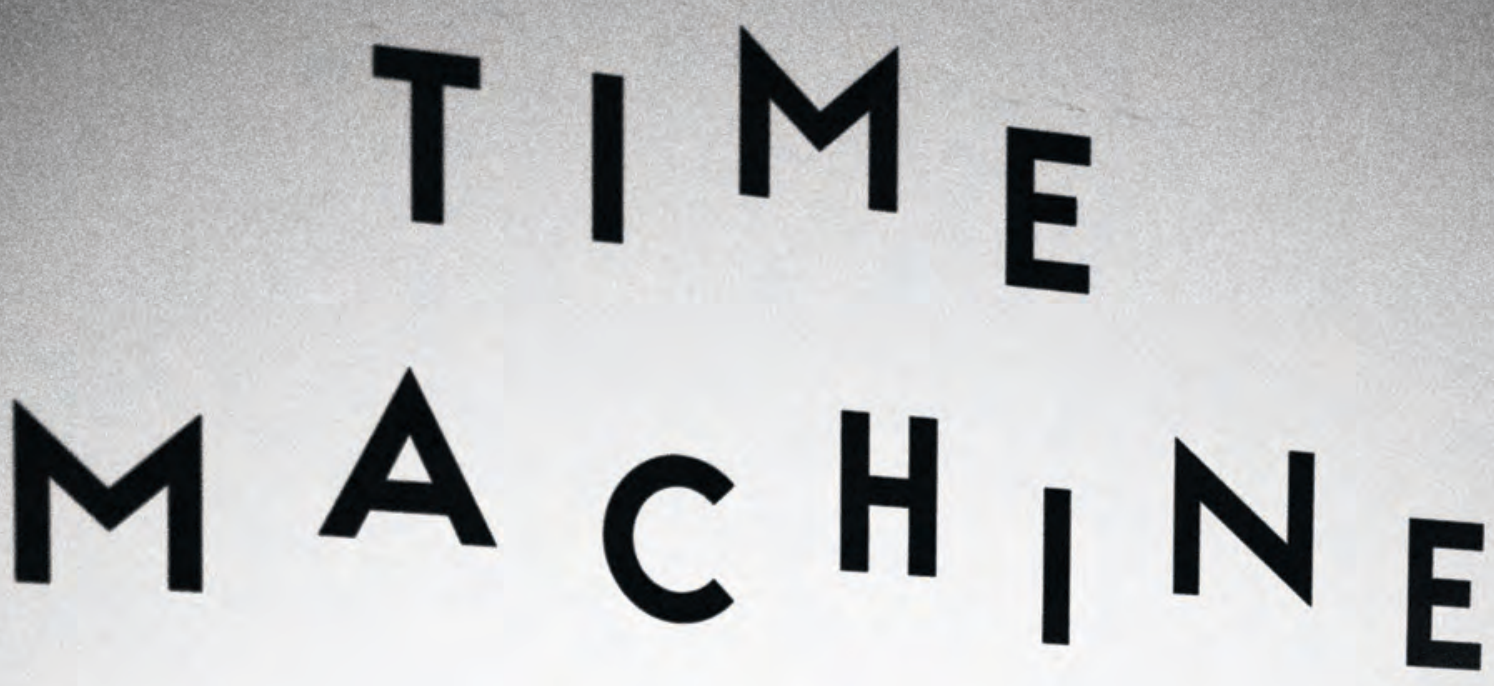

ENTERING

2024

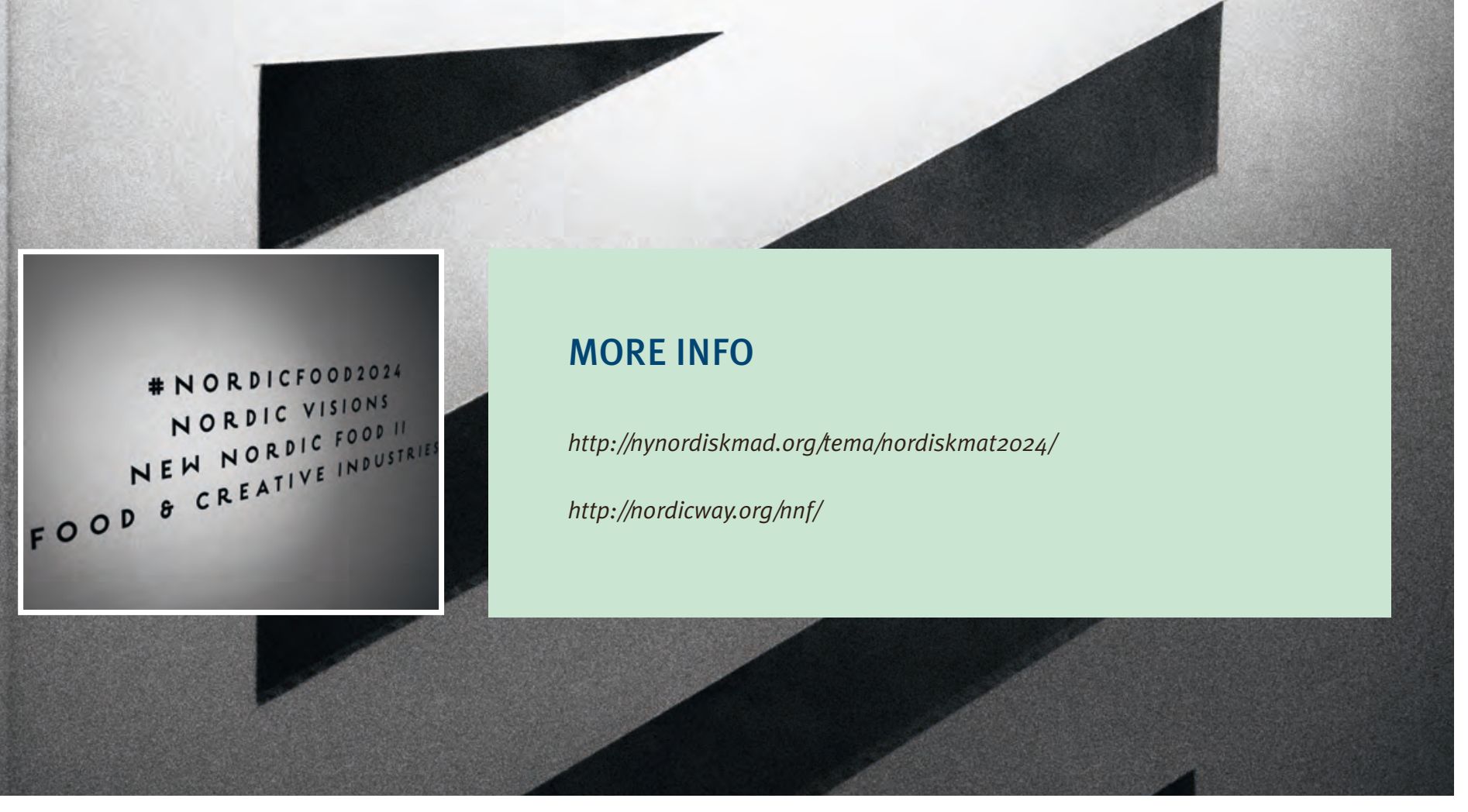




\title{
FOOD \& CREATIVE INDUSTRIES
}

\author{
Cultural and creative industries create jobs and exports that are vital to the Nordic countries and \\ their future economies. There is a potential to generate new growth areas and create new products \\ by combining creative forces in new ways. Food has established itself as a creative industry and a \\ connector, but it is still an "underdog" compared to the more established creative industries. On the \\ other hand, we see progress every day. What seemed highly creative a few years ago is considered \\ standard today.
}

The aim of the New Nordic Food II project Food \& Creative Industries is to stress the importance of food as an independent creative industry, and also to establish food and culinary experiences as an active, creative and significant element when Nordic countries market other creative industries internationally.

Within the project, we have dedicated time and effort to explore food as a creative tool and an art form equal to architecture, music and fine arts. How can food and creative collaboration create value into the future? We have established a range of projects aiming to develop new networks and methods and combine food and the creative industries in new ways in order to meet future demands.

During 2012-2014, we have conducted more than 10 pilot projects internationally, together with other creative industries such as fashion, music, film, the gaming industry, digital and tech, culture, design, visual art, and architecture. These pilot projects have produced important output, also in strategic terms. The projects have provided access, ambassadors and experiences that our Nordic and international partners have integrated into their networks, agendas and branding activities. Media response has been extensive and there has been broad Nordic participation in the projects. We have also tried to influence policy makers and highlight the importance of creative food by initiating a range of workshops, conferences, labs, panel debates, articles and networks. Moreover, methods for working with networks, innovation and design in the interspaces between food and other sectors have been developed (See e.g. Paper: NSB - Re-defining food design as pop-culture on page 24, and Essay Bertelsen \& Skylare (2015), Connecting creative potential - http://bit.ly/1ycAFr7)

\section{DESIGNING PRODUCTIVE NETWORKS}

There are many skilful collaborators working within the creative industries in the Nordic countries. We have started out with a small number of them, and they are now reaching out to new players creating visionary arenas where food becomes more than just food. We can see that an interdisciplinary climate is a state of mind for tomorrow's players and entrepreneurs when interplaying and creating. The number of new collaborations and contacts that have emerged from the Food \& Creative Industries network clearly shows that investment in activities similar to the ones developed by NNF II, as well as support of new platforms and hubs, has great prospects for future Nordic collaborations. These collaborations can become important new ways of looking at and dealing with the challenges we face in the global economy.

\section{ACTIVITIES 2012-2014}

\section{NORDIC SOUND BITE - REDEFINING FOOD DESIGN AS POP-CULTURE, PAPER 2014}

The paper describes the process and method for developing the concept Nordic Sound Bite. When food and music is co-designed to strengthen the concert experience, food plays a more artistic role than it usually takes. Food design in this context can strengthen the existential experience of being and being together. This is a pilot project that aimed to create a position where food design can play a more strategic and powerful role than just being an add-on to a meal.

http://bit.ly/1z5XCdp 

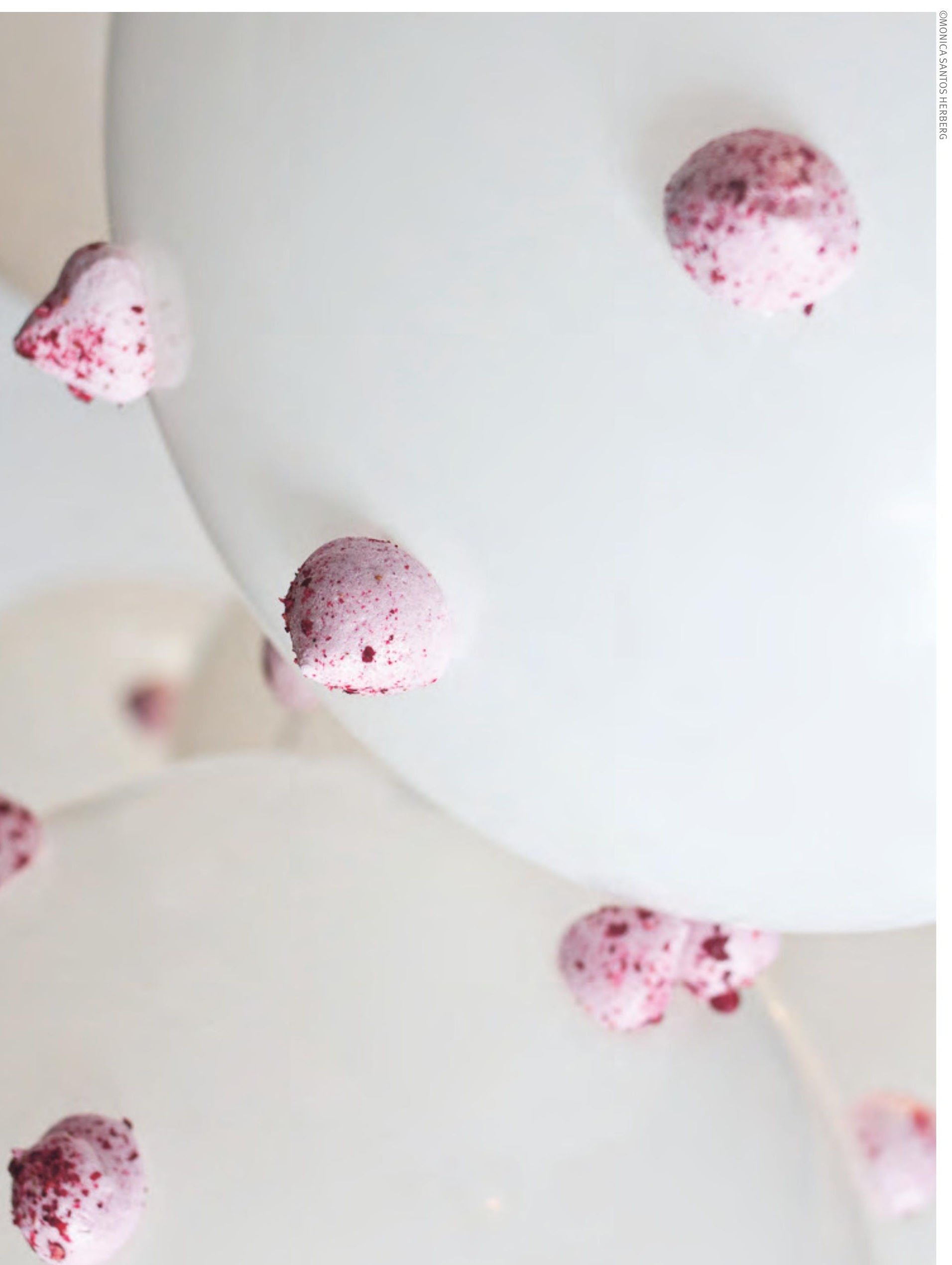


\section{"The invitation was a great opportunity and an acknowledgement}

of our results. The International Food Design Experience is a highly relevant platform to promote New Nordic Food, and in particular our work on food as an art form and a creative industry in itself."

\section{INTERNATIONAL FOOD DESIGN \\ EXPERIENCE, DUNEDIN, JULY 2014 RESEARCH CONFERENCE}

NNF II Food \& Creative Industries project manager Elisabet Skylare and designer Nikolaj Danielsen were invited to give keynote presentations of Food \& Creative industries' pilot projects, networking methods and the Nordic Sound Bite concept at The International Food Design Experience in New Zealand on 2-4 July 2014. In addition, a studio session was held where conference delegates could explore the methods developed by the project. See PAGE 24 for a separate sum up.

\section{NORTH FOOD FESTIVAL*,} NEW YORK, SEPT 2014

PILOT: FOOD, CULTURE, TOURISM

NNF II was a partner during NORTH Nordic Food Festival and collaborated with the NORTH project team to add new activities and a more strategic content to the festival. Almost all the Nordic Visitorganizations participated in the festival that took part during a week in NY, offering more than 25 different Nordic food related activities. NNF II initiated the opening panel discussions about the future of Nordic food, as well as the street food element as part of the festival programme. See PAGE 40 for a separate sum up.

\section{JA JA JA FESTIVAL, LONDON, NOV 2014 PILOT: FOOD, MUSIC, FILM}

For the second edition of the Nordic Ja Ja Ja Festival in London, Finnish chef - and former member of legendary rock band HIM - Antto Melasniemi curated a cutting edge food programme. The NNF II collaboration focused on the communication around the event. A documentary video was made about the exploring journey to Iceland, where the food concept was developed together with Antto Melasniemi and headliner Emilíana Torrini. See PAGE 26 for a separate sum up.

\section{NORDIC PLAYLIST RADIO BAR, ICELANDIC AIRWAVES, REYKJAVIK, NOV 2014 PILOT: FOOD, MUSIC \& DESIGN}

The Nordic Playlist (NPL) Radio Bar was a food and radio pop-up concept during the Iceland Airwaves Music Festival. The NPL turned into an online radio station as part of the festival's off venue programme, inviting international radio DJs to share their love for Nordic music. The Radio Bar invited the festivalgoer to hang out, eat, drink, charge up and to experience the sounds, tastes and stories from the Nordic region. NNF II collaborated by supporting young creative talents joining the project. See PAGE 28 for a separate sum up.

\section{SCANDINAVIAN LIGHT \& DESIGN} FESTIVAL*, VIENNA, NOV 2014 PILOT: FOOD, DESIGN, ARCHITECTURE, VISUAL ART

This year's annual Nordic design event, Scandinavian Light and Design, invited 300 guests to a special experience designed by food designer Vanja Franzén, Embassy Chef Christoph Finch and visual designer Florian Tanzer. They created an experience combining food, sound and visuals, in order to strengthen the Nordic branding during the event in Vienna. This was a collaborative project between NNF II, the Swedish and Norwegian embassies, and Nordic exhibitors. See PAGE 42 for a separate sum up.

\section{STAGING NORDIC TABLE 2024, STOCKHOLM, DEC 2014 VISION WORKSHOP}

Staging Nordic Table 2024 was a closing statement from the Food \& Creative Industries project, and at the same time, the beginning of a new platform for interplay between creators, investors, and agenda setters. The most powerful way to vision \#NORDICFOOD2024 was to find out what the important players of the present wish to emphasize, and to create a disclosure that illustrates where Nordic food is heading. Five stagings were presented. https://youtu.be/hXu_hK_urug

\section{NORDIC SOUND BITE, JA JA JA FESTIVAL, LONDON, NOV 2013}

PILOT: FOOD, MUSIC, FILM \& ART

During the first Ja Ja Ja Festival at the iconic Roundhouse, a range of innovative food experiences were presented. These included "Nordic Sound Bite" - a concept described as the ultimate collaboration between music and food. Three emerging Nordic food artists designed a special 'sound bite' based on their favourite band's musical DNA (Mew, NONONO, Sin Fang, Sakaris and Kid Astray). http://bit.ly/1cXAylE

FOOSHION, NDIW, SHANGHAI, NOV 2013 PILOT: FOOD \& FASHION

New Nordic Food strengthened the Nordic brand at Nordic Design \& Innovation Week. Food and fashion merged in Fooshion - an experimental treat for 60 invited guests (press and bloggers). Fooshion was an innovative cross collaboration showcasing the Nordic countries as front-runners in sustainable fashion and food. http://bit.ly/1yW3atq 


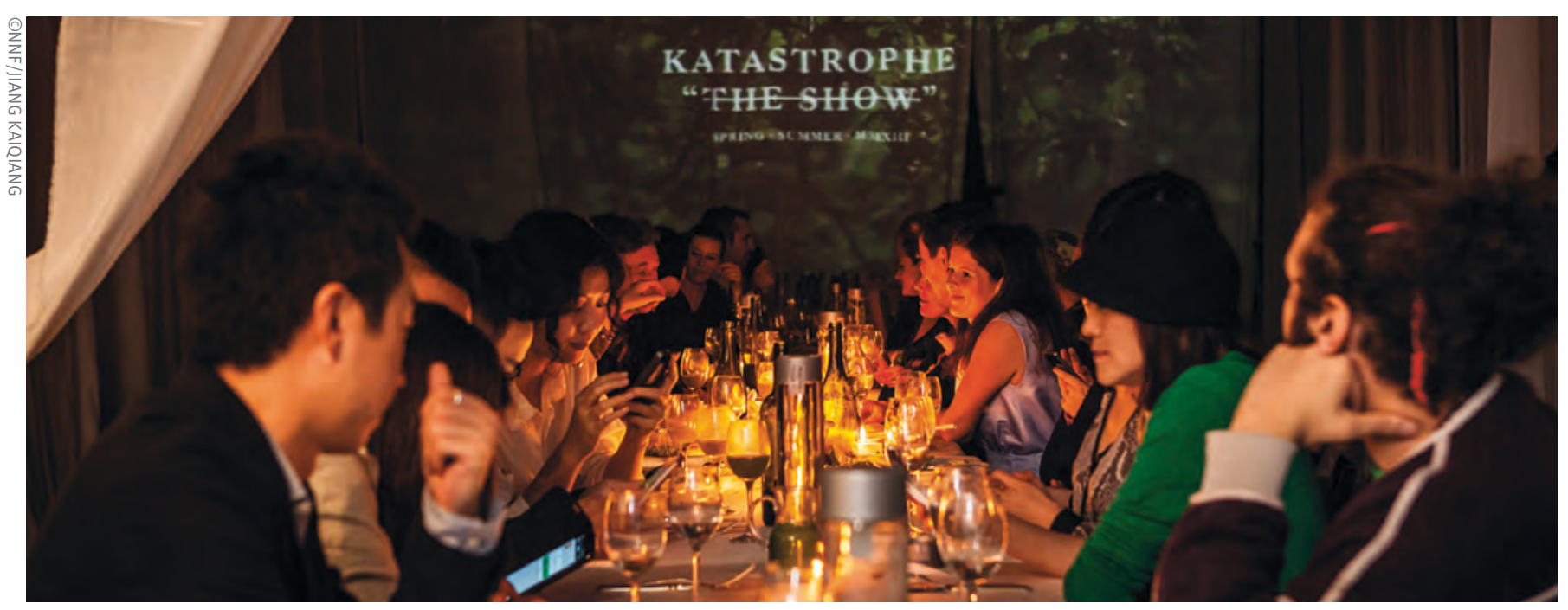

FOOSHION AT NDIW SHANGHAI 2013

\section{CONFERENCE: KREALAB NO 1, STOCKHOLM, OCT 2013}

KreaLab was a Nordic conference initiated by KreaNord and NNF II. Its purpose was to start a discussion and a process with the objective to establish the Nordic countries as the creative hub of the future. The phenomenon of creative and cultural businesses has gained increased attention on the political agenda. A number of international and Nordic creative minds participated. http://bit.ly/1BNwqBM

\section{NORDIC COOL* \\ WASHINGTON DC, FEB 2013 \\ PILOT: FOOD \& CULTURE}

In the third week of February, the Kennedy Center in Washington organised the Nordic Cool Festival, with focus on Nordic culture. More than 700 Nordic artists took part. The new Nordic kitchen was a central feature of the official programme, and NNF II supported diplomacy initiatives related to the festival. A Nordic menu was designed and served in the restaurant during the entire festival. http://bit.ly/1GdxyhC

\section{PANEL DEBATE, STAGE,} CPH FOOD FAIR, FEB 2013

NNF II promoted food as a creative industry by hosting a panel debate with participants from different Nordic industries at CPH Food Fair. The debate addressed the question: "How do we lift a new industry with an outset in Nordic food's impressive momentum and strengthen the experience of food as art and as design? What does this entail and what is the relevance? http://bit.ly/19ieldJ

\section{YAIC - A CREATIVE APPROACH TO NORDIC FOOD EXPERIENCES, REYKJAVIK, NOV 2012 PILOT: FOOD \& DIGITAL}

You Are In Control is an international annual conference, which explores digital development for the creative industries in music, art, design, media, games, literature, performing arts and film. By collaborating with NNF II in 2012, Nordic culinary experiences were for the first time included in the conference programme a new platform bringing food and creative industries together. $h t t p: / / b i t . l y / 14 d f U N K$

\section{WORKSHOP: FOOD \& CREATIVE INDUSTRIES, HELSINKI, SEPT 2012}

A significant initiative within the Food and Creative Industries project was a workshop, staged in the World Design Capital 2012, Helsinki. For the first time, professionals were gathered to discuss Nordic food as a creative industry and how it should relate to other creative industries. Crucial input was produced, relevant connections made, and visions for future Nordic cross-collaborations took shape. A follow-up workshop was organised in Copenhagen in December 2012. http://youtu.be/2xNoo-4suyo

\section{SEMINAR: A SOCIAL UPGRADE OF QUALITY OF LIFE IN RURAL AREAS, STOKКØYA, SEPT 2012}

Population statistics show a predominant one-way traffic from rural communities to cities. The trend is that more areas are being taken up by urban spaces and less and less productive soil is left to provide food for the growing population. In 2012,
NNF II hosted a seminar on food and architecture's significance for the Nordic societies. The workshop shed light on how creative and cultural sectors can create value, whether in economically challenged rural areas or those with more stable economic resources. $h t t p: / / b i t . l y / 1 A f N k s W$

\section{NORDIC KITCHEN PARTY*,} CANNES, MAY 2012

\section{PILOT: FOOD \& FILM}

The Cannes film festival is the single most important platform for promotion and sales in the film industry. In order to strengthen Nordic film's presence in Cannes 2012, the Nordic Film Industries, in collaboration with NNF II, invited buyers, the press and important festival organisers to a Nordic Kitchen Party with the taste of an innovative, Nordic cuisine and a strong message. http://bit.ly/1Dp7Sov

\section{NEW NORDIC COMPUTER FOOD*, SAN FRANCISCO, MAR 2012 \\ PILOT: FOOD \& GAME}

Game Developers Conference is arranged annually in San Francisco and is one of the largest events in the rapidly growing gaming industry. During the conference in 2012, The Nordic Game program, in collaboration with NNF II, invited 150 selected guests to experience the concept New Nordic Computer Food - a new networking platform of which food is a natural part. $h t t p: / / b i t . l y / 1 B A D G O x$ 


\title{
INTERNATIONAL FOOD DESIGN EXPERIENCE, DUNEDIN, JULY 2014
}

\author{
RESEARCH CONFERENCE \& PAPER PRESENTATION
}

The New Nordic Food II (NNF II) project Food \& Creative Industries was invited to present its pilot projects, networking methods and the Nordic Sound Bite concept at The International Food Design Experience in Dunedin, New Zealand, on 2-4 July 2014. The participation was a great opportunity and an acknowledgement of our results within the project.

The International Food Design Experience is a progressive forum where chefs, cooking enthusiasts, researchers and designers come together to explore cutting edge culinary arts. This year, NNF II project manager Elisabet Skylare and designer Nikolaj Danielsen, alongside speakers like Emilie Lucie Baltz and Chloé Morris, were invited to give keynote presentations of Food \& Creative industries' work. The topic was how to design productive collaborations across various creative industries, such as music, film and fashion, with Nordic food and design as a key element.

\section{PAPER PRESENTATION: THE NOR- DIC SOUND BITE - REDEFINING FOOD DESIGN AS POP-CULTURE}

The Nordic Sound Bite was used as a showcase of the approach, and the programme featured a presentation of a new paper "Nordic Sound Bite - redefining food design as pop-culture". The paper describes the process and method for developing the concept Nordic Sound Bite. When food and music are co-designed to strengthen the concert experience, food plays a more artistic role than it usually takes. A concept that aimed to create a position where food design can play a more strategic and powerful role than just being an add-on to a meal. Link Paper: http://bit.ly/125XCdp

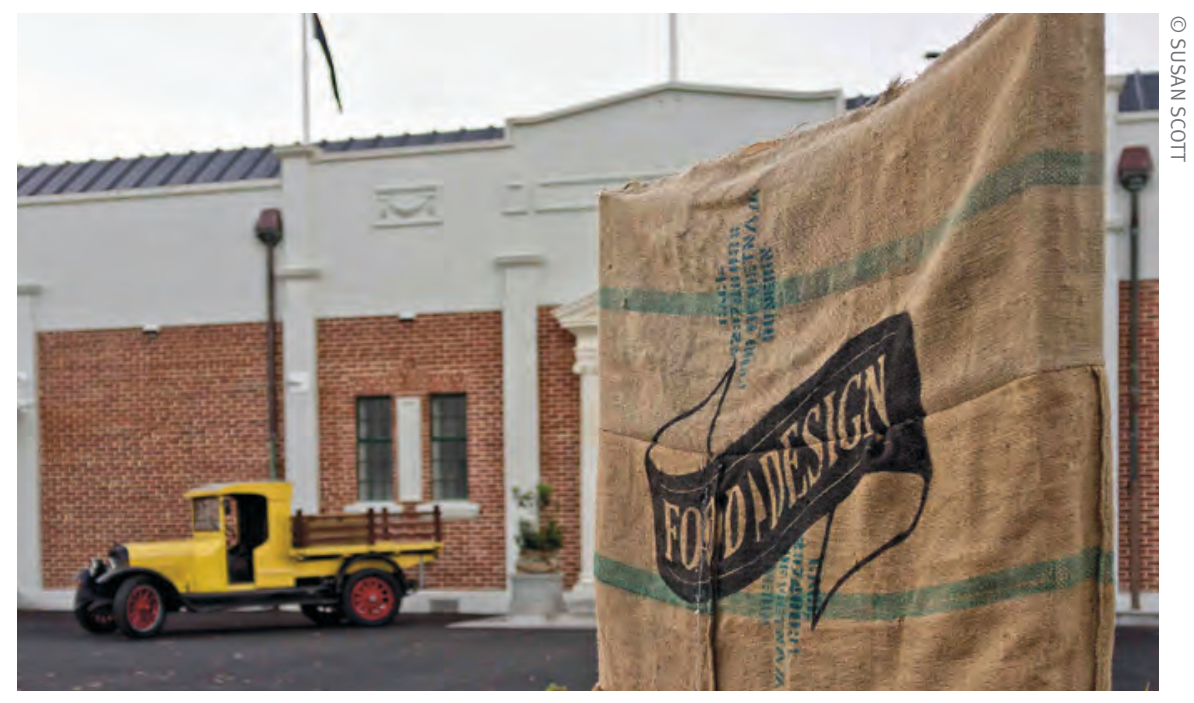

DUNEDIN, NEW ZEALAND

In addition, we hosted a studio session where conference delegates could explore the methods developed by Food \& Creative Industries. Participants got the opportunity to create their own version of a sound bite, based on the musical DNA of various bands.

\section{CONCLUSION \& COMMUNICATION}

The International Food Design Experience was a relevant platform to promote New Nordic Food, and in particular our work on food as an art form and a creative industry in itself. The academic blueprint is important for the area in general and for the methods developed within the project.

The story of New Nordic Food was spread during the conference in articles, television and social media. Contacts and networks were boosted and the idea of a future conference in the Nordic region seems relevant. Selection of media coverage:

- Article: The rise of multi-sensory dining: http://bit.ly/1P8aKVe

- Article: 'Nordic experiment created culinary identity': http://bit.ly/1P8aNR3

- Tv \& article: http://bit.ly/1DsYkgi

- Photo: http://on.fb.me/1gMfisD 

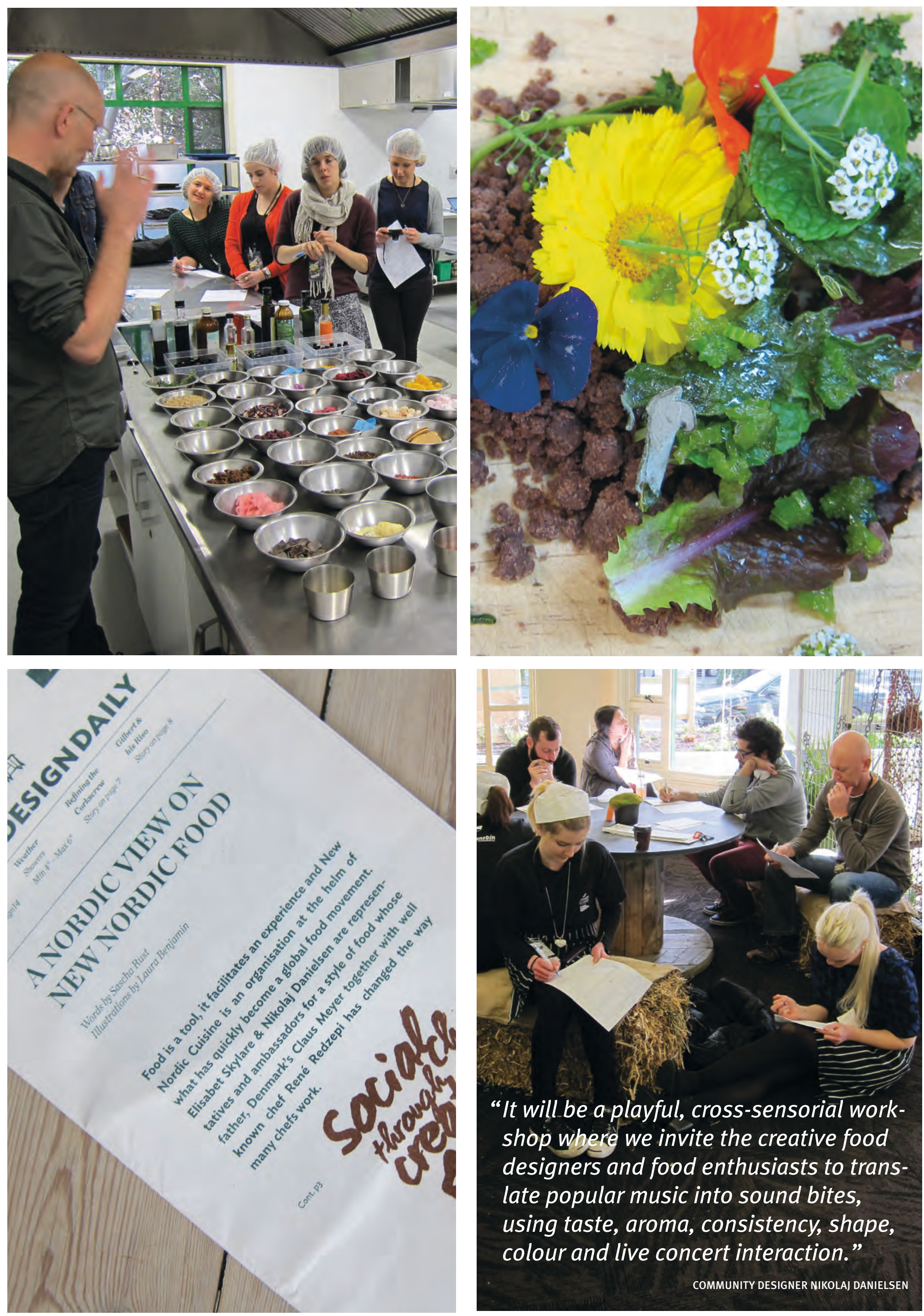

"It will be a playful, cross-sensorial workshop where we invite the creative food designers and food enthusiasts to translate popular music into sound bites, using taste, aroma, consistency, shape, colour and live concert interaction." 


\title{
JA JA JA FESTIVAL LONDON, NOVEMBER 2014
}

\author{
PILOT: FOOD, MUSIC, FILM
}

The Nordic culture has invaded the British psyche. In music, television, film, furniture, food, art and beyond, a remarkable number of things entering the British design and entertainment scene now come from the Nordics. The Ja Ja Ja club nights in London expanded in 2013 to host the first ever Ja Ja Ja Festival at the Roundhouse in Camden. The festival featured performances from Mew, NONONO, Sin Fang, and others. Music and food were united via the Nordic Sound Bite, a concept where food designers turned the sounds of artists performing at the event into culinary experiences. In 2014, the Ja Ja Ja Festival returned with a three day programme of music, food and culture, spread across two venues - The Great Hall in Mile End, and The Lexington.

The Ja Ja Ja Festival 2014 showcased the best new music from Denmark, Iceland, the Faroe Islands, Finland, Norway and Sweden alongside a menu of Nordic cuisine, exclusive screenings and more. The Finnish chef - and former member of legendary rock band HIM - Antto Melasniemi curated a cutting edge food programme inspired by a creative collaboration with the festival headline act, Icelandic singer Emilíana Torrini. Link: http://jajajamusic.com/festival/ line-up/food/

"Using catfish cheeks was one of Emiliana's suggestions, and I couldn't agree more. Of all the fish I tasted in Iceland, the catfish cheeks had the most amazing texture. The seaweed salt is also one of the oldest Nordic recipes, known since the Vikings. It is seaweed and salt burnt together and then ground. It has a wonderful taste of green sea..." Antto Melasniemi

Kitchen soundtrack by Melasniemi: http://bit.ly/1xD7Fmr

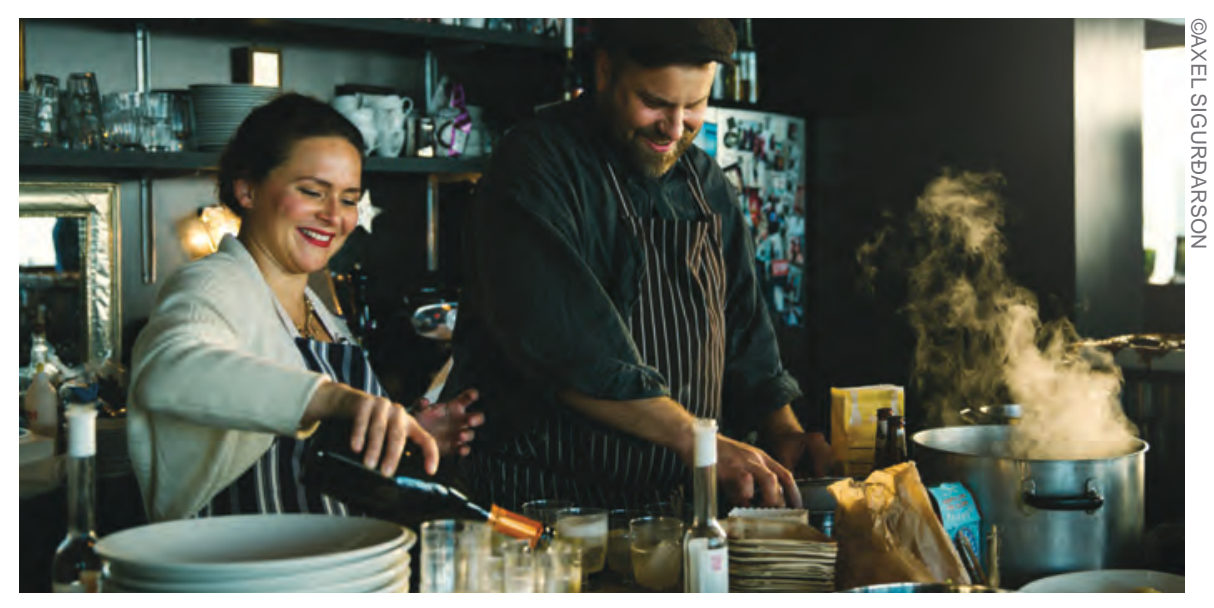

VIDEO: HTTPS://WWW.YOUTUBE.COM/WATCH?V=WRTJWGLQ9ZG\&FEATURE=YOUTU.BE

\section{COLLABORATION \& COMMUNICATION}

In 2014, NNF II further developed the ongoing collaboration with Nomex and the Ja Ja Ja festival, focusing on communication. We wanted to raise the awareness of - and the expectations for - Nordic food experiences at the festival - but also test new platforms for cross-creative collaborations that could create new experiences and stories.
During a road trip in Iceland, the food concept was developed by Melasniemi and Torrini, and also experienced on site at an informal dinner event together with international journalists. The dishes and stories behind were explored, and the following media coverage highlighted the food program for the upcoming festival. In addition, a documentary video from this creative journey was produced and widely spread. The festival was sold out. Media coverage exceeded all expectations and thus strengthened the Nordics as a brand. 

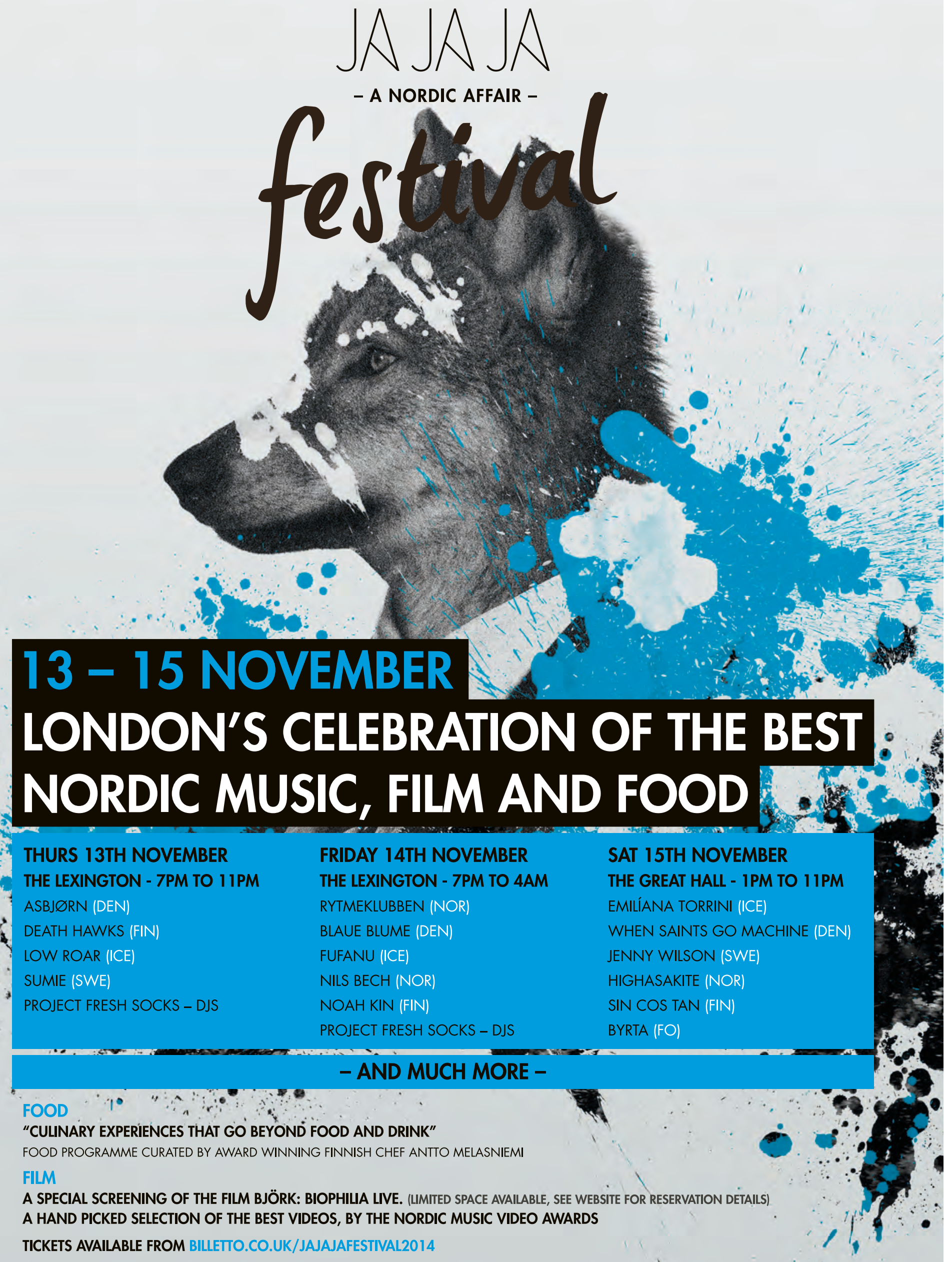

THE LEXINGTON, 96-98 PENTONVILLE ROAD, LONDON, N1 9JB (THURSDAY \& FRIDAY)

THE GREAT HALL, 327 MILE END ROAD, LONDON, E1 4NS (SATURDAY)

JAJAJAMUSIC.COM - FACEBOOK.COM/JAJAJAMUSIC - TWITTER.COM/JAJAJANORDIC - INSTAGRAM.COM/JAJAJANORDIC

norden islandsstofa

newnordicfood

Sito

중

残 


\section{NORDIC PLAYLIST RADIO BAR \\ ICELANDIC AIRWAVES, REYKJAVIK} NOVEMBER 2014

PILOT: FOOD, MUSIC \& DESIGN

The Nordic Playlist* Pop Up Radio Bar (NPL) was a food and radio pop-up concept, which unfolded in Reykjavik during the Iceland Airwaves Music Festival. The Nordic Playlist turned into an online radio station as part of the festival's off venue programme, inviting well-known radio DJs such as BBC Radio One's Huw Stephens, NRK P3s Christine Dancke and SVT PSL's Per Sinding-Larsen, to share their love for Nordic music. The three-day programme also included live performances from artists from the North, special food programme etc.

The NPL Radio Bar space and interior were specially designed for the occasion by one of Iceland's best-known experience designers, Kristín María Sigthorsdottir, who also prepared some unique food and cocktails. From the menu, guests could enjoy festival dishes like; Lamb stew, Catfish in lime and chilli and the signature NPL cake. Kristín María was recently awarded the Reykjavik Grapevine Design Award 'Project of the Year' for the event 'Story Delicious'.

\section{YOUNG TALENTS}

In 2013, the Food \& Creative industries project started to focus on tools like "open

* The Nordic Playlist was launched in 2014 and features weekly playlists curated by the regions most prominent artists and tastemakers. It is made available to stream via licensed streaming partners Deezer, Spotify and WiMP. It is produced by NOMEX, which is owned by the five music export offices in the Nordic Region and supported by the Nordic Council of Ministers. calls" in order to give emerging young talents access to different projects. The main purpose of the collaboration with the NPL Pop Up Radio Bar was to continue supporting young creative talents in bringing value into projects, exchanging ideas and expanding the Nordic network. Two creatives joined the project; Hafdis Sunna Hermannsdottir, an industrial designer from Iceland, now living in Oslo and working at Design without Borders (NGO), and Italian-born Veronica Fossa. She studied in Helsinki and has been a strong spokesman for the city's street food movement.

\section{TRAVELLING CONCEPT}

This NPL concept and project was the first of its kind and this creative experiment worked out very well. It invited the festivalgoers to the cosy hub, to hang out, eat, drink, charge up and to experience the most exciting sounds, tastes and stories from the Nordic region. The ambition to develop the project further and take the Nordic Playlist Radio Bar to events in other Nordic countries seems to succeed: The NPL Radio Bar popped up again in Oslo during the By:Larm, in March 2015.

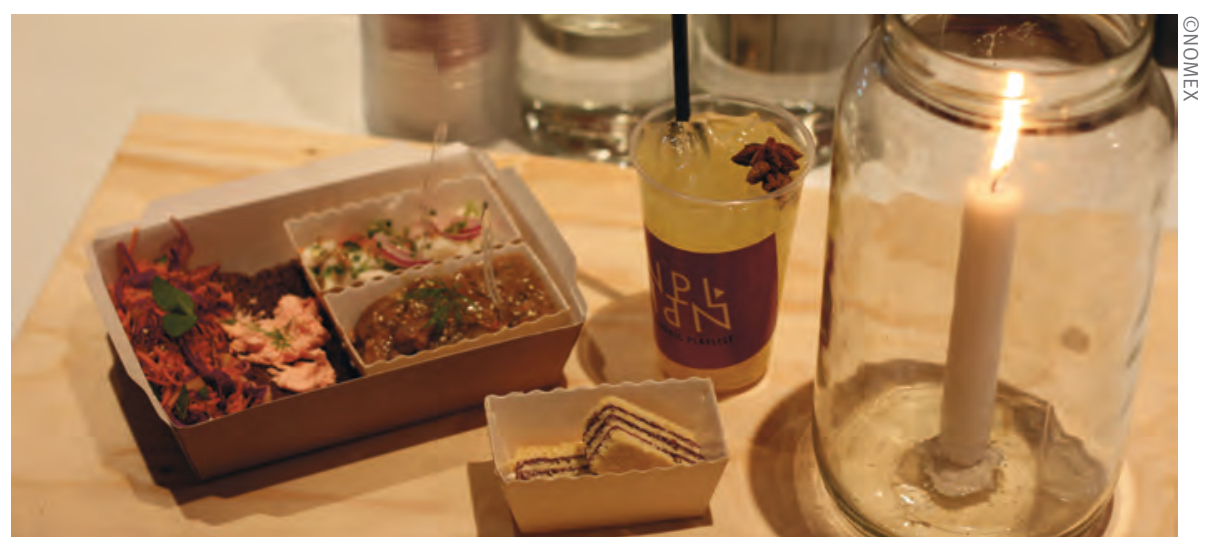




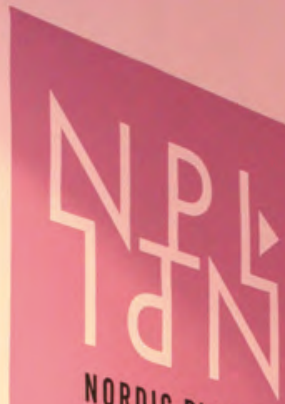

NORDIC PIAYIST POP-UPAYIST
BAR MENA

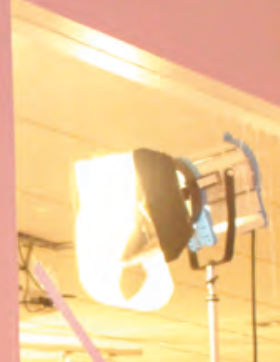
(E)
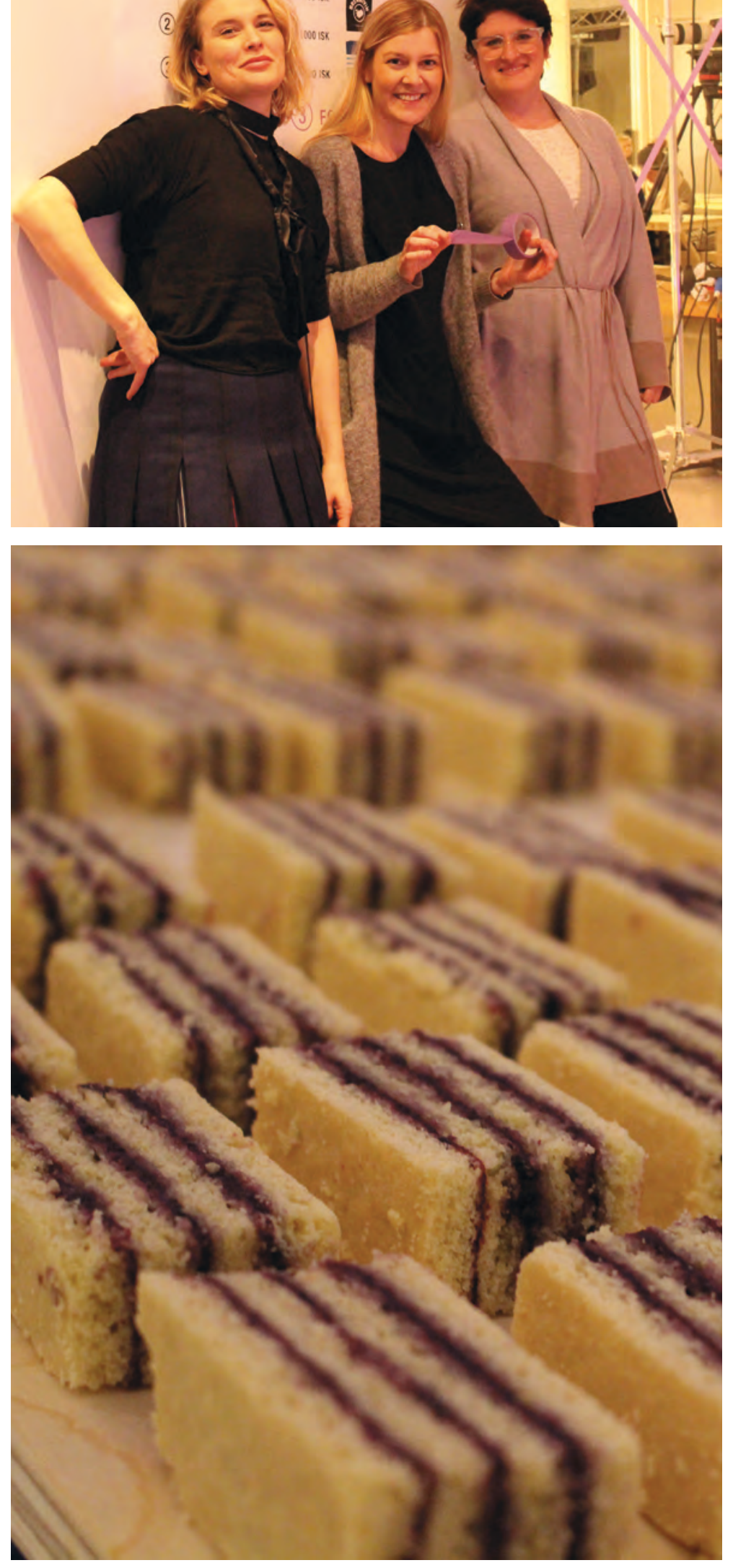

I
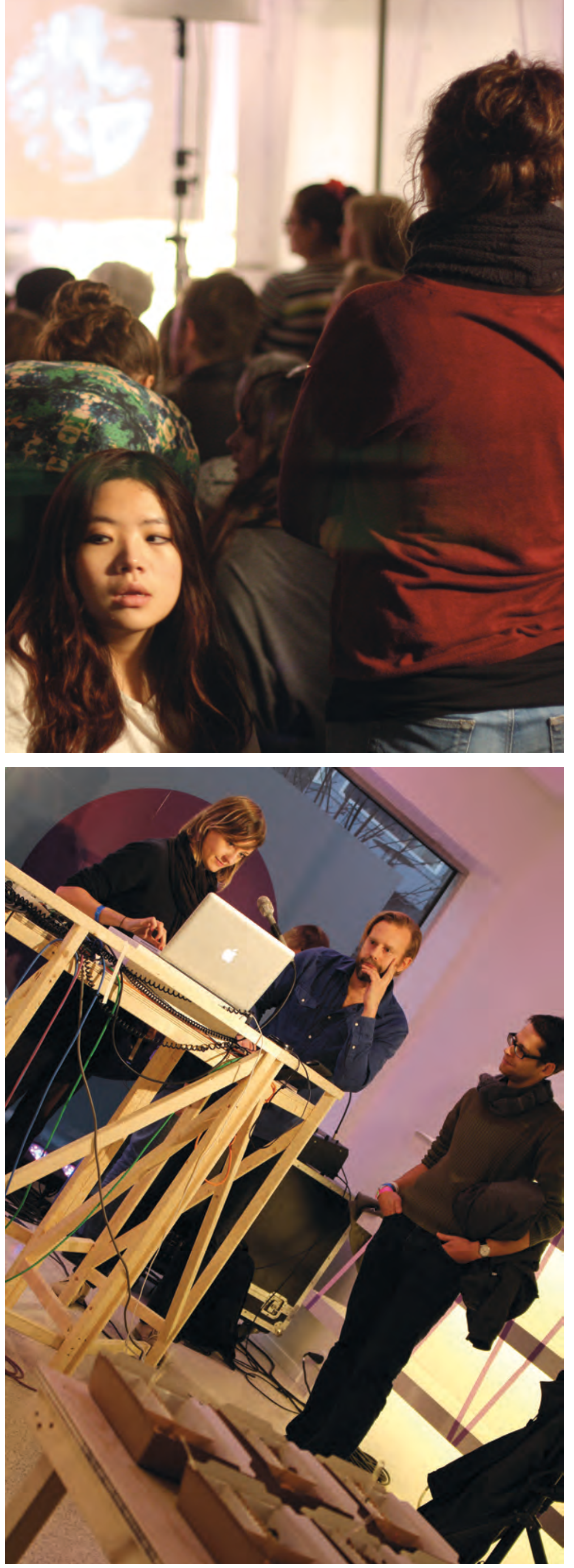


\section{NORDIC FOOD DIPLOMACY}

In 2011, the programme New Nordic Food II organised a workshop around the topic of Public Food Diplomacy. During the workshop, participants discussed how (and if) Nordic embassies use food, nationally and internationally to build and strengthen the Nordic/national brand. The conclusion was that there is a need for a toolkit with tools that can be utilised when using food and meals as a branding tool. Participants also expressed a need to define what Public Food Diplomacy really was, when used on a Nordic level. Public Food Diplomacy was later renamed Nordic Food Diplomacy to signal a Nordic focus. Nordic Food Diplomacy has thereafter been used in a seria of event to express nordic values with food and meals.

\section{NORDIC FOOD DIPLOMACY is used to} convey a tangible experience of a country or region - i.e. the taste and feel of the Nordic countries. In doing so, it strengthens the Nordic brands' position while, at the same time, underlining core values such as an innovative and sustainable development. Nordic Food Diplomacy enhances the guests' experience and allows the host to give the meal an extra dimension apart for the guest just being served. When used properly, food and meals are powerful tools for branding a region. It can also be used to tell a story or to convey a message, through the Nordic cuisine and its unique values. Nordic Food Diplomacy can be applied to all kinds of meetings, during official events, trade shows, cultural events, export initiatives, etc. By applying Nordic Food Diplomacy catering becomes an active, visible and integral part of the meeting, which reinforces the agenda and, by sending a stronger message, provides a richer experience. There is a web based tool kit developed containing lots of tools and inspiration of how to use Nordic Food Diplomacy. See page 32

\section{ACTIVITIES 2011-2014}

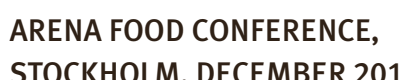

A group of Nordic people working with different project revolving around arena food met during a lunch to lunch conference in Stockholm to discuss the development of Arena Food in the Nordic Countries. The purpose of the workshop was to bring the topic of better and healthier arena food into a Nordic discussion. This was done through knowledge sharing and inspiration through a number of presentations and discussion.

\section{MASTER CLASS OF THE NORDIC KITCHEN, SHANGHAI, NOVEMBER 2013,}

\section{PILOT: FOOD \& EXPORT}

New Nordic Food strengthened the Nordic brand at Nordic Design \& Innovation Week in Shanghai. Nordic TV-chef Tareq Taylor from the BBC show "Tareq Taylor's Nordic Cookery" introduced the Chinese media, chefs, students and representatives from the import businesses to Nordic Food by conducting a master class on the Nordic Kitchen. 250 people showed up and
Tareq was afterward invited to come and cook on a local TV-show with over a million viewers. Link: https://www.youtube.com/ watch?v $=x m Q v \times 084 z C 4$

\section{NORDIC COOL, WASHINGTON DC, FEBRUARY 2013}

PILOT: FOOD \& CULTURE *

During the third week of February, the Kennedy Center in Washington organised the Nordic Cool Festival, which entirely focused on Nordic culture. More than 700 Nordic artists were represented in the American capital. The new Nordic kitchen was a central feature of the official programme, and in initiatives by the Nordic embassies.

\section{NORDIC STAR CHEFS IN JAPAN, TOKYO, OCTOBER 2012}

Five Nordic chefs participated in a week of guest appearances, at Japanese restaurants, cooking demos, workshops and talks of the Nordic Food movement. It was a collaboration between NNF II, Nordic Innovation and the Nordic Embassies in Japan. 


\section{"By applying Nordic Food Diplomacy catering becomes an active, visible and integral part of the meeting, which reinforces the agenda}

and, by sending a stronger message, provides a richer experience."

\section{NORDIC KITCHEN PARTY, CANNES MAY 2012, PILOT: FOOD \& FILM * \\ The Cannes film festival is the single most important platform for promotion and sales in the film industry. In order to strengthen the Nordic Film Industries' presence in Cannes 2012, the Nordic film industries, in collaboration with NNF II, invited buyers, the press and important festival organisers to a Nordic Kitchen Party with the taste of an innovative, Nordic cuisine and a strong message. Link: https://www.youtube.com/ watch? $v=D \times 8|B| \times h u V_{4}$ \\ NEW NORDIC COMPUTER FOOD, SAN FRANCISCO, MARS 2012 PILOT: FOOD \& GAME *}

Game Developers Conference is arranged annually in San Francisco and is one of the largest events in the rapidly growing game industry. During the conference in 2012, The Nordic Game program, in collaboration with NNF II, invited 150 selected guests to experience the concept New Nordic Computer Food - a new networking platform where food is a natural part. Link: https://www.youtube.com/ watch? $=15 / h n p E 4 O w Y$

\section{STARTING WORKSHOP,}

\section{STOCKHOLM, MARS 2011}

This first phase of the project was to search ideas for tools and cooperation. This started with a workshop in Mars 2011, with participants from Nordic foreign ministries and export organizations.

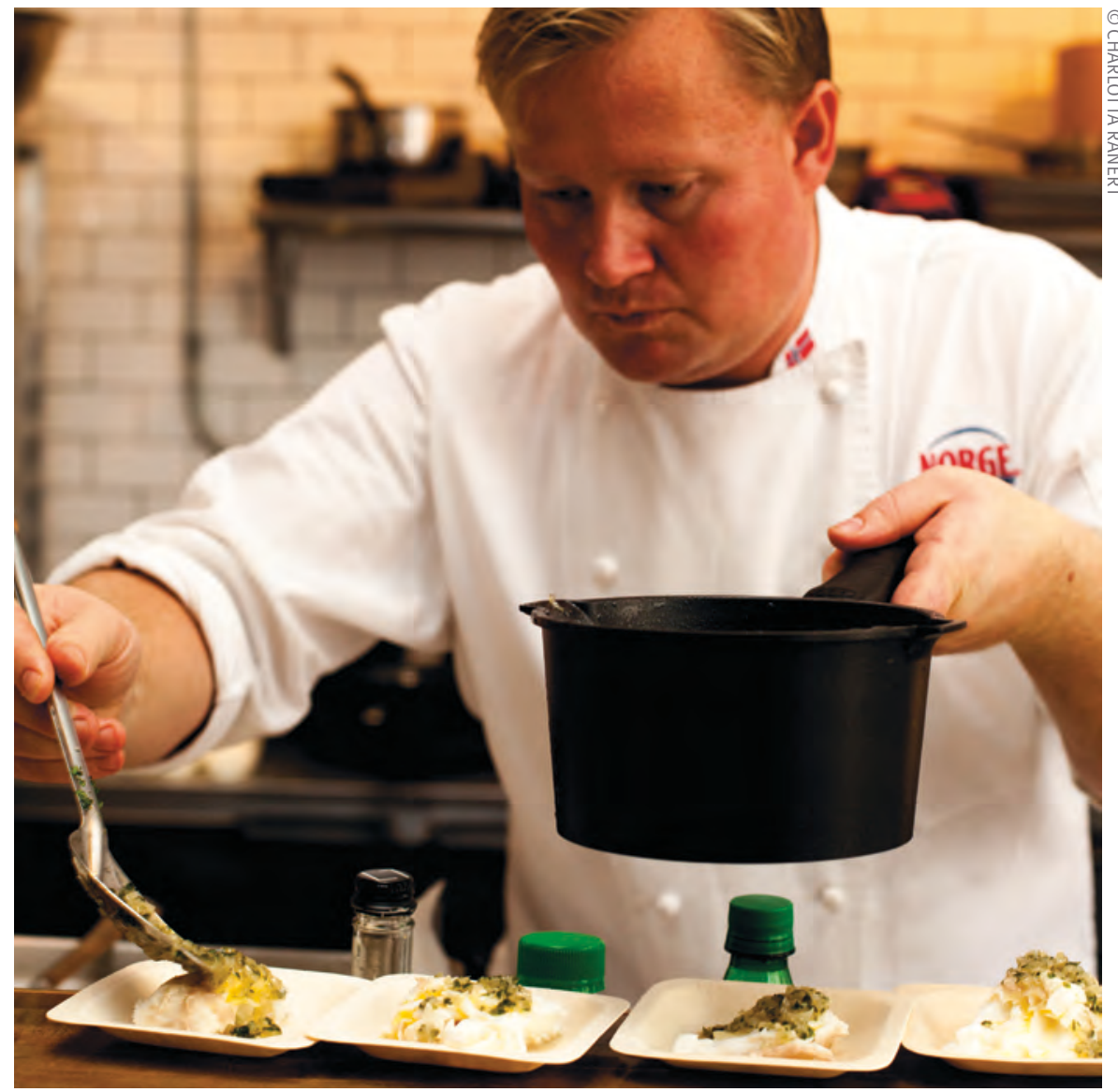

\section{MORE INFO}

All project can be seen at:

http://nynordiskmad.org/projekt/nordic-food-diplomacy/

New Nordic Food II - A Popular Movement Continues. ANP 2013:740. page 16-17

Ny Nordisk Mat Årsrapport 2013, page 12-17 see http://nynordiskmad.org/fileadmin/webmasterfiles/Billeder/NNM-Årsrapport-2013_final.pdf 


\section{NORDIC FOOD DIPLOMACY AND CREATING A WEB-BASED TOOL KIT}

The Steering Committee for NNF II decided to develop "Public Food Diplomacy" according to the guidelines in the final report from the workshop held with representatives from the Nordic Foreign Ministries, in Stockholm in the spring of 2011. The report highlighted three areas of focus for the next phase of the project.

- Construct a website with a Tool Kit

- Develop pilot cases to test the tools and the concepts

- Communicate the pilot cases and the website

The following aspects were to be considered when developing the website:

- Develop the Tool Kit with diplomatic affairs in mind, but this should not be the only target audience. Target groups would be all those who work with food and entertainment, or food for national, Nordic or international meetings and events.

- Further develop the network of contacts that was set up during the workshop in Stockholm in March 2011. This initially established a dialogue with all the foreign ministries in the Nordic countries.

- Emphase the development of inspirational material and useful guidelines and concepts in the Tool Kit mentioned in the report.

- Co-operate with NICe's initiative related to this area.

- Maintain regular contact with KreaNord to develop links to their work.

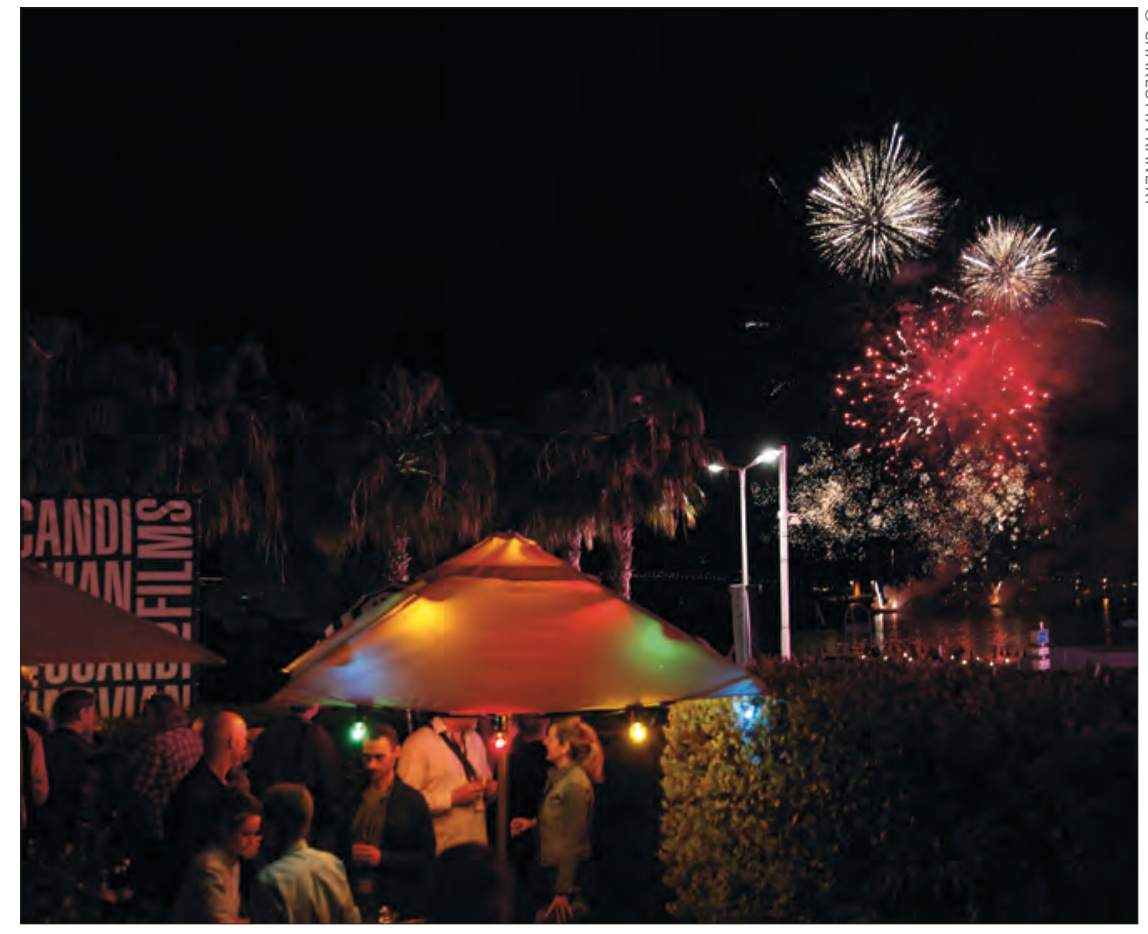

- Another important task was to engage and seek potential sponsors and partners who might participate in the financing of future work.

- Link "food \& culture" and "food \& creative industries".

- Create a brokerage section, where chefs who adhere to the Kitchen Manifesto can make contact with prospective clients.
To make it clear that the project was aimed at using Nordic Food it was renamed Nordic Food Diplomacy. This has now become a widely used phrase. The website with the Tool Kit was launched in the spring of 2012, and several pilot projects have been conducted. The tools have been used and tested extensively during all the pilot projects. All of the above mentioned guidelines were included in the project. 


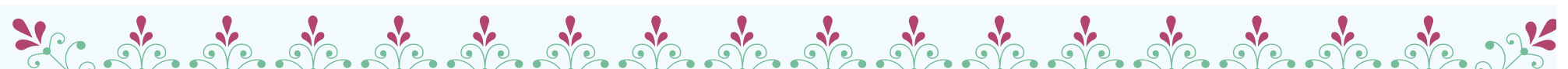

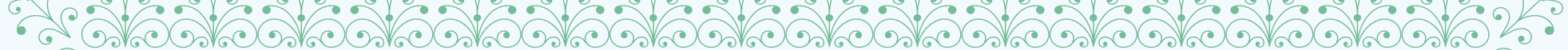
- ?

$\rightarrow \frac{6}{6}$

NORDIC KITCHEN PARTY

CANNES FLLM FESTIVAL 2012

$-\frac{6}{6}$

$-5$

$\rightarrow$ e

Iil

$-\frac{0}{6}$

$\rightarrow$

$6=600$

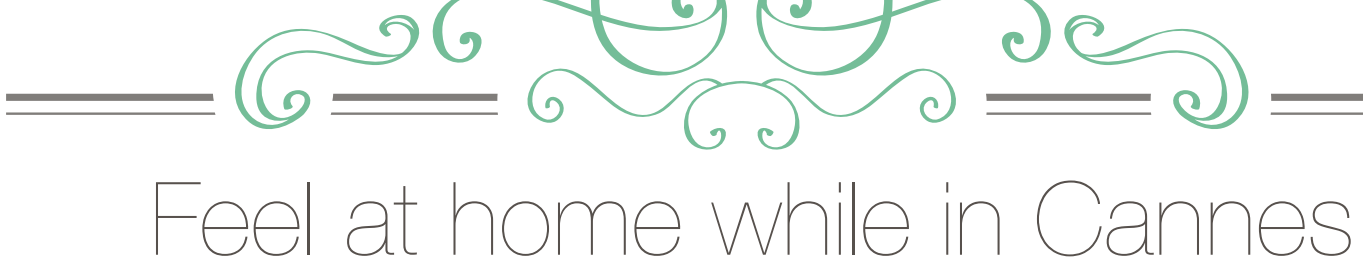

-

$-\frac{0}{6}$

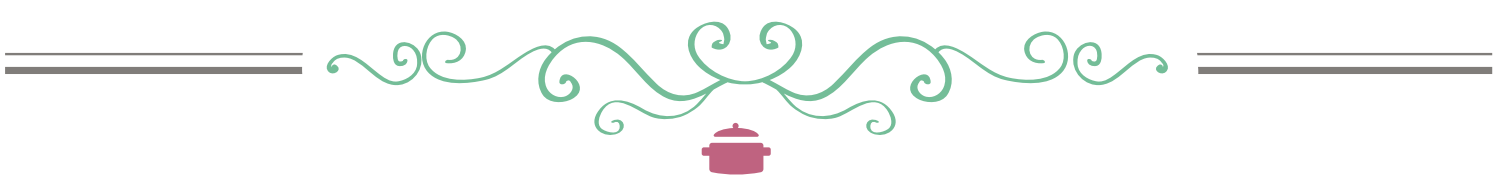

$\rightarrow$

$\rightarrow$ c

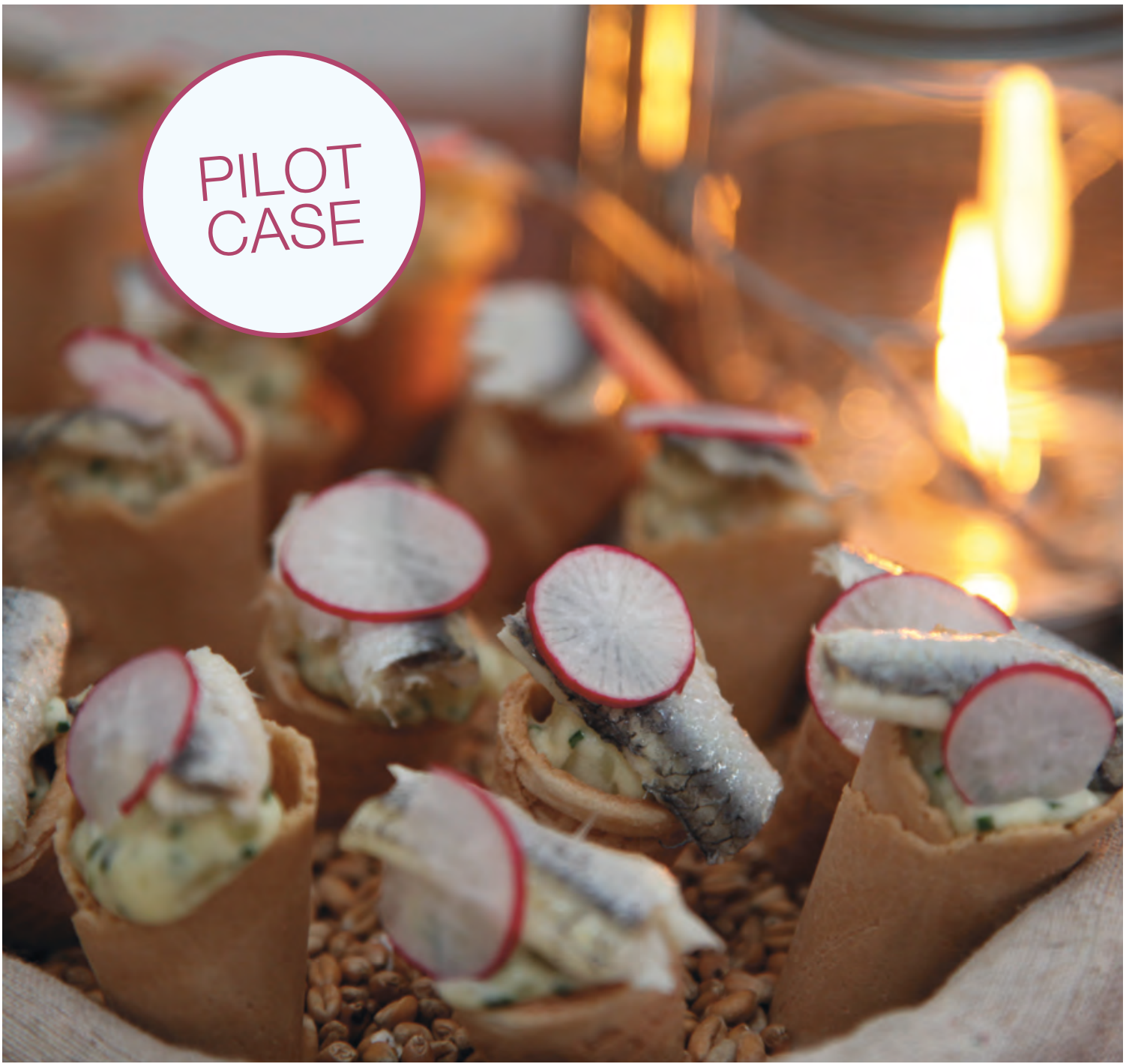

क)

2) $\%$

2.

3

(3)

2.

(3)

3.

c)

o)

क)

:

?

:

S?

c.

?.2?

c)

(อ)

$\rightarrow \frac{0}{6}$

$\rightarrow$ ?

6.

$\rightarrow$

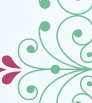

ec

6)

- की

$\rightarrow$

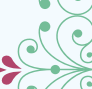

C

- 6

$\rightarrow$ C

$\rightarrow$ e?

$\rightarrow$

०.

- 6

-

()

2) \%

(.)

\%?

(อ)

2)?

(อ)

(9)?

(อ)

ग) कै

3.)

s.

?

2.

(3)

9)

(3)

श) ?

3.)

\%?

c.)

(9)

2.

(c)

9) 2 


\section{THE NORDIC COUNTRIES AS A SUSTAINABLE GASTRONOMIC REGION}

The region's rich food culture and quality restaurants have become world-renowned in recent years and tourists increasingly associate the Nordics with the pleasure of enjoying fresh, local and sustainable food. All the national Nordic tourism entities have in recent years actively use food, gastronomic events and the culinary heritage in their national branding. New Nordic Food have initiated and encourages cooperation between the Nordic countries, through various events, to strengthen the common gastronomic profile even further and optimise the use of it, as a selling point in tourism.

\section{SOME OF THE PILOT PROJECTS during} the period had a street food focus and others focused on Nordic Food Diplomacy, e.g. using food as a tool to strengthen the Nordic countries and Nordic brands. Cross creative collaborations between the creative industries and organisations promoting the Nordic countries branding wise abroad, have been at focus trough out this period. To take advantage of all senses using food as a branding tool should be a common practice. Then a more holistic approach should be used in different events of branding initiatives. Here collaborating with the creative industry is of great value and adds new and exciting elements.

\section{COMMENTS}

It has been four years of extensive collaborations and it its obvious that the Nordic networks started during this projects will keep on working together sharing knowledge and inspiration. The relevance of the Street Food movement with New Nordic Food as a neutral platform for collaboration is a great showcase for future initiatives and areas strengthening the Nordic region as an attractive and sustainable gastronomic region. Nordic Food is still the food of the moment across the world with NOMA moving to Japan and Claus Meyer opening a Nordic Food Hall in NY.

\section{ACTIVITIES 2012-2014}

\section{SCANDINAVIAN LIGHT \& DESIGN, VIENNA, NOVEMBER 2014*}

Scandinavian Light \& Design is an export promoting activity, jointly organised by Business Sweden and the Swedish and Norwegian embassies in Vienna. The event has established itself among the main target group; designers and architects, as an exciting and steadily growing opportunity to meet and to showcase the Nordic light and furniture exhibitors' products. This year the SLD event had a theme called Acoustics and a food designer, a visual arts designer and the embassy chef created a multisensory experience based on this theme. See page 42

\section{NORTH NORDIC FOOD FESTIVAL, NEW YORK, SEPTEMBER 2014*}

In September 2014 Nordic Tourist organizations participated during NORTH - the Nordic Food Festival in New York. The Food Festival was organised by

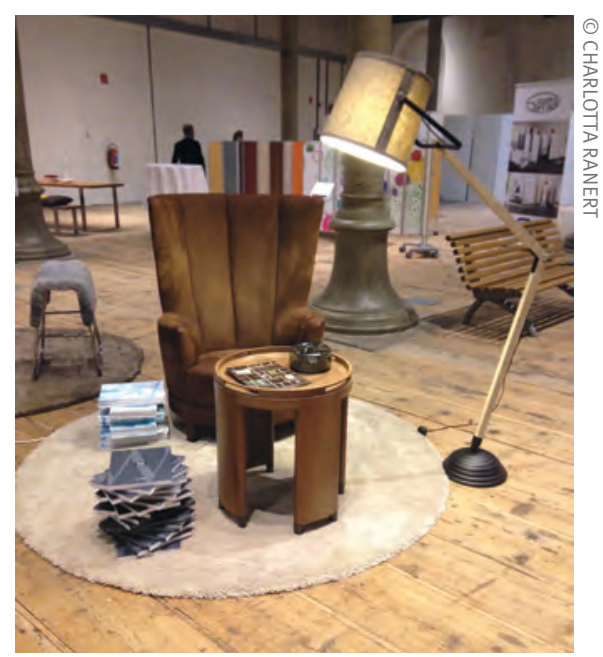

SCANDINAVIAN LIGHT \& DESIGN, VIENNA

Honest Cooking and this was the second year the festival took place. People from several countries came to the Big Apple to experience the New Nordic movement in a unique and innovative way. Top chefs from Scandinavia teamed up with new young talent as well as locally based culinary legends to ignite the New Yorkers' senses. See page 40

\section{STREAT HELSINKI,} HELSINKI, MARCH 2014

In February 2013, New Nordic Food kick-started the Nordic Street Food 


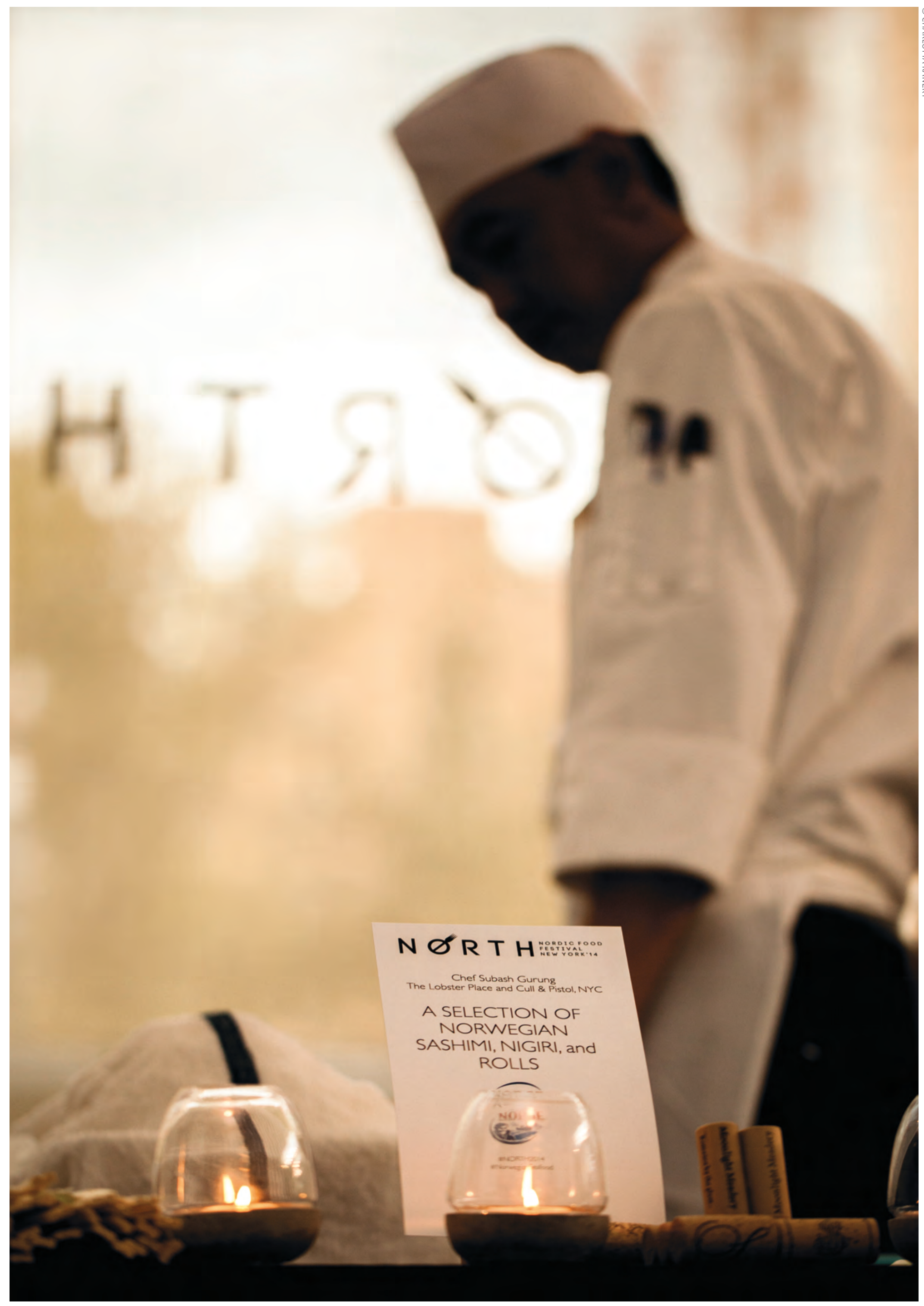




\section{"Cross creative collaborations between the creative industries and organisations promoting the Nordic countries branding wise abroad, have been at focus trough out this period."}

revolution with a conference in Malmö. As one result of this, Helsinki decided to build on this initiative and included a Street Food Conference at their yearly Gastro Fair 2014, as a part of the town's strategy for culture. During a two-day event 500 people attended the conference Streat Helsinki Talks and over 20000 joined the party Streat Helsinki Eats, in the city center. Link: https://www.youtube. com/watch? $v=H k_{13} E_{Z} Y_{180}$

See page 38

\section{WORLD FOOD TRAVEL SUMMIT,} GOTHENBURG, SEPTEMBER 2013

New Nordic Food acted as partner for the World Food Tourism Association at the second World Food Travel Summit in Gothenburg. Participants from around 40 different countries spent three to five days learning about the latest trends in culinary travel. New Nordic Food was deeply involved in creating the programme for the conference, adding Nordic speakers and best cases to the conference programme and serving a lunch focusing on Nordic Street Food.

\section{STREET FOOD FESTIVAL AND CONFERENCE, SAN FRANCISCO, AUGUST 2013}

A Nordic delegation headed off to San Francisco in August to participate in the world's first and largest street food festival and street food conference. The aim of this trip was to gain further knowledge about street food and inspiration to develop the Nordic street food scene.

\section{EUROVISION SONG CONTEST, MALMÖ, MAY 2013 \\ PILOT: FOOD \& MUSIC}

The New Nordic Food Programme raised the question of using food as a branding tool during the ESC in Malmö in May 2013 and contributed to the first ever food strategy for the event. A flavour profile was developed containing five different flavours, which represented the Nordic countries, Sweden, Skåne and Malmö

\section{MORE INFO}

The project "The Nordic Countries as a Sustainable Gastronomic Region" is funded by the Swedish Ministry of Foreign Affairs

New Nordic Food II - A Popular Movement Continues. ANP 2013:740. page 20-21

Ny Nordisk Mat Årsrapport 2013, page 32-37 see http://nynordiskmad.org/fileadmin/webmasterfiles/Billeder/NNMÅrsrapport-2013_final.pdf 


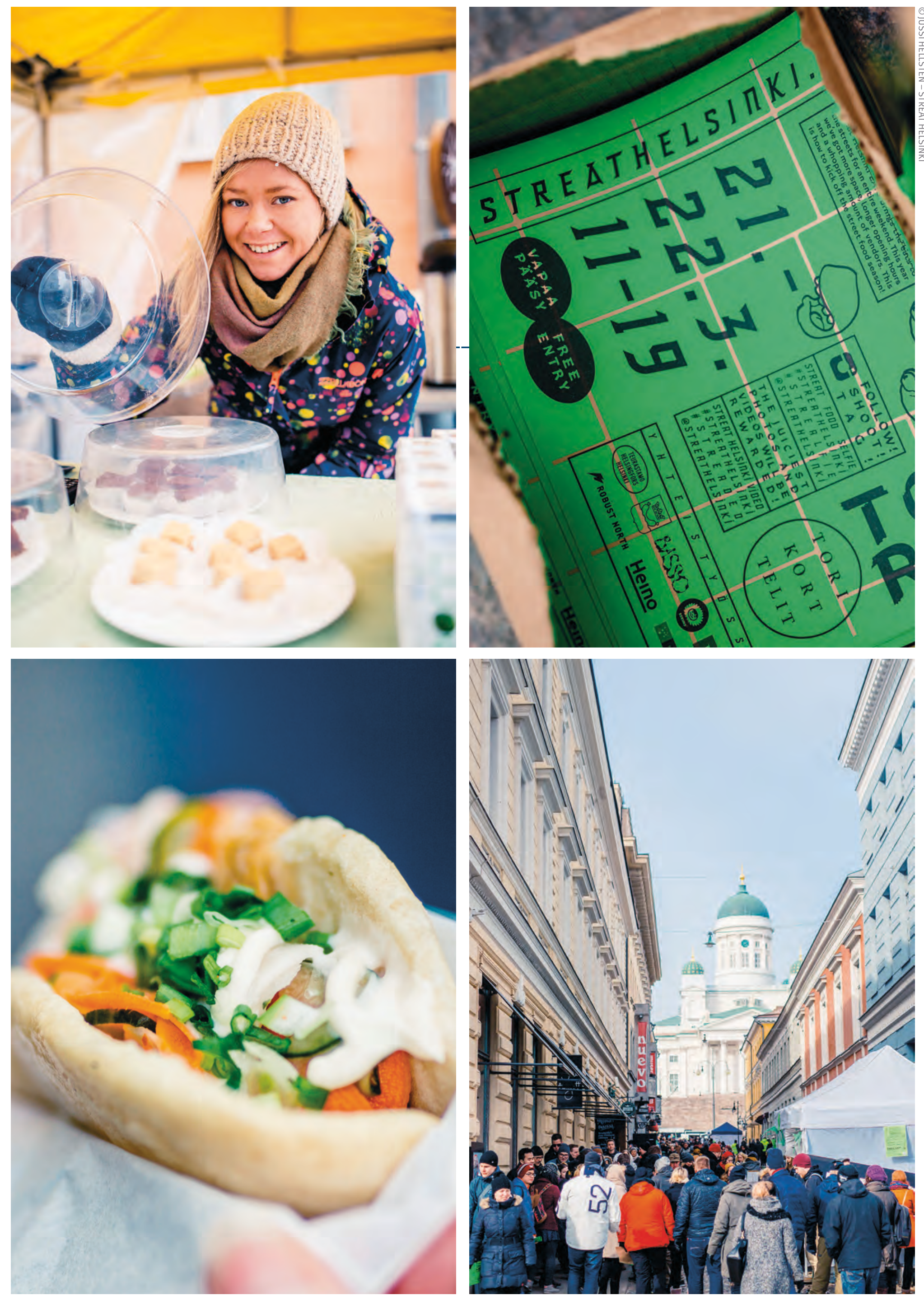




\section{STREAT HELSINKI \\ HELSINKI, MARCH 2014}

The Nordic Countries as a Sustainable Gastronomic Region

In February 2013, New Nordic Food kick-started the Nordic Street Food revolution with a conference in Malmö. Encouraged by the success of the conference and the interest the participants showed in gaining more knowledge about street food and its possibilities NNF initiate more street food activities. A Nordic street food network was established and the programme attended the Street Food Festival and conference in San Francisco in August 2013.

As a result of this Helsinki decided to build on this initiative and included a Street Food Conference at their yearly Gastro Fair 2014, as a part of the town's strategy for culture. During the two-day event 500 people attended the conference Streat Helsinki Talks and over 20000 joined the party Streat Helsinki Eats, in the city center.

\section{STREET FOOD IS A GROWING FOOD} TREND all over the world, and an attractive part of what a country can offer to visitors. Street Food is also a great way to start a business for budding entrepreneurs in the catering sector, since start-up costs are low. The numbers of street food vendors in the Nordic countries are growing. Since the conference in Malmö, Copenhagen has opened a unique Street-Food venue at Papiröen in the town centre. Moreover, inspired by the New Nordic Food Programme initiative, a

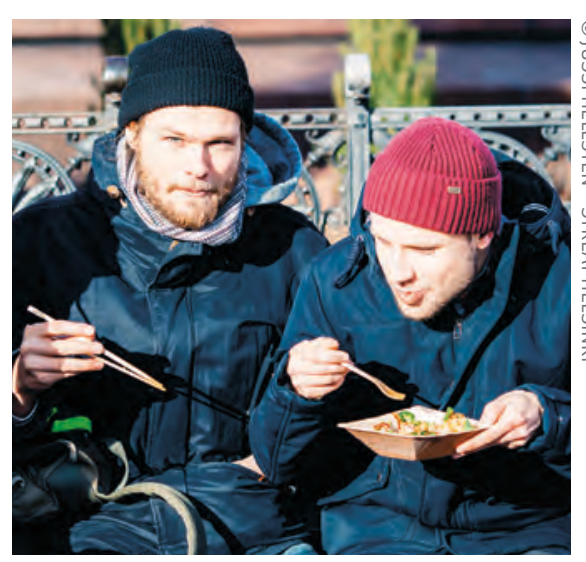

Nordic Street Food company has started in Malmö, using solely regional and Nordic ingredients. In Stockholm there is a great turn out of both food trucks and people who love good food at the Horntulls Market and food trucks are spreading around the county of Sweden.

The Nordic countries are continually raising their profile by participating in Street Food activities such as British Street Food Awards, San Francisco Street Food festival etc. Therefore, Street Food can be used to build on the Nordic countries' food profile and be used as a tool for promotion. Moreover, Street Food can attract more entrepreneurs and thus create job opportunities. Most importantly, Street Food is fun, young and attractive and can liven up cities and village in many parts of the Nordic countries.

\section{ACTIVITIES}

On Friday the 21 March, Streat Helsinki Talks gathered 22 top international speakers and 500 excited attendees at the Helsinki Expo and Convention Centre. The guests were a mix of food entrepreneurs, facilitators, food writers, business developers, council officials and chefs. Several had been flown in from the US, South Africa and the Nordic countries. During the day, lessons were taught and learned from top business incubators, and inspiration drawn from Street Food revolutions taking place in other cities, as well as from success stories in the field. In the evening of the first day of the event, a street food celebration was held at the Abattoirs Kellohalli restaurant, where hundreds of Street Food lovers gathered for a feast.

The next day, 37 street kitchens filled the old Tori quarters in Helsinki. Local Finnish Street Food vendors such as Tortilla House, Richars McCormicks's Oyster Bar, Twisted Street Kitchen and many others as well as several trucks from Stockholm were parked in the area. The people of Helsinki participated with great joy and an estimated 20000 people attended the venue. 


\section{"Street food is a growing food trend all over the world, and}

an attractive part of what a country can offer to visitors."

\section{RESULTS}

The most obvious result is that Streat Helsinki will be a returning event in March 2015 and hopefully for many more years to come. Another result is the Street Food carnival happening in Helsinki on a weekly basis. The networking part between participating organizations, vendors, delegates, speakers, etc. will keep on growing and Street Food becoming an addition to the North - Nordic Food Festival in NY as well. The FB page has over 8500 likes and over 1000 pictures were posted to Instagram. The City of Helsinki's food culture strategy has included Street Food as an important part of the city's marketing. In addition to the Street Food kitchens, a number of opinion leaders and chefs from the local food world took part and saw it as a chance to develop their businesses too.

\section{DISCUSSION}

The Nordic Street Food movement is here to stay but it is still in its very early stages. People will demand better Street Food in the future and also to be able to sample the Nordic food culture in the streets. It is still difficult for food trucks and other food vendors to act in many Nordic cities. Not all city officials understand the value of food trucks serving local and regional food. This is something that has to be worked on, in the future. Also the pricing for hiring a spot and the criteria for getting one of the sought after food truck permits are things that have to be taken into consideration, if we really would like the Nordic Street Food revolution to take off.

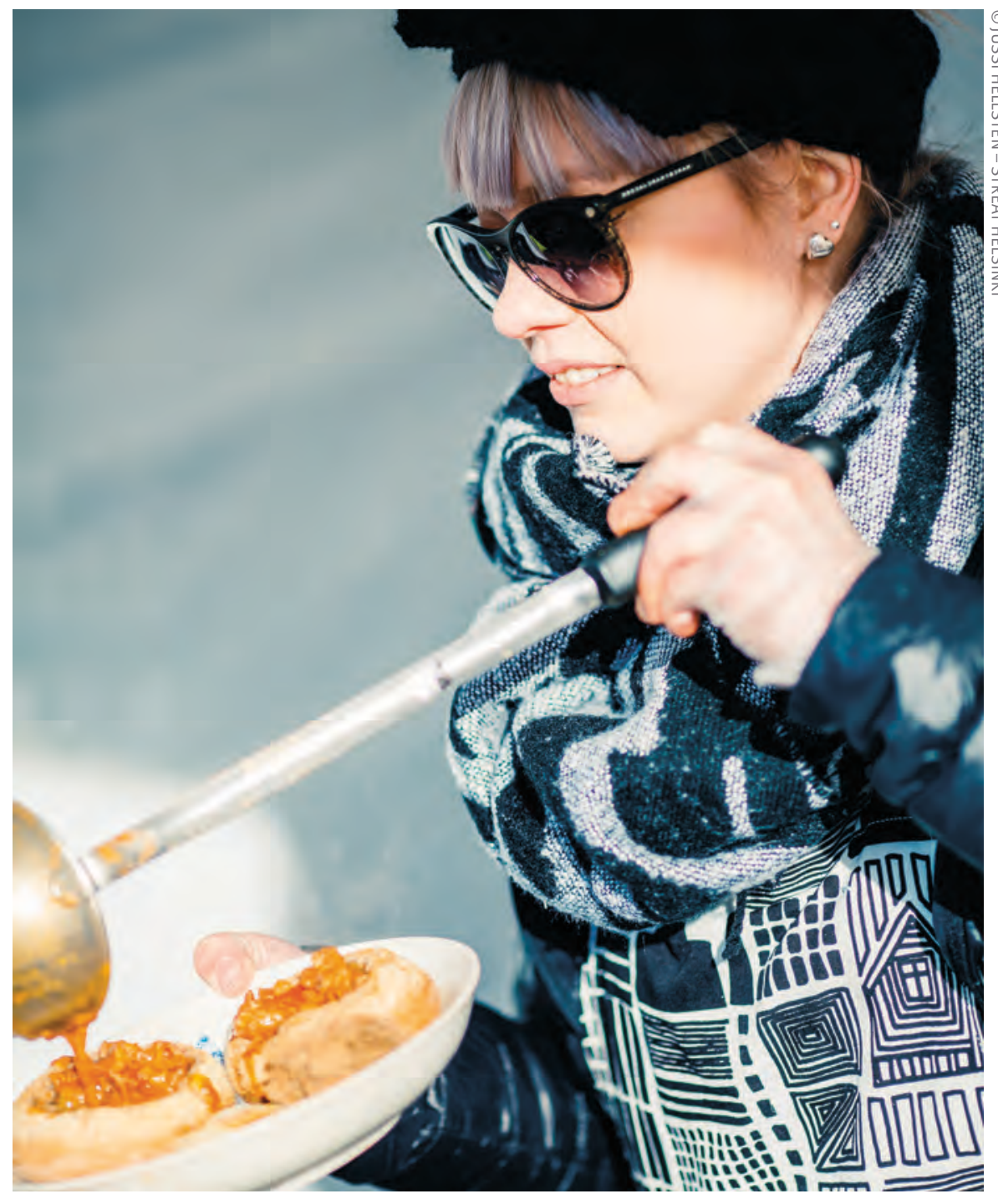

\section{MORE INFO}

See full report:

http://nynordiskmad.org/tema/norden-som-gastronomisk-region/ 


\title{
NORTH NORDIC FOOD FESTIVAL IN NEW YORK, SEPTEMBER 2014
}

\author{
The Nordic Countries as a Sustainable Gastronomic Region
}

\section{In September 2014 Nordic Tourist organizations participated during NORTH - the Nordic Food Festi- val in New York. The Food Festival was organised by Honest Cooking and this was the second year the festival took place. People from around the world came to the Big Apple to experience the New Nordic movement in a unique and innovative way. Top chefs from Scandinavia teamed up with new young talent as well as locally based culinary legends to ignite the New Yorkers' senses.}

\section{AS PART OF THE NEW NORDIC FOOD II} PROGRAM, the project named "The Nordic Countries as a sustainable Gastronomic Region" was set up to increase cooperation between national tourist organizations. Together, around 30 organizations in the Nordic countries have identified areas in which they will cooperate in order to strengthen the Nordics as a gastronomic region. As part of this work NNF participated during NORTH - the Nordic Food Festival in New York

The aim of the festival was to brand Nordic gastronomy to NY foodies and media. By participating, New Nordic Food aimed to introduce some new element as well as bringing young talents into 2014's food festival. To make the festival more democratic and appealing to wider audience activities around, Nordic Street Food were included. Another element was the panel sessions, which opened the festival and were added to create a platform for a more academic and strategic discussion around Nordic Food and lifestyle in general.

\section{ACTIVITIES}

All together the festival offered somewhat over 25 different activities. The activities

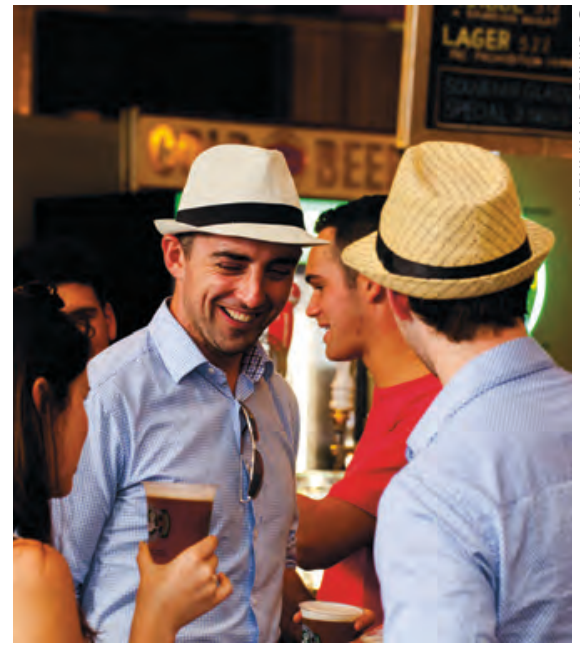

NORTH NORDIC FOOD FESTIVAL, NEW YORK

took place all over New York. Among the activities offered during the week were exclusive dinners and pop up restaurants. Here Nordic chefs collaborated with American chefs or dinners where the Nordic chef took over the Pop Up space for a night. The festival opened with two panel sessions on the topics of Nordic Food and Nordic Lifestyle. The idea of the panel sessions where introduced by the program. There were also a lot of different cooking classes and demos being offered as well as press only exclusive dinners. The Nordic Hot Dog Championship and the street food festival at The Brooklyn Brewery were events that New Nordic Food introduced to the festival.

\section{DISCUSSION}

NORTH - Nordic Food Festival was a great success as a Nordic branding initiative. The timing was right as interest for the Nordic cuisine is on the up. And when food concepts such as Meyers Madhus, MAD and Noma move into New York as planned, it predicted to grow even further.

The festival has grown bigger year by year and management and organization has room for improvement. The hostmanship and networking arenas could be much improved. The chefs had to work under some pretty bad conditions.

However, happy guests and extensive media attention carry a big value. The strong collaboration with the creative industries around the Nordics and the US, this event offers means that there is a great potential for creating a strong arena for a Nordic presence in New York. Furthermore, the event offers valuable networking opportunities for participating Nordic organisations and chefs. 



\section{SCANDINAVIAN LIGHT \& DESIGN} VIENNA, NOVEMBER 2014

\section{The Nordic Countries as a Sustainable Gastronomic Region}

\section{Scandinavian Light \& Design is an export promoting activity, jointly organised by Business} Sweden and the Swedish and Norwegian embassies in Vienna. The event, which was arranged for the seventh consecutive year, has established itself among the main target group; designers and architects, as an exciting and steadily growing opportunity to meet and to showcase the Nordic light and furniture exhibitors' products. Thus the concept has become a platform for networking and meetings between Scandinavian design enterprises and key individuals on the Austrian market. This year the SLD event had a theme called Acoustics and a food designer, a visual arts designer and the embassy chef created a multisensory experience, based on this theme.

\section{TO STRENGTHEN THE NORDIC AMBIANCE} AND BRAND, this year Scandinavian Light \& Design collaborated with the New Nordic Food Programme. The main purpose was to create a multi-sensory experience by serving food with an unmistakably Scandinavian feeling and character. This was a new collaboration between the Swedish and Norwegian Embassies, the Embassy chef, the visual artist, the food designer and Business Sweden.

\section{ACTIVITIES}

At the event there were visuals showing the dense and quiet Nordic winter

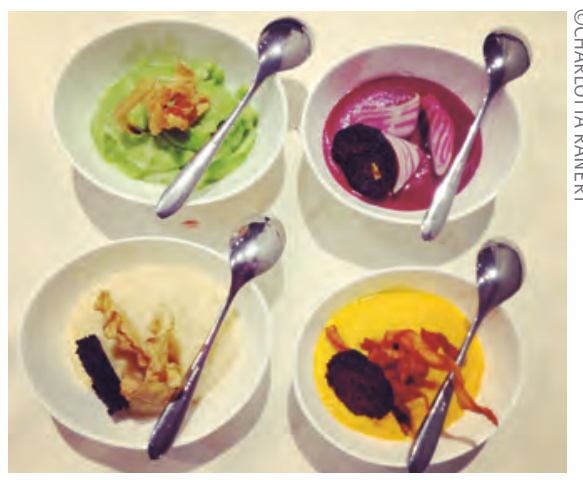

landscape when the guests entered the exhibition area supported by winter sounds. A seasonal Nordic dashi being served and the menu introduced to the guest to greet them. Then small portions of food where served throughout the evening to keep the guests at the exhibition talking to the exhibitors and making business connections. At the event in Vienna, 300 persons participated. Christoph Fink, chef at the Swedish embassy in Vienna, together with Swedish taste designer, Vanja Franzén, and Austrian light designer, Florian Tanzer, constituted the creative team. Together they composed an all-encompassing Scandinavian feel in taste, light and design. The drinks menu reflected the theme of the event, i.e. the Scandinavian nature, the change of the seasons and the sustainable use of ingredients that are growing wild.

\section{DISCUSSION}

Having run for more than five years it was time for Scandinavian Light \& Desing to incorporate food in the exhibition

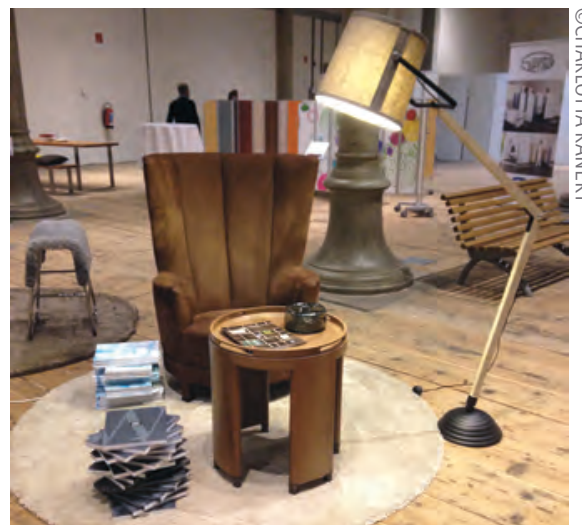

experience. There had been served food before but in the form of canapés and no with direct connection to the theme. This year however it became obvious that food really can strengthen a branding activity in a very positive way. Having the menu based on the theme for the event, in this cases Acoustics, and also using a visual arts designer who's illustrated this theme even further using sounds and pictures adds many extra dimensions to an event. The feedback from guests, exhibiting furniture companies and the organizers regarding the Nordic Food experience was overwhelming and it showed the power of using food as a tool for communication. 



\title{
FOOD CULTURE AND YOUNG TALENTS
}

\author{
Besides the previously described events there have been other events linked to food culture. \\ The focus has been, like in most other cases, on co-working with other sectors to make food more \\ visible and more creative. But food can also be seen as art, in its most elaborated form to develop \\ this we need young talents.
}

One important driving force in this work has been the "Nordic houses" within the Nordic Council of Ministers. Especially the Nordic House in Reykjavik has been active and succeeded in integrating food in its very progressive programme activities. The work within Food and Culture started with a creative seminar in 2011, and was later followed up with several different events around the Nordic Region. See the inspiring video https://www. youtube.com/watch? $\mathrm{v}=$ ngwKFaTDql8 and http://newnordicfood.org/projects/ prosjekter/food-culture/

\section{ACTIVITIES 2011-2014}

\section{FOOD CULTURE, TING. HELSINKI NOV.}

\section{2}

New Nordic Food was in the spotlight at the culture festival TING 2012 in Helsinki, held in conjunction with the 64th Nordic Council Session. A broad range of food activities were on the programme, organised in co-operation with Nordic Culture Point and the Finnish cooking scene. Culinary experiences were more prominent at the festival than ever before.

\section{NORDIC CULTURAL HERITAGE AND SEAFOOD, JUNE 2012}

Fishing and seafood processing have always had great impact on employment in local coastal economies and been a crucial resource for the Nordics. Despite this, the presence of traditional food in Nordic coastal museums is limited. 100 participants met at a conference in Bergen in June 2012 to discuss how seafood's cultural heritage can be of use in value creation and destination development. See http://newnordicfood.org/projects/ prosjekter/food-culture/seafood-andcultural-heritage/

\section{CHALLENGES AND POSSIBILITIES FOR THE CHEF PROFESSION, 2012}

A group consisting of capacities within culinary education, Nordic cuisine and tourism have looked into ways to encourage more young people to become chefs. The results of the study show that the many interesting career choices in Nordic gastronomy need to be better announced to ensure a continued influx of youth into the profession. This is vital for Nordic cuisine's future. See http:// newnordicfood.org/projects/prosjekter/ challenges-possibilities-for-the-chefsprofession/

\section{COMPETITION FOR YOUNG NORDIC CHEFS - NORDIC FOOD DAY IN NEW YORK, OCTOBER 2011}

The winners of Nordic Innovation's competition for young Nordic chefs travelled to Washington to cook for 30,000 American school children. They demonstrated Nordic cuisine's ability to spark the joy of food through tasty and nutritious school meals. This was an initiative by Nordic Innovation who invited Nordic youth, aged 18-24 and passionate about cooking, to participate in a competition about creating a simple and healthy meal using Nordic produce. See http://nynordiskmad.org/tema/prosjekter/ nordic-innovation-food/

\section{NEW NORDIC FOOD AND CULTURE, MARCH 2011}

The subject of food as a principal cultural element has been given high priority on the New Nordic Food II agenda. Food specialists, artists, designers and researchers have contributed to the definition of food as culture - from a traditional gastronomic perspective and from a broader cultural view. A diverse mix of experts met up in the Nordic House in Reykjavik in March 2011 to talk about the crossovers between food, design, art and culture. See http://newnordicfood.org/ projects/prosjekter/food-culture/

\section{SIRHA 2011 - NORDIC CO-OPERATION IN FOOD PROMOTION JAN 2011 \\ The Nordic stand at SIRHA 2011 in Lyon, an international food service fair held in conjunction with the world's most pres- tigious chef competition, Bocuse d'Or, is a good example of successful joint Nordic food promotion initiatives. \\ See http://nynordiskmad.org/tema/ prosjekter/sirha-2011/}




\title{
A NORDIC TASTE OF CULTURE
}

\author{
The project is about how food and food culture can be developed to enhance the experience of a visit \\ to the museum. How can one use the meal to further facilitate meetings and creative conversations? \\ Can food itself be thought provoking? Can it be part of the museum experience? It is the ambition of \\ many museums to attract new visitors; can the creative meal contribute to this?
}

The aim is strengthen museums in experiences, finances and to provide a basis for new visitors. It is about increasing the attractiveness of museums in an increasingly developed experience market. But also contributing to increased revenue and attracting new visitors to the museums through the meal.

\section{SOME PRELIMINARY EXAMPLES}

The Museum at the Norweigan University of Life Science: We want to develop the meal as a knowledge broker. There are major benefits to be gained by using food as a vehicle for sharing new research findings. This is because many senses are stimulated in the learning process. This may involve taste as well as using visualisation techniques to see how the food has been made. The idea is that food/the meal can be a key component in bringing the various results within Life Science to life.

THE OPEN AIR MUSEUMS: They have taken the initiative to combine food/the meal with a museum visit but also as communicators of knowledge. In Finland they have chosen to highlight the historic perspective of what is served, particularly in the open air museum. It has been decided to continue the work of linking food to the historic narrative, as the first work has proved successful.
THE MUSEUM OF SPIRITS: "SPRITLANDET SVERIGE" is about Swedes bittersweet relationship with alcohol. The exhibition is designed as a ramble through the centuries, shaped by scenery, scents, tastes and music. The visitors can sit on park benches or hang out in bars, share in the joy and suffering, pleasure and hangovers, dark and light, heat and cold.

THE NOBEL MUSEUM: The project Meal, Science and Creativity. The project created an event consisting of a 90-minute workshop where between 5-25 participants discussed the conditions for creativity based on the work of Nobel laureates. Special importance was attached to the importance of meetings, conversations and stimulating environments. A number of practical exercises were conducted where delegates reflected on their own creativity. The lecture concluded with the serving of a meal inspired by Nobel prize menus, but with an innovative twist. The meal acts in its own way as part of the actual workshop.

\section{DISCUSSION}

Interest for elevating food/the meal in order to increase synergy and the experience for museum visitors is a current trend in all the Nordic countries.
However, they are all at different stages in the process and therefore interested in developing a Nordic network. The areas specifically needing enhancement were how to use food and meals to increase/ extend the experience regardless of the theme, and how to share knowledge. However, development opportunities have also been seen in that the meal and museums have created reasons to travel and an increase in museum tourism. Another need was to get an overview and support around the thinking required to create greater synergy between museums, food and museum shops. The workshop clearly demonstrated that food/meals are not an integrated part of most museums' activities. Therefore, it is essential that ways are found to exchange experiences and drive these developments forward. If this is to succeed, it requires someone to take responsibility for the network.

\section{CONCLUSION}

There are now plans for food to become a theme at several museums in the years to come. However, food/meals are still not an integrated part of most museums' activities. Contacts must, therefore, be considerably developed in order for this to become an intentional part of the visitors' experience. 


\title{
CHILDREN AND FOOD IN THE NORDIC REGION
}

\author{
Promoting a healthy food culture among Nordic youth has been a major priority for New Nordic Food II \\ from the beginning. The aim is to lead children to richer taste experiences and quality foods, and thus \\ prepare them to make qualified food choices in the future.
}

Children's culture has a strong position in the Nordic Region and food culture also received the attention it deserves in the New Nordic Food programme. A working group identified 78 initiatives for children, food and health in Sweden, Norway, Denmark and Finland. A common focus was found in sustainability and closeness to nature, and in school meals in Finland and Sweden. A survey was carried out to create a pan-Nordic network which would encourage long-term co-operation on children, food and health.

The survey which launched New Nordic Food II's children's project looked for greater emphasis on experiences with all the senses, play and love of food. These factors are important because children develop their eating habits and their attitudes to food at an early age. The eating habits which follow us through life are formed early - at home, pre-school and school play important roles. Prioritising children and food is an investment that pays off in the long run.

The aim of the project has been to convey and reinforce Nordic competencies and to communicate current topics. A common vision was drawn up as the starting point for this work: "Every Nordic child has the right to learn how to cook new Nordic food and to come into contact with this

CHILDRENS TASTE DAY IN THE HEALTH GARDEN, KRISTIANSTAD IN 2013.

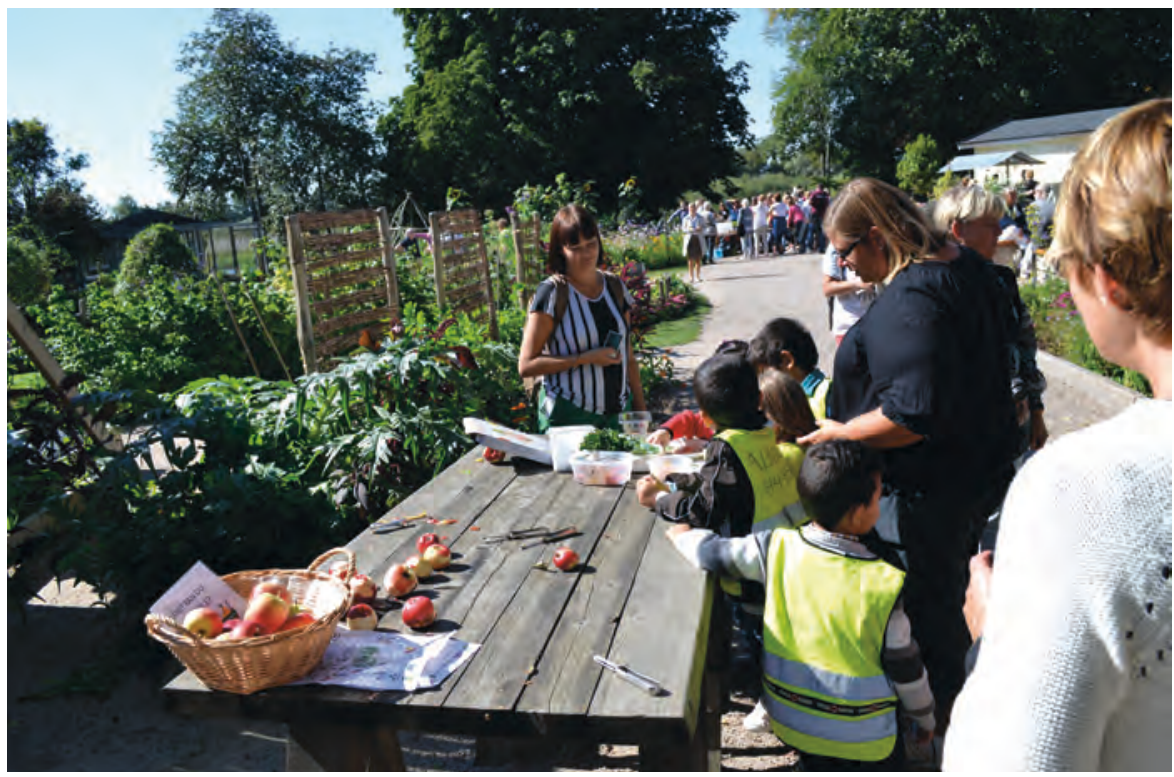

fantastic local food culture." Based on this vision and the Nordic Kitchen Manifest, the Nordic Children's Kitchen Manifesto was drawn up. This comprises the core values for work with children and food, see appendix on page 49. The vision and the manifest are important components of common Nordic values. Food education was the concept and topic the project focused on by way of conclusion. The role of the teachers and the staff in schools and day care has been emphasised, and initiatives are underway to develop the potential of meals in public institutions.

\section{ACTIVITIES 2010-2014}

- Survey and stocktaking of the project on children, food and health

- New Nordic Food's conference in Oslo 2012 on the theme of children, food and health

- In 2013, the project worked in partnership with the Swedish National Food Administration with a network meeting in Kristianstad

- 2014 , see page 48

\section{DISCUSSION}

"Every child has the right to good food" is an important expression and which has followed the work aimed at children and food. The expression has also been a key for the New Nordic Food II project, Children, Food and Health. What is good 


\section{"Every Nordic child has the right to learn how to cook new Nordic}

food and to come into contact with this fantastic local food culture."

food then? It covers both the nutritional value and the actual meal situation. Good food for children is first and foremost nutrient rich food, made from nutritious ingredients. The opposite of this is nutrient poor food, made from ingredients which provide energy but have no nutritional value. Nutrient poor food is often heavily processed, which is not unusual food for many children and young people today. The expression good food also includes the right of children to be surrounded by good role models, adults who prepare and eat good food themselves, and who can communicate good eating habits. There is consensus on the question of the importance of our children's wellbeing. Mistreatment of children arouses strong emotions, on the other hand, children who are malnourished is a poor state of affairs that is easily unseen.

Success factors with regard to developments in this area are about enjoyable experiences with food, ingredients and meal situations. Participation is the key to success. When children are allowed to be in the kitchen and involved in the preparation of meals, we give them the keys to acquiring knowledge about good food.

Children are our future, also with regard to food culture and knowledge of food, ingredients and where they come from. Starting in childhood, society needs to provide knowledge and instil pride in the Nordic countries as a rich gastronomic region. Eating habits and attitudes to food are formed in childhood. The natural platform for this knowledge sharing is basic education. It should be a matter of

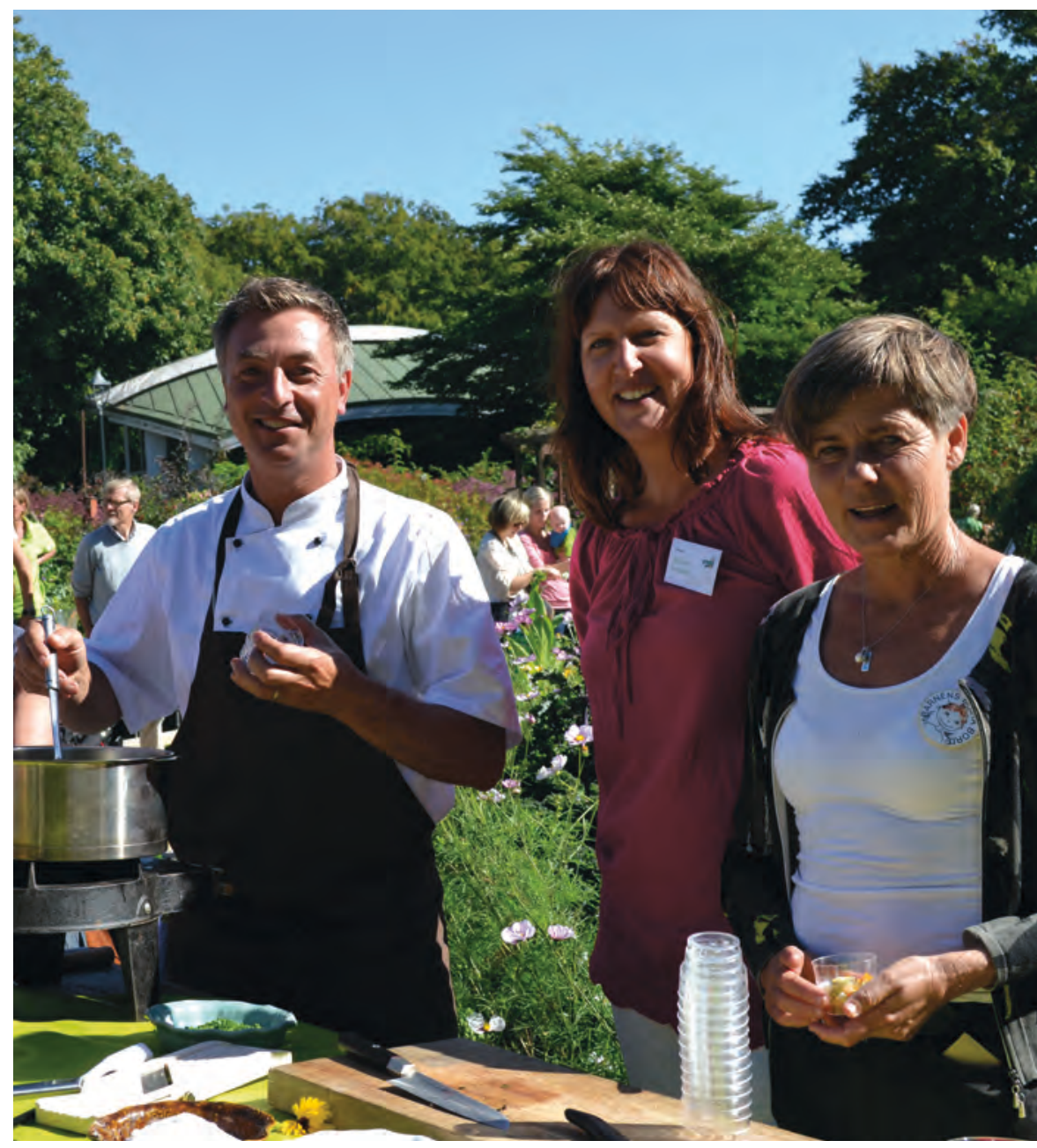

NORDIC NETWORK MEETING IN KRISTIANSTAD IN 2013. THE CHEF TAREC TAYLOR, PROJECT LEADER HARRIET STRANDVIK AND SUSANNE THOREN.

course that children learn in school about our own ingredients and where they come from, and about the special characteristics of the Nordic food culture. It is just as important for schools in the future to teach about the ingredients that make up our Nordic larder as it is to teach about flowers, birds and animals. Food culture should be a common Nordic education issue.
Public awareness on the importance of developing children's food culture has increased significantly during this period. There are several good examples of where initiatives have been incorporated into institutions, authorities and associations. One example is the Swedish National Food Agency's major venture. The challenge in the future is to increase the visibility of food culture in basic education. 


\section{CHILDREN AND FOOD IN THE NORDIC REGION, 2014}

In 2014, the project Children, Food and Health in the Nordic countries (New Nordic Food II's project Children and Food) worked in close co-operation with Leader Söderslätt and their network platform BoMIN - Children and Food so very Nordic (Barn och mat så in i Norden) in Sweden. This was a Swedish initiative and the collaboration began in 2013. New Nordic Food II's project Children and Food added a Nordic dimension to this new network platform. The purpose of co-operation and the common platform is to work towards continuity in the network and gather competencies from the Nordic Region, even after the ending of the New Nordic Food II project.

\section{ACTIVITIES}

- 3 different network meetings. In Sweden, Åland and Iceland. A total of 70 people attended

- We drew attention to the celebration of the Nordic School Meals Week along with the Norden Association

- We also drew attention to Children and Food during the political debate week, Arendal Week, in Norway

- Exchanges and activities amongst the 350 members on Facebook. Here we shared everything from new research findings, projects, and articles on children and food. There was even a lively discussion on whether porridge makes a good lunch for children?

- Five newsletters were published by New Nordic Food II, three of which included news about children and food

\section{COMMENTS}

The challenge in co-ordinating the network lies in the breadth of the area covered. A clear profile has nevertheless become clear during the year, focusing on food education or the growth of interest in food. Since children often eat most of their meals outside the home, meals served in public institutions are of particular interest. Work in the future should boost skills with school staff and dinner ladies and increase knowledge about food and Nordic food culture.

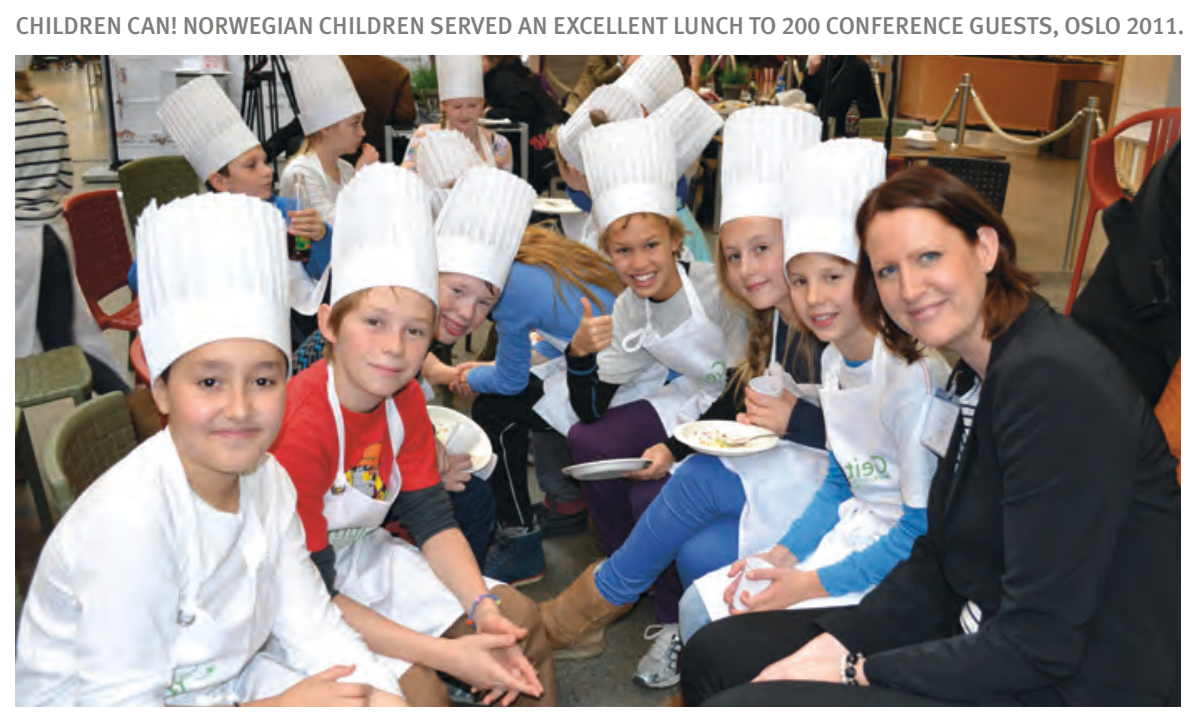

\section{MORE INFO}

Yearly report 2013: http://nynordiskmad.org/fileadmin/webmasterfiles/Billeder/ NNM-Årsrapport-2013_final.pdf

Halftime report 2010-2012: NNF II - A Popular Movement Continues. ANP 2013:740. pages 22-23

Homepage EN: http://newnordicfood.org/projects/food-children/

Homepage SCAN: http://nynordiskmad.org/tema/barn-mat-haelsa-i-norden/

www.nynordiskmad.blogspot.com

www.youtube.com/nynordiskmat

www.facebook.com/nynordiskmad 


\section{THE MANIFESTO - CHILDREN AND FOOD IN THE NORDIC REGION}

The project "Children and Food in the Nordic Region" is a network of enthusiasts working with children's meals from both the content (nutritional) and educational aspects. We are facing huge challenges with overweight and poor health in our target group. It is important to unite and engage those who work with issues concerning children, food and health. The Nordic Children's Kitchen Manifesto summarises our joint work and communicates our common Nordic values.

The manifesto is an initiative of the project "Children and Food in the Nordic Region" (New Nordic Food II) and through joint discussions amongst food educators in Social Media and at the Nordic network meeting in Kristianstad 2014.

Nordic Children's Kitchen Manifesto Every Nordic child has the right to learn how to cook good healthy food.

The Nordic Children's Kitchen Manifesto is based on the new Nordic kitchen Manifesto, see page 66.
1. Children's food is nutritious and tasty

2. Children's food is prepared from pure, local ingredients according to season and tradition

3. Children's food is ethical and fair

4. Children's meals are regular

5. Children's meals have variety

6. Children's meals activate all the senses

7. Children are surrounded by examples of good food and meals

8. Children are involved in the meal preparation - children can!

9. Children learn different skills and obtain knowledge through shared meals

10. Children have the right to their own tastes and positive experiences with the Nordic food treasures 


\section{PUBLIC MEALS AS A FUTURE WELFARE SOLUTION}

\section{More than six million public meals are served in the Nordic region every day and each of these} meals could potentially incite a healthy and sustainable food culture. Public meals throughout the Nordic region hold great potentials for sociale change with regards to welfare, local and sustainable growth and development. The project set out to connect key stakeholders working with public meals to develop a Nordic platform and cooperation for identifying common challenges and the sharing of future solutions.

The aim was to develop a dynamic framework and platform for co-operation for new Nordic initiatives for public meals as a future welfare solution. Within the project, we have focused on the potential in and interest for establishing a future network for public meals among key actor within the field. Furthermore, we have identified and mapped the possibilities of establishing a Nordic network and knowledge-sharing platform focusing on the pitfalls and potentials of forging more sustainable, public food procurement systems.
During 2014, we highlighted the potential of the Nordic public meals by mapping the area, key stakeholders, hosting several conferences, seminars, workshops and by helping a dedicated network with bringing ideas and visions to life. The events have focused on bringing Nordic partners together and putting public meals as a vehicle for societal change on the political agenda. On the basis of these connected events the project formulated two new platforms for further co-operation. First, the network for public procurement to be kick-started at a Nordic procurement

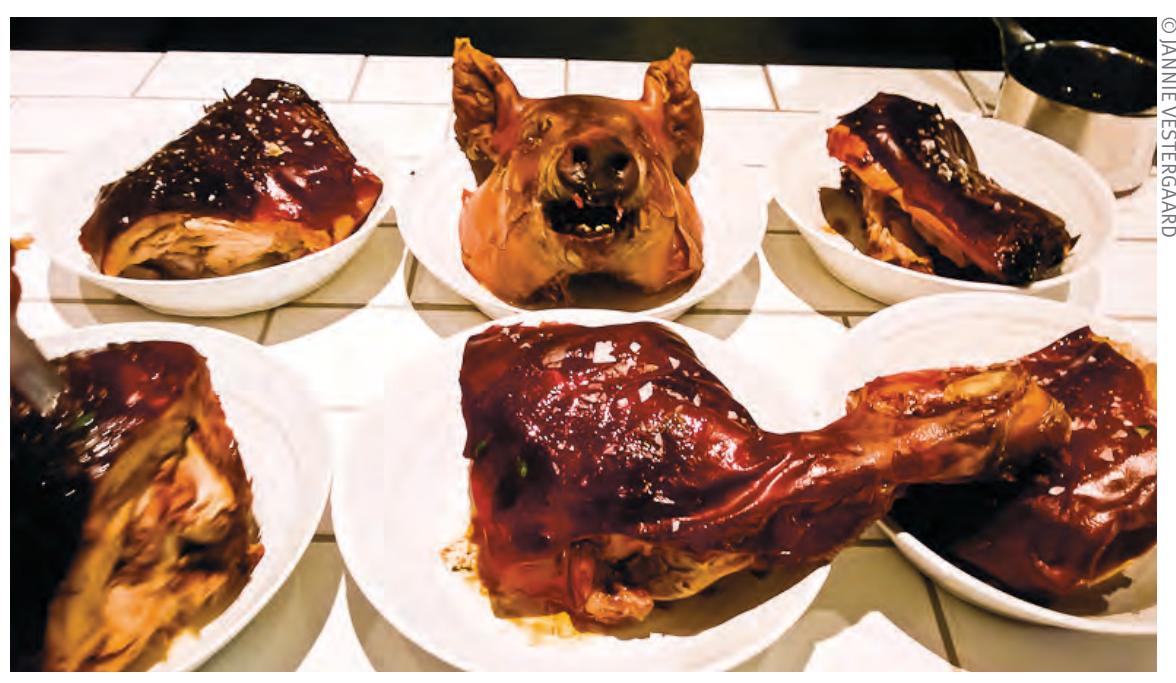

conference in Bruxelles 2015, and second a new platform for co-operation on public meals between numerous Nordic partners.

\section{MAPPING PUBLIC MEALS IN THE NORDIC COUNTRIES}

We draw two central conclusions from the mapping public meals. First, Nordic public meals hold a great potential for change both in terms of purchase, power and outreach. Second, there is a significant lack of knowledge and data-production on key performance indicators within the area despite its reach and scope.

\section{KEY STAKEHOLDERS AS CRITERIA FOR SUCCESS}

Seeing how we focused on establishing new relations between key stakeholders - both persons and organisations, who work with the development of public meals from farm to fork on different levels, the work with these actors has been a key success criteria. We have focused on decision makers, professionals, change leaders, universities, administrations and project managers who all work with meals, procurement, societal change, health, sustainability within a broad range of sectors. Such actors include Livsmedelsakademin, Madkulturen, EkoCentria, 


\section{"The aim was to develop a dynamic framework and platform for co-operation for new Nordic initiatives for public meals as a future welfare solution."}

EMIL BRUUN BLAUERT

Meyers Madhus, Skolmatens Vänner, Københavns Madhus, Smaka på Skåne, etc.

\section{ACTIVITIES}

WORKSHOP ON SMART AND SUSTAINABLE PUBLIC FOOD PROCUREMENT IN THE NORDIC COUNTRIES, MALMÖ, JANUARY 2014

18 procurement specialists met for 24 hours in Malmö, Sweden to exchange best practice and discuss the foundations of a Nordic collaboration on public food procurement. The purpose of the workshop was to exchange experiences and to formulate recommendations to the overall framework on Food for Many within New Nordic Food.

NORDIC CONFERENCE FOR SUSTAINABLE PUBLIC FOOD PROCUREMENT, HELSINKI, OCTOBER 2014

In partnership with EkoCentria more than 100 Nordic participants decided to continue the work with sustainable public food procurement and strengthen the Nordic co-operation on sustainable public food procurement

NORDIC NETWORK SEMINAR FOR STAGING THE NORDIC FRAMEWORK FOR SUSTAINABLE PUBLIC FOOD PROCUREMENT AND SOCIETAL EFFECTS, HELSINKI, OCTOBER 2014

Two leading international experts Robert Pederson (ARC2020) and Olivier De Shutter (Former UN Special Rapporteur) positioned sustainable, public food procurement in a local and global economy and described why and how this could be one of the most important political tools of the future. The conversation around public procurement and global, sustainable food systems kick-started the conversation and strengthened the relations between the Nordic participants.
THE RISE AND FALL OF NEW NORDIC FOOD? - SKAFFERIET, STOCKHOLM, OCTOBER 2014

We positioned public meals a part of future welfare solutions at the Nordic debate at Skafferiet in Stockholm visited by more than 70 participants hosted by journalist Per Styrgaard.

\#NORDICFOOD2024 - PUBLIC MEALS AS A FUTURE WELFARE SOLUTION, COPENHAGEN, DECEMBER 2014 The fourth \#NORDICFOOD2024 workshop was held at Copenhagen House of Food in December where key stakeholders from the region gathered to discuss the role of public meals in the transition towards sustainable societies in the Nordic countries. The participants formulated a proposal for a future framework for the Nordic Council of Ministers.
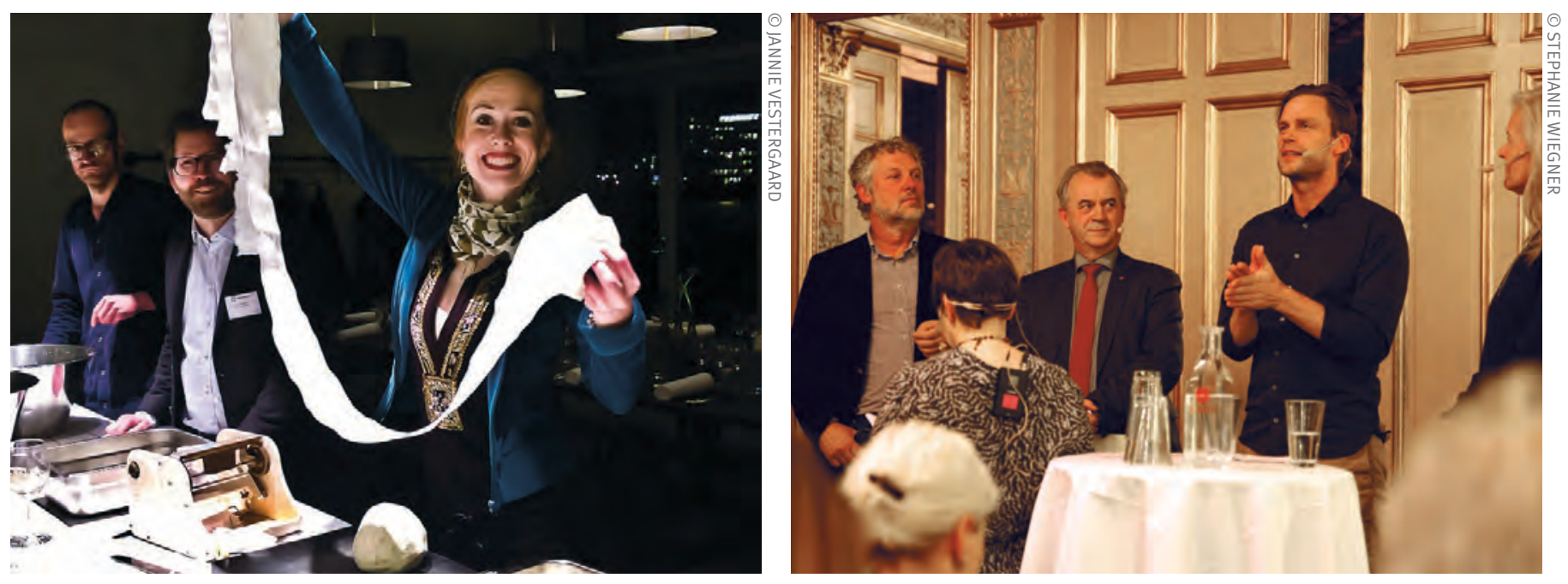


\section{NEW NORDIC FOOD FOR MANY - IN NORDIC HIGHER EDUCATION}

In the Nordic Region there are many small departments in colleges and universities with studies in dietetics, nutrition, food service and culinary arts \& meal science in their curriculum. Many of them are also interested in the area "Food for Many", which ranges from hospital food to meals at major events.

The objective was therefore to share knowledge in higher education in the Nordic Region. The approach we chose was to create meeting places and networks. The meeting place was the House of Culinary Art, Grythyttan School of Hospitality, Culinary Arts and Meal Science at Örebro University, which has twice hosted representatives from 15 institutions of higher education interested in Nordic co-operation.

Based on this meeting and the network that was set up, an attempt was made to get funding from SIU for an application for a Nordic Master in "Food for Many", written by representatives from four countries. However, the application was not granted.

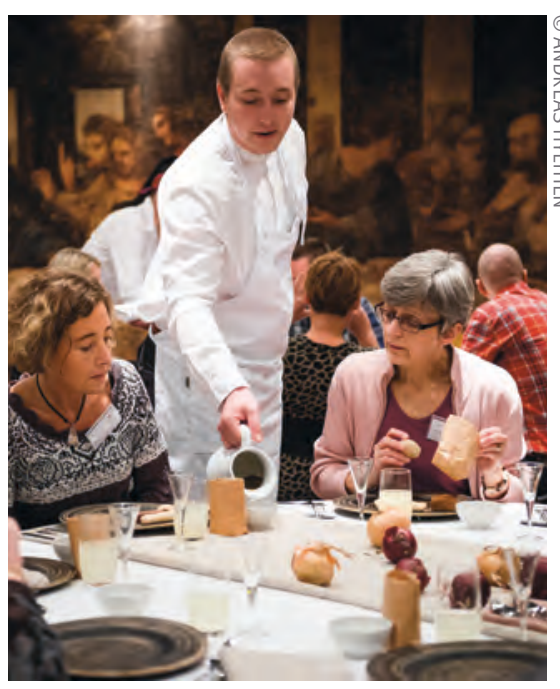

The objective of these activities was to create a two-year joint Nordic Master Programme. In addition, the aim of the network was to be a permanent arena for knowledge sharing between higher education and research in the Nordic countries.

\section{ACTIVITIES}

In 2013, a project group was created for a Masters application with representatives from Sweden, Finland, Norway and Denmark. An initial meeting was held in Copenhagen. Later a conference was organised on the Grythyttan campus at Örebro University, which was held with 30 participants from 15 Nordic institutions.

In November 2013, an application for funding to set up a Nordic Master Programme was submitted to SIU, the Nordic Centre for International Cooperation in Education. However, the application was unsuccessful.

In the autumn of 2014, a second network meeting was organised and held with about thirty participants, and this time all the Nordic countries were represented. It was decided that the project managers from Örebro University would continue to hold an annual meeting in Grythyttan, Sweden to ensure the network's continued existence.

\section{DISCUSSION}

New Nordic Food is today a well-known subject in gastronomy, but also in education and research. During networking conferences in 2013 and 2014, scientists and teachers from 15 Nordic university departments with culinary art and meal science in their curriculum, agreed that collaboration between the Nordic nations is essential for innovative development. There is a constant need to hold meetings across knowledge boundaries to develop innovative and creative collaborations to develop the food service sector/catering industry. There is also a growing need to consider the meal from a more holistic perspective, including food

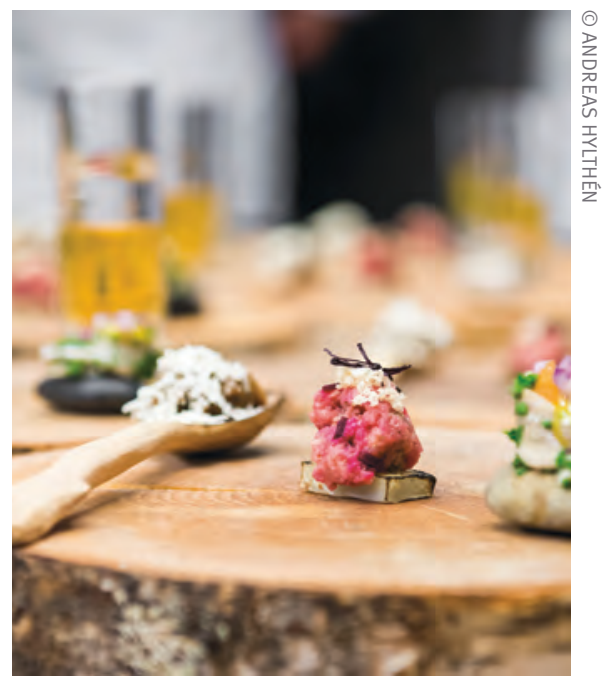




\section{"The aim of the network was to be a permanent arena for knowledge}

sharing between higher education and research in the Nordic countries."

for people from social, cultural, nutritional, safety and sustainable aspects.

This includes:

- Collaboration on education at undergraduate and graduate levels

- Research projects that strengthen the catering/food service sector and the hospitality industry

- Scientific publications

- Popular science publications

- Creation of new scientific journals in the field

- Teaching materials

- Teacher and student exchanges in the Nordic region and internationally

- Meetings and events for food research in collaboration with industry, increasing its application in everyday life

To develop Nordic collaboration we need to use internet-based meetings, meetings via social media, but also meetings in real life where we share meals. The idea behind Nordic interchanges is to free resources and knowledge, leading to openings for collaborations in a field where different institutions have different starting points and goals. It is also important to involve students in networking so they can be at the forefront of innovation in the catering/food service sector. This includes childcare meals, school meals, meals for the elderly and disabled, but also major events such as the Eurovision Song Contest or different sporting events.

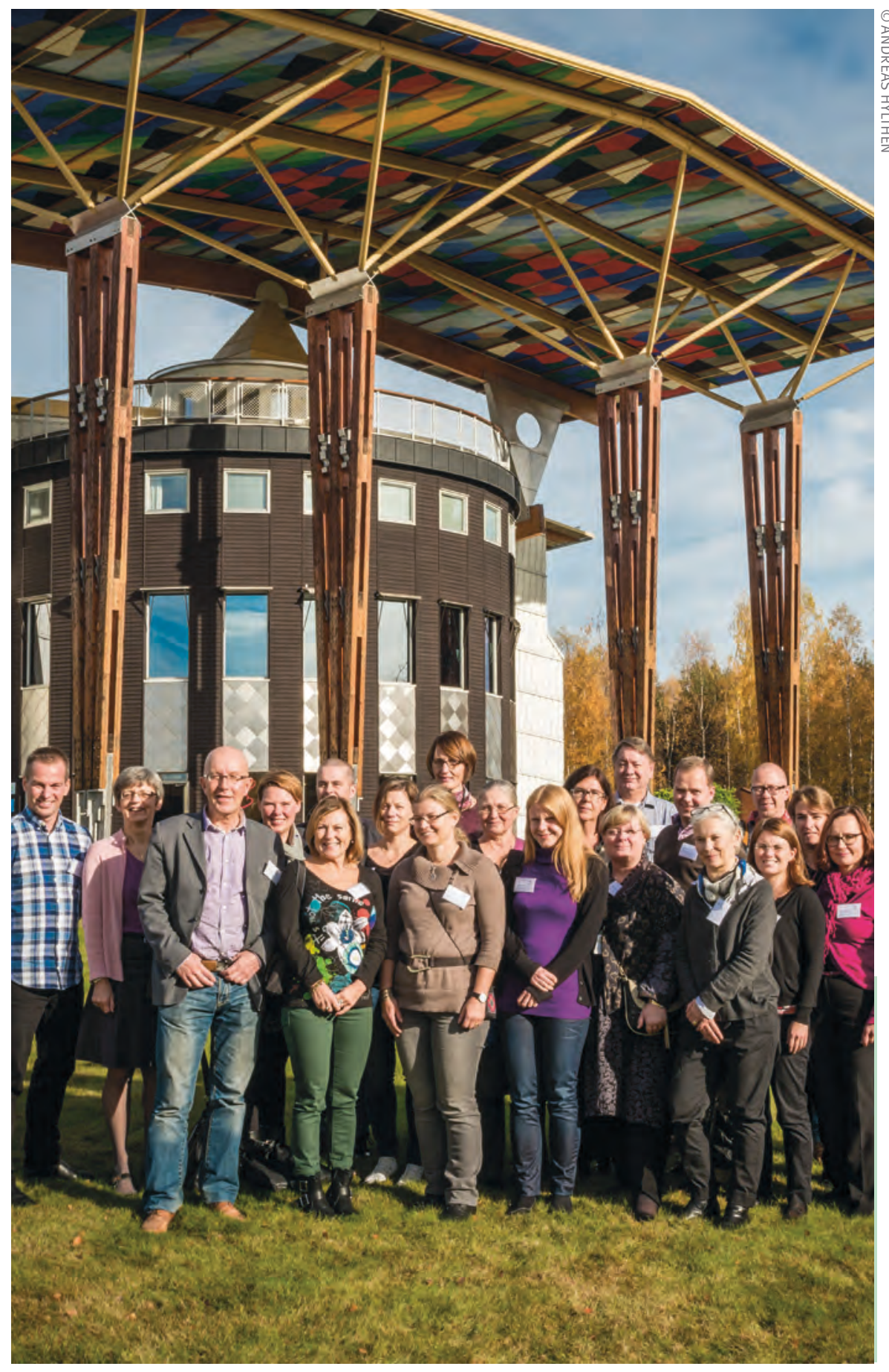




\title{
SME IN THE BIO-ECONOMY
}

\author{
Small and medium sized food enterprises (SME's) in the Nordic countries produce products of \\ high quality from local raw materials. The aim of the project was to inspire and encourage \\ knowledge exchange between SME's for product development and marketing of local food.
}

All Nordic countries have competence centres that offer entrepreneurs and small-scale producer's various services on different levels, like consultation, processing facilities, courses and more. In 2012 a network was created through this project by holding a workshop in Reykjavik connecting the Nordic centers for the first time. The network has grown and become stronger in these three years and now includes both competence centers and small-scale producers from all the Nordic countries.

The support for SME's differs between countries. In Sweden they have come very far with a National Centre for small-scale artisan food producers, Eldrimner. SME's in Iceland, Faroe Islands and Greenland

EXAMPLES OF PRODUCTS COMPETING IN THE ICELANDIC CHAMPIONSHIP 2014

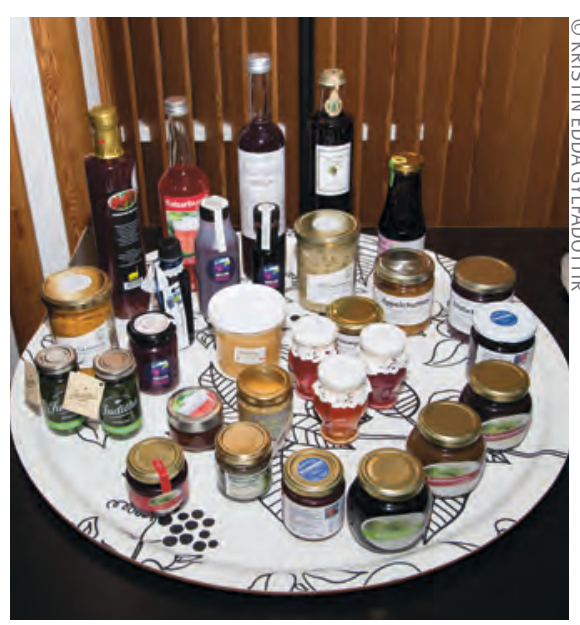

have not come as far in their development as the other Nordic countries and they need more support. A network like this is very valuable for both the centers and the SME's, helping each other to develop and grow. Each country has special knowledge and experiences that can be shared. This project has contributed to knowledge exchange between the centers and the SME's by holding seminars, study tours and courses as well as co-organising two national championships in artisan food, which were open for all SME's in the Nordic countries. The first one held in Östersund in Sweden 2013 and the second one in Reykjavík, Iceland 2014. All Nordic countries competed in both championships.

A platform for a "Nordic Championship in Artisan Food" was established and first steps taken in creating harmonized rules. Much is to gain by holding a Nordic championship for SME's, such as higher quality standards of the products, access to Nordic markets, stronger networking, increased knowledge and inspiration.

\section{DISCUSSION}

Through the network the cooperation between the competence centers has increased and strengthened. The SME's face the same challenges in each country e.g. lack of competence in some areas, strict regulations, logistics and marketing.

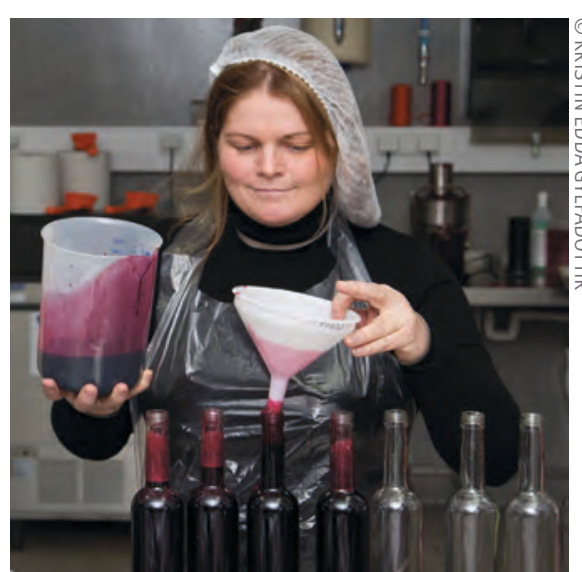

ELDRIMNERS COURSE IN BERRY PROCESSING, DRINK AND JAM MAKING AT MATIS 2014

Many of the small companies are now starting to grow. They are employing, expanding their processing facilities, adding farm-based restaurants, exporting their products etc. All artisan businesses will not become large. But through cooperation and creation of many more businesses, the SME's create growth. Support of SME's is very important to keep tradition alive and further develop food culture, create high quality diverse products and jobs in rural areas as well as creating new and exciting destinations for food tourism. All these aspects are important factors in strengthening the bio-economy. Future projects in this area can therefore be carried out in various bio-economy programs and calls e.g. in the innovation projects under the Icelandic chairmanship program Nordbio. 


\section{“Much is to gain by holding a Nordic championship for SME's, such as higher quality standards of the products, access to Nordic markets, stronger networking, increased knowledge and inspiration."}

\section{ACTIVITIES 2012-2014}

\section{ICELANDIC CHAMPIONSHIP 2014}

For the first time an Icelandic championship for artisan food producer's was held in Reykjavík, in November 2014. The competition welcomed SME's from all the Nordic countries to take part. The event was a continuation of the work that started a year earlier, at Sweden's national “Championship for Artisan Food" (SM i Mathantverk). Both competitions were very successful and gave the SME's great inspiration and knowledge exchange. See page 56

\section{SAERIMNER 2013}

Særimner is a Swedish idea- and knowledge forum for artisan food producers held every second year parallel to "SM i Mathantverk". In 2013 Eldrimner and New Nordic Food welcomed together SME's from all the Nordic countries to take part in the Særimner seminar and the open "SM i Mathantverk" which was held in Östersund. The programme of the seminar consisted of artisan food workshops mixed with debates and lectures. Over 600 products were sent to the competition from all the Nordic countries and 108 prizes where handed out to producers in various categories.

\section{INITIAL WORKSHOP}

In 2012 a workshop was held in Iceland to bring the Nordic competence centers closer together. Focus were how to get to know and learn from each other, build networks and to discuss how these activities can support and strengthen New Nordic Food.

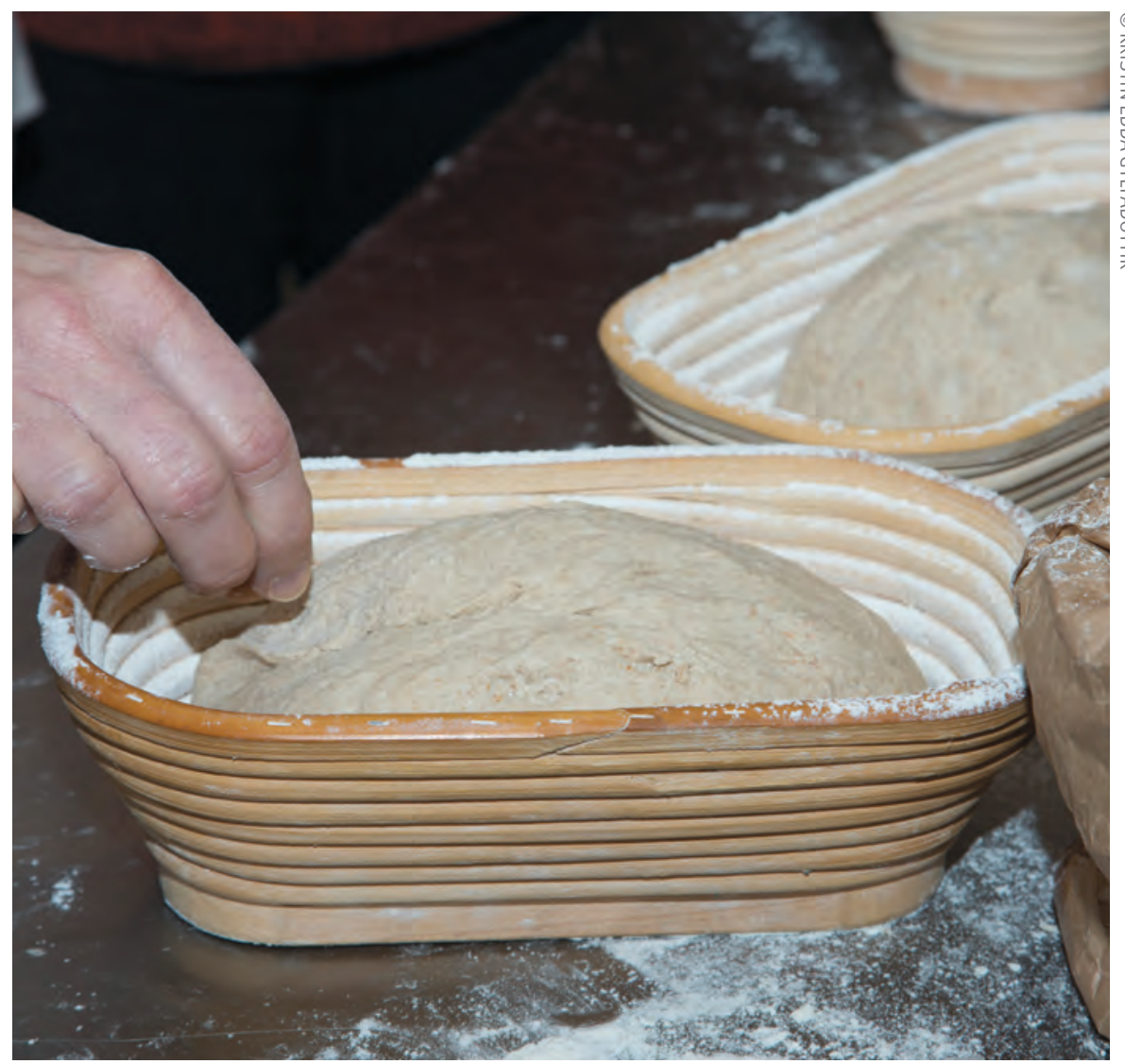

ELDRIMNERS COURSE IN SOURDOUGH BREAD MAKING AT MATIS 2014

\section{MORE INFO}

http://nynordiskmad.org/tema/sme-in-the-bioeconomy/

New Nordic Food II - A Popular Movement Continues. ANP 2013:740. page 42-43

Ny Nordisk Mat Årsrapport 2013, page 30-31 see http://nynordiskmad.org/fileadmin/webmasterfiles/Billeder/ NNM-Årsrapport-2013_final.pdf 


\section{ICELANDIC CHAMPIONSHIP WITH NORDIC PARTICIPANTS 2014}

The aim of the project 2014 was to inspire and encourage knowledge exchange between Nordic SME's for product development and marketing of local food. To fulfill this aim an "Open Icelandic Championship in Artisan Food" was held in Reykjavík for the first time. Artisan food producers from all the Nordic countries came and participated in the competition, a seminar, study tour, courses and Iceland's biggest food market.

For the first time an Icelandic championship for artisan food producer's was held in Reykjavík in November 2014. The competition welcomed SME's from all the Nordic countries to take part. The event was a continuation of the work that started a year earlier in Sweden's national "Championship for Artisan Food". Both events were in cooperation with the New Nordic Food II program.

Parallel to the championship a seminar was held where speakers from all the Nordic countries gave valuable insights on how to support and promote local food. Other events connected to the champion- ship was a study tour where Icelandic local food producers where visited and short courses on e.g. bread, cheese and jam making where held at Matis (Icelandic Food and Biotech R\&D). The courses were organized by specialists from Eldrimner. To better market the Icelandic championship all the 110 products from all the Nordic countries were exhibited at the biggest food market in Iceland and some of the products were also for sale at the market. Link:

http://www.matis.is/nordicartisanfood

Earlier the same year, in connection with "SM i Mathantverk 2014" in Växjö, a

WINNERS OF THE “OPEN ICELANDIC CHAMPIONSHIP IN ARTISAN FOOD” 2014

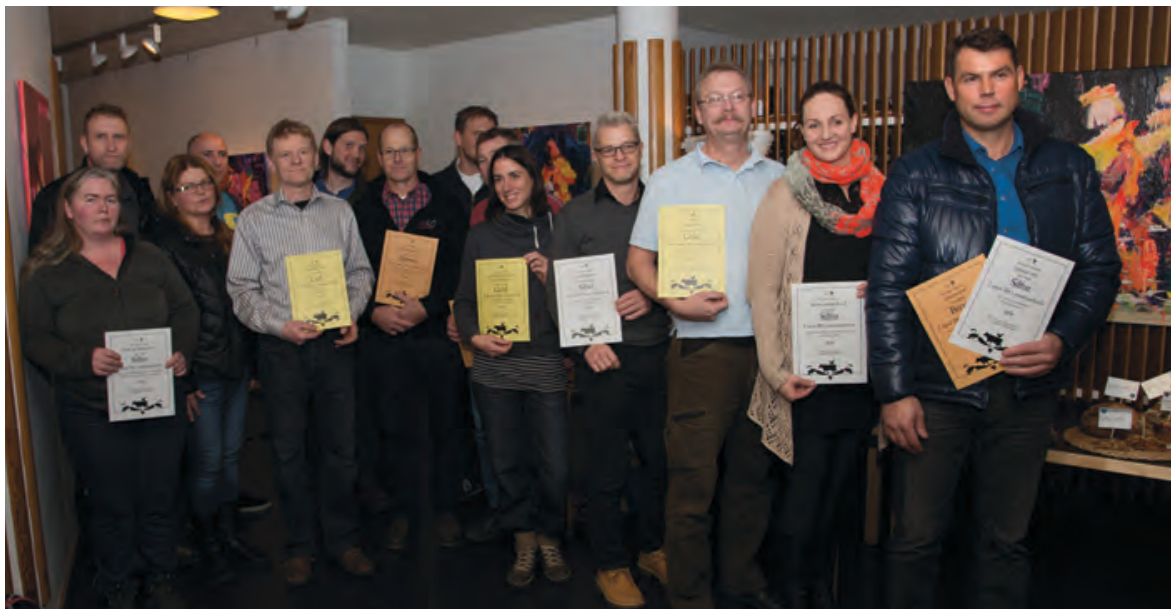

meeting was held focusing on creating Nordic rules for a "Nordic Championship in Artisan Food”. As Eldrimner has 18 years of experience in holding a national championship for SME's the Swedish rules were used as a base. The outcome of this important work was the slightly modified rules from Eldrimner, which were used at the competition in Iceland.

Much is to be gained for SME's with common Nordic rules, such as higher quality standards of the products, access to Nordic markets, stronger networking, increased knowledge and inspiration. An additional event was created in the

PRODUCTS FROM ALL THE NORDIC COUNTRIES COMPETING IN THE ICELANDIC CHAMPIONSHIP 2014

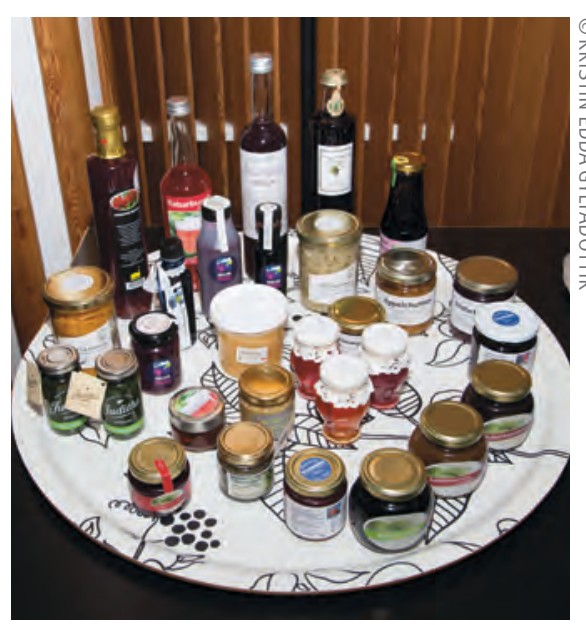




\section{"High quality products made from local raw material are increasingly in demand. This is a great opportunity for SME's to create a strong and thriving business."}

beginning of June as a group of SME's from Norway, Finland and Sweden came to Iceland for a three day study tour funded by Interreg. The aim of the study tour was to gain new knowledge and inspiration from different Icelandic SME producers, as well as creating valuable network.

\section{DISCUSSION}

High quality products made from local raw material are increasingly in demand. This is a great opportunity for SME's to create a strong and thriving business. But there is however several challenges that need to be addressed. The lack of strong marketing has been identified as being the key factors in hampering the growth of SME's. The seminar held parallel to the Icelandic championship was designed to give the participants information on how different marketing strategies have been implemented in the Nordic countries. A championship for artisan food is a marketing tool in itself. It will create an interest and coverage in media, which is very valuable.

One of the outcomes of this project was that a platform for a "Nordic Championship in Artisan Food" was established and first steps taken in creating harmonized rules. Much is to gain by holding a Nordic championship for SME's, such as

strengthening the image of local food production, higher quality standards of the products, access to Nordic markets, stronger networking, increased knowledge and inspiration. An interesting angle for better marketing in the future could be to take further "The Designers and

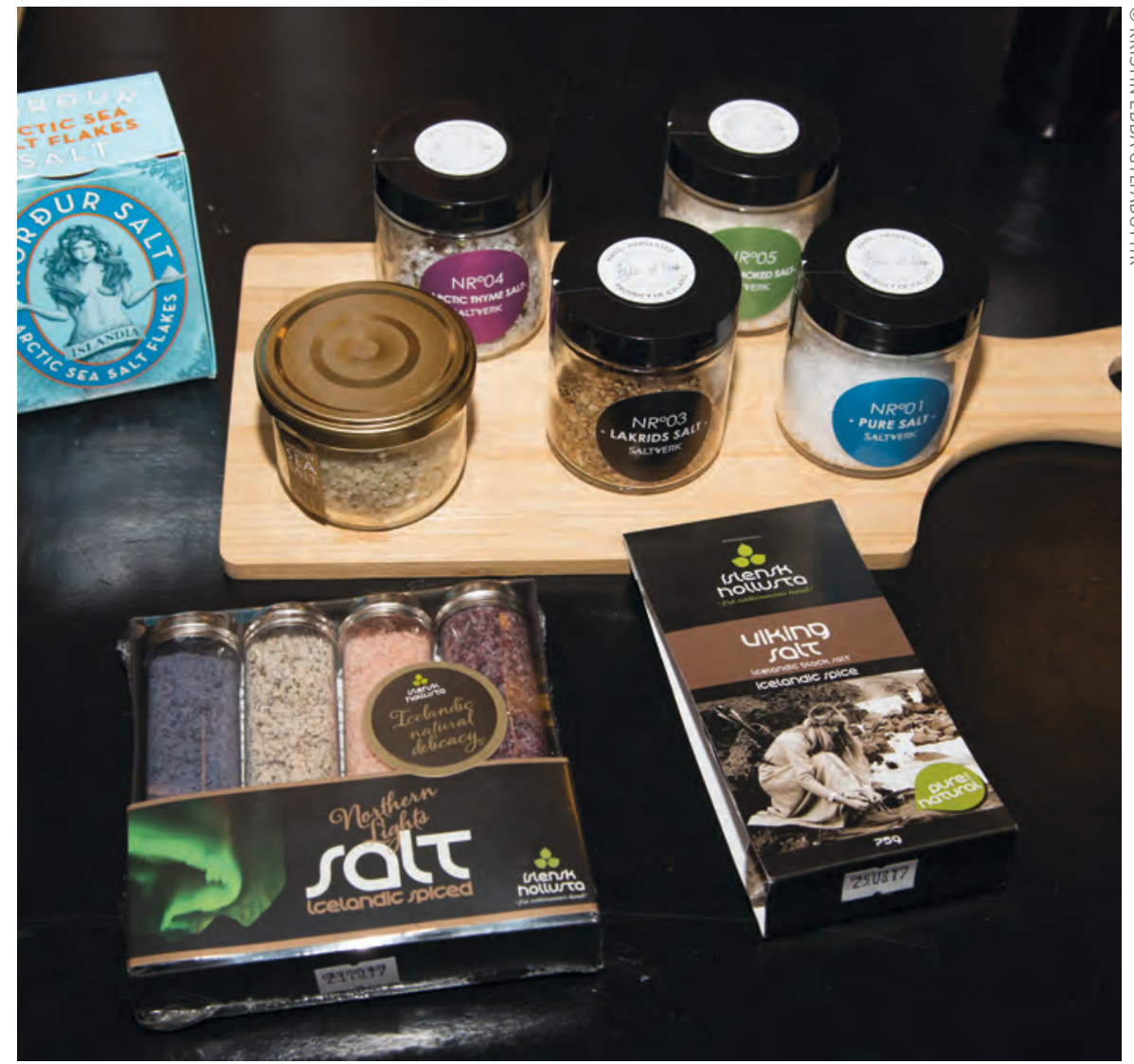

PRODUCTS FROM ALL THE NORDIC COUNTRIES COMPETING IN THE ICELANDIC CHAMPIONSHIP 2014

Farmers project” (http://www.designersandfarmers.com/en/). This was a multidisciplinary innovative project where designers, farmers and food scientists were given a platform to work together to develop unique food products.

SME's in the Nordic countries have very different support systems. They are therefore not equally prepared to take on the challenges of producing high quality local food products. This project has addressed this need for more knowledge and education for SME's. For example courses were held in connection with the Icelandic competition to educate and inspire the participants. Specialists from Eldrimner held the courses. The support system that Eldrimner has created is a very good example on how to support and build up local food production.

In the future it could be very interesting to look at other support systems from other countries, e.g. UK, Ireland and Canada. This provides guidelines for authorities on how to support SME's in the most effective manner. 


\section{SEAWEED - THE UNIQUE FOOD OF THE NORTH}

Out of many Nordic raw materials, seaweed is still an unused resource. This in spite of the fact that it is literally growing right outside the door. Seaweed has a unique potential for human consumption being full of minerals, vitamins and other useful nutrients, which make seaweed a healthy and good supplement to the Nordic Kitchen. There is a lot of umami in seaweed, and seaweed simply adds a more interesting touch to the food, which the Nordic gourmet chefs have discovered. New Nordic Food II is focusing on a better utilization of seaweed and through Seaweed Events teaching the consumers how to prepare and eat seaweed, thus giving seaweed a natural place in the New Nordic Kitchen.

In August 2011, star chefs, seaweed farmers, researchers, entrepreneurs and producers meet in Copenhagen. At the workshop people were working with several suggestions for improving the utilization of the Nordic seaweed in the New Nordic Kitchen. Two of these suggestions were to distribute information about seaweed and to train the consumers in the Nordic region to eat seaweed. The second part of the New Nordic Food II project has been to continue working with these two projects.

\section{DISCUSSION}

Seaweed from the cold waters of the North is a unique product, which is both tasty as well as nutritious. The natural sweetener in some seaweed is mannitol, which neither is rich in calories nor does it cause Caries, and it is recommended that there be made a special programme for learning and urging children to eat seaweed. In addition to the Seaweed Events there is a necessity for a Nordic webpage about seaweed, enhancing the distribution of information about seaweed. From the angle of food safety and sustainability it is important to gather more knowledge about seaweed. It is also important to make knowledge about seaweed more user-friendly and thus enabling it to be used both in the kitchen at home as well as in companies working with product development. Providing the consumers with possibilities for buying good Nordic seaweed requires that the supply of seaweed must be increased.

In addition to strengthening the food culture, an increased consumption of seaweed will lead to economical growth for Nordic companies working with farming and food production. An increased consumption of seaweed is a very good incentive for increased efforts with regard to innovation and development activities of products and adventures in the Nordic region.

\section{ACTIVITIES 2011-2014}

\section{SEAWEED EVENTS DURING 2014}

Seaweed Events were in 2014 arranged in the Faroe Islands, Denmark, Iceland, Greenland and in Sweden. In order to reach a large number of consumers, at a low expense, the major part of the Seaweed Events were arranged with and in cooperation with other Nordic food and cultural festivals. In each country contact persons have been responsible for the Seaweed Events. Extensive posters and folders have been prepared about seaweed and recipes and were distributed at the different events.

\section{DENMARK}

In September 2014 a Seaweed event was arranged in Denmark together with "SMAGforLIVET" at Aarhus Food Festival, which is the largest food festival in the Nordic region. The Food Festival was visited by approx. 30.000 people, out of

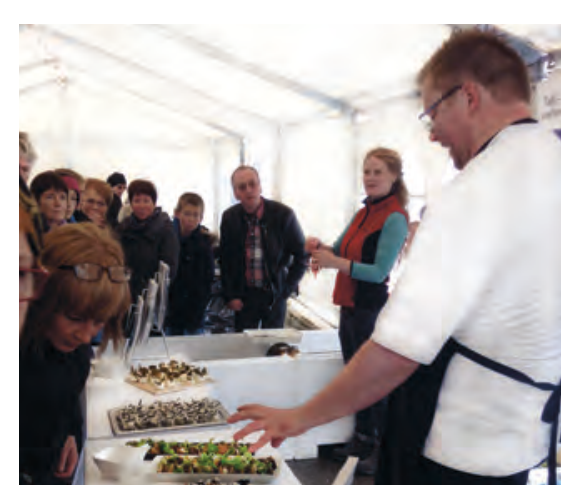

RUBEN M. BUSK, CHEF OG AGNES MOLS MORTENSEN, PHD, SEAWEED EVENT IN FAROE ISLANDS 2014 


\section{"Seaweed has a unique potential for human consumption being full of minerals, vitamins and other useful nutrients, which make seaweed a healthy and good supplement to the Nordic Kitchen."}

which many visited the Seaweed Mystery. Chefs were preparing tastings and telling about their experiences with using seaweed in the kitchen. Seaweed tastings were distributed to approx. 1000 people.

\section{ICELAND}

In August and in November 2014 a Seaweed Event was arranged in Iceland in connection with the "Matarmarkaður Bursins", the largest Artisan Food Market in Iceland. There were seaweed samples from all the seaweed producers in Iceland. There were approx. 25.000 visitors at the arrangement, and a great many visited the seaweed stand. Seaweed tastings were distributed to approx. 1000 people.

\section{THE FAROESE SEAMAN DAY}

The Seaweed Event in the Faroese was arranged in connection with the event “Føroya Sjómannadag” in August 2014. Approx. 10.000 people visited the event, and quite many took the opportunity to visit the Seaweed Event. Tastings were prepared and approx. 1000 seaweed tastings were handed out.

\section{SWEDEN}

Several smaller Seaweed events have been arranged in Sweden. In Havstenssund in July 2014 the event "Tång och sånt i Havstenssund" was held. Another Seaweed Event was held in Hunnebostrand together with Hummerakademin in Hunnebostrand. At all events sample bags with seaweed were distributed, all of them labelled with the logo of New Nordic Food and with a recipe on as well. In total 250 sample bags were handed out in Sweden.

\section{GREENLAND}

In Greenland the Seaweed Event was arranged in connection with the Food Festival in Nuuk in September 2014 and the Food Festival in Narsaq in August 2014. Furthermore there have been seaweed events in connection with several smaller arrangements in Nuuk, in Narsaq and in Qaqortoq. At the event in Narsaq 19 different kinds of tastings were served. The information about seaweed has been communicated to several thousand people in the Nordic region.

\section{MORE INFO}

Se full reports at: http://nynordiskmad.org/tema/tang-og-tare-til-mat/ 


\section{EVENT OVERVIEW \\ - NEW NORDIC FOOD II}

\section{SEE ALSO WWW.NEWNORDICFOOD.ORG, FACEBOOK AND TWITTER}

\section{1}

\section{JANUARY}

SIRHA 2011 IN LYON. A Nordic pavilion at an international food service fair, held in conjunction with chef competition Bocuse d'Or. Organised in cooperation with the Danish, Swedish and Finnish embassies in Paris.

\section{MARCH}

CULTURAL FORUM IN THE NORDIC HOUSE IN REYKJAVIK. Food specialists, artists, designers and researchers discussed food as a cultural element, a medium of expressing ideas and values, and as an art form.

NORDIC FOOD DIPLOMACY WORKSHOP IN STOCKHOLM. Representatives from Nordic businesses and the Nordic Ministries of Foreign Affairs participated in a preparatory workshop about the use of food in the region's branding.

\section{MAY}

CHILDREN AND FOOD IN THE NORDICS. A workshop in Stockholm, which summarized the efforts to map Nordic initiatives dealing with children, food and health.

\section{JUNE}

NORDIC FOOD DAYS IN WASHINGTON. Nordic chefs introduced the innovative and ambitious Nordic cuisine to Washington DC. Organised by Nordic Innovation and the Nordic embassies in Washington.

\section{AUGUST}

WORKSHOP ON USE OF SEAWEED IN THE NORDIC KITCHEN, HELD IN COPENHAGEN. Chefs, seaweed farmers, researchers and producers discussed how seaweed could regain its popularity and importance in Nordic cuisine.

\section{OCTOBER}

NEW NORDIC FOOD II CONFERENCE, HELD IN HELSINKI - 'The potential and future of Nordic food when eating outside home.' The conference had three main themes; Children and Food, Public Foodscapes and Nordic Oat Days.

\section{OCTOBER}

NORDIC INNOVATION announces the winners of the Cooking competition for young chefs. Five winners were selected because of their ability to create and present a simple and healthy meal, using Nordic produce.

NORDIC FOOD DAY IN DC SCHOOLS, organised by Nordic Innovation. Winners of the Cooking competition for young chefs cooked a healthy, Nordic school meal for an impressive 30,000 school kids in Washington.

\section{2}

\section{JANUARY}

WHAT IS NORDIC NEW DIET? Workshop at Lund University. Experts discussed the nutritional qualities of the New Nordic Diet and initiated research to further document its health promoting qualities.

\section{MARCH}

NEW NORDIC COMPUTER FOOD, a pilot project organised by Nordic Food Diplomacy and Food \& Creative Industries at Game Developers Conference 2012 in San Francisco.

WORKSHOP on how Nordic food competence centres can assist food entrepreneurs and SMEs in developing and producing new Nordic food products. Held in Reykjavik.

\section{APRIL}

ÅLAND - LOCALLY PRODUCED. A food fair introducing the island's local food products to restaurants, cafés, canteens and food retailers. Initiated by New Nordic Food II's reference group in Åland.

SEMINAR ON PUBLIC FOODSCAPES, held in Copenhagen. The aim was to consolidate the project's working group and develop Public Foodscapes concepts for presentation at the New Nordic Food II 2012 conference.

\section{MAY}

NORDIC KITCHEN PARTY AT THE CANNES FILM FESTIVAL. A pilot project organised by Nordic Food Diplomacy and Food \& Creative Industries, in cooperation with the Nordic film industry. 


\section{"New Nordic Food II is a communication programme. Our mission is to initiate diverse campaigns and events that draw attention to the new Nordic cuisine and support its continued development"}

\section{MAY}

WORKSHOP ON THE NORDICS AS A GASTRONOMIC REGION. The Nordic Visit organisations gathered to talk about the value of strengthening the common Nordic food profile as a means to increase tourism in the region.

\section{JUNE}

SEAFOOD AND CULTURAL HERITAGE. A conference held in Bergen, aimed at increasing knowledge about seafood's cultural heritage and its potential value for local and regional development and employment. Special emphasis was directed towards the use of seafood in coastal museums.

10th NORDIC NUTRITION CONFERENCE, held in Reykjavik. Nordic New Diet was presented and a Nordic lunch was served. The event focused on current research on food, nutrition and health in the Nordic countries and globally.

FROM NEW NORDIC FOOD TO NEW RURAL ECONOMY. A seminar presenting the potential of New Nordic Food's ideology to promote local economies. Side event at Rio+20, United Nations Conference on Sustainable Development.

\section{SEPTEMBER}

POINT OF NO RETURN. Innovation workshop organised by Food and Creative Industries at a conference about food and architecture's significance for Nordic rural areas. Held at Stokkøya in Norway.

WORKSHOP ON FOOD \& CREATIVE INDUSTRIES in the World Design Capital 2012, Helsinki. Nordic professionals discussed Nordic food as a creative industry and how it should relate to other creative Nordic industries.

\section{OCTOBER}

NORDIC FOOD DIPLOMACY launches its new website, nfd.nynordiskmad. org. The site presents a comprehensive tool kit for those making use of food when promoting the Nordic countries, at home and internationally.

NORDIC STAR CHEFS IN JAPAN. Five Nordic chefs introduced Nordic cuisine at workshops and selected restaurants in Tokyo. Organised by the Nordic embassies in Tokyo, with support from Nordic Food Diplomacy and Nordic Innovation.

\section{OCTOBER}

FOOD, COASTAL CULTURE AND HISTORY, a workshop organised by The Nordics as a gastronomic region. Coastal museums and maritime attractions met in Oslo to discuss how to further integrate Nordic food in their activities.

TING 2012 CULTURE FESTIVAL IN HELSINKI, held alongside the Nordic Council's 64th session. New Nordic Food II organised a broad range of food activities, in cooperation with Nordic Culture Point and the Finnish cooking scene.

\section{REPORT ON THE CHALLENGES AND POSSIBILITIES FOR THE NORDIC} CHEF PROFESSION published, showing a wide range of interesting carrier opportunities in Nordic gastronomy.

\section{NOVEMBER}

NEW NORDIC FOOD II CONFERENCE, 'Local, nutritious, delicious', held in Oslo. The conference had three main sessions; Children and Food, Public Foodscapes and Food and Nutrition.

FOOD AS A BRANDING TOOL AND AS ART! - A presentation about Food and Creative Industries at an event organised by GeneratorSverige.

YOU ARE IN CONTROL - a conference on digital business opportunities in creative industries, held in Reykjavik. Food and Creative Industries introduced an innovative approach to New Nordic Food experiences.

FARMER SEEKS A CHEF - event organised by New Nordic Food II, Åland, bringing together local food producers and chefs.

\section{DECEMBER}

WORKSHOP (SEQUEL): FOOD \& CREATIVE INDUSTRIES COPENHAGEN 


\section{FEBRUARY}

NORDIC STREET FOOD. CONFERENCE IN MALMÖ.

NORDIC COOL FESTIVAL. WASHINGTON

PANEL DEBATE "CREATIVE FOOD IS A POWERFUL LANGUAGE" STAGE, CPH FOOD FAIR, COPENHAGEN

\section{MAY}

LAUNCH JA JA JA FESTIVAL, LONDON

NNF WORKSHOPS AND STEERING GROUP MEETING, FAROE ISLAND

\section{SEPTEMBER}

SUSTAINABLE GASTRONOMIC REGIONS. SEMINAR LINKÖPING, SWEDEN

MEAL EDUCATION - CHILDREN \& FOOD IN FOCUS. KRISTIANSTAD,

SWEDEN

WORLD FOOD TRAVEL SUMMIT. GOTHENBURG SWEDEN

\section{OCTOBER}

SÄRIMNER - NORDIC CHAMPIONSHIP IN ARTISAN FOOD. ÖSTERSUND, SWEDEN

NORDIC MASTER, FOOD FOR MANY. SEMINAR IN GRYTHYTTAN, SWEDEN

KREALAB - CREATIVE INDUSTRIES, AS A RESOURCE FOR BUSINESS. CONFERENCE IN STHM

\section{NOVEMBER}

NORDIC DESIGN AND INNOVATION WEEK. NFD AND FOOSHION (FOOD \& FASHION). SHANGHAI

NORDIC SOUND BITE AT THE JA JA JA FESTIVAL. FOOD, FILM AND MUSIC, WITH NOMEX, LONDON

\section{DECEMBER}

FOOD ON BIG ARENAS. WORKSHOP STHM

\section{4}

\section{JANUARY}

WORKSHOP, PUBLIC PROCUREMENT, MALMÖ

\section{MARS}

STREET FOOD HELSINKI. CONFERENCE \& NORDIC CULTURE FESTIVAL

\section{MAY}

STAND ON GASTRONORD \& BOCUSE D’OR, STHM

WORKSHOP AND STEERING GROUP, NARSAQ AND NUUK, GREENLAND

\section{JUNE TO OCTOBER}

SEA WEED. PARTICIPATED IN FIVE NORDIC FOOD FESTIVALS

\section{JULY}

NNF: KEY NOTE PRESENTATION AT INTERNATIONAL FOOD DESIGN CONFERENCE AND STUDIO 2014, NEW ZEALAND

\section{AUGUST}

ARENDALSUKA 2014 - CHILDREN, FOOD \& HEALTH. NNF IN COOPERATION WITH NORDEN IN FOCUS. NORWAY

\section{SEPTEMBER}

WORKSHOP ON NORDIC ARTISAN FOOD, SM IN ARTISAN FOOD, VÄXJÖ, SWEDEN

ÅRHUS FOOD FESTIVAL, WORKING GROUP AND PANEL DISCUSSION, DENMARK

CHILDREN \& FOOD - NORDIC WORKSHOP ON ÅLAND WITH BOMIN

NORTH I NEW YORK (STREET FOOD, DEBATT \& FASHION)

\section{OCTOBER}

NORDIC MASTER. SEMINAR IN GRYTHYTTAN, SWEDEN

PUBLIC PROCUREMENT \& FOOD FOR MANY. CONFERENCE, HELSINGFORS, FINLAND

\#NORDICFOOD2024. INTRODUCTION SEMINAR ON BERNS IN STHM

\section{NOVEMBER}

\#NORDICFOOD2024. BIOECONOMY - OPPORTUNITIES AND INNOVATION IN NORDIC AGRICULTURE, REYKJAVIK, ICELAND

SCANDINAVIAN LIGHT \& DESIGN, WIEN.

NORDIC PLAYLIST RADIO BAR, ICELANDIC AIRWAVES, REYKJAVIK CHILDREN \& FOOD. SEMINAR WITH BOMIN, INST FOR HEALT \& BIOPHILIA, IN REYKJAVIK, ICELAND

SME AND NORDIC CHAMPIONSHIP IN ARTISAN FOOD, REYKJAVIK, ICELAND

FOOD EXPERIENCES AT THE JA JA JA FESTIVAL, LONDON

\section{DECEMBER}

\#NORDICFOOD2024 STAGING NORDIC TABLE 2024, STOCKHOLM \#NORDICFOOD2024. PUBLIC MEALS AS A SUSTAINABLE WELFARE SOLUTION. KPH

\#NORDICFOOD2024. THE NORDIC COUNTRIES AS A SUSTAINABLE GASTRONOMIC REGION, KPH

\#NORDICFOOD2024. FUTURE NORDIC GUALITY AND EXPORT PRODUCTS. MALMÖ

FOOD \& MUSEUMS, NOBELMUSEET, STHM 

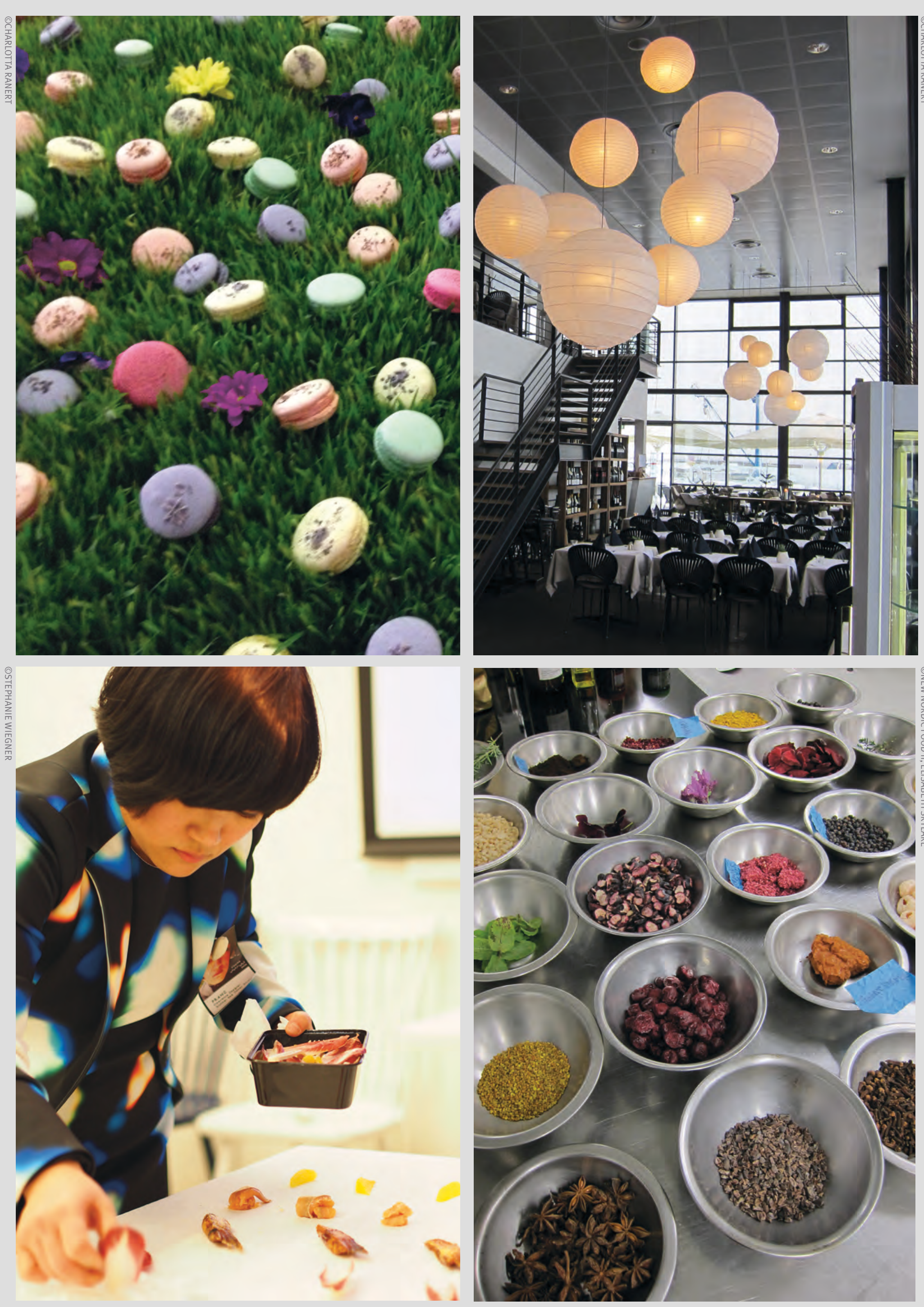


\section{MIDWAY EVALUATION OF NNF || 2010-2012}

\section{SUMMARY OF THE RESULTS}

\section{PLANNED ACTIVITIES ARE CARRIED OUT AND PROJECTS ARE CLEARLY DEFINED}

The majority of the respondents from the groups Project Managers and Work group find the activities planned by Ny Nordisk Mat to be carried out. They also consider the projects financed by Ny Nordisk Mat to be clearly defined.

However, only a few agree with the statement that they have enough time/resources to complete their part of the work within Ny Nordisk Mat in a satisfying way.

\section{THE PROGRAM IS ON A GOOD WAY TO REACH ITS GOALS}

The answers of the questions regarding NNF's goals indicates that the program is on a good way to reach them. Many find the program to be a great way to collaborate and expand their network.

\section{NEED OF INFORMATION IN DIFFERENT LANGUAGES}

Three of four respondents have visited NNF's website during the last six months. The majority of the respondents find the information on the website and the informational letters to be interesting.

Even though the majority of the respondents find the informational letters and the information on NNF's website interesting, many would like to see them being translated into English and other Nordic languages in addition to Danish and Norwegian.

Furthermore, many find the information on NNF's Facebook site to be interesting, but the site itself could become better if $\mathrm{Ny}$ Nordisk Mat posted more pictures as well as materials in different languages.

\section{CONCLUSIONS}

“Together we stand strong”

There is a common perception where promoting the region is seen as an overarching goal. To reach that goal we need to work together, share ideas, experiences and information and inspire each other to strengthen the Nordic identity. In this lies the strengths of Ny Nordisk Mat. Ny Nordisk Mat works as a stage where representatives can meet to expand their network, discuss different issues and participate in various projects.

However, some aspects of the program have potential for improvement. The programs general communication could become more clearly and better reach out to the public and raise awareness amongst ordinary people. Some respondents find the program to be a bit too focused on the professionals operating the food market and that the common people are being overlooked. Another issue seems to be that the program is much more known amongst public and private actors in Denmark and Norway compared to Sweden.

Furthermore, the available information from Ny Nordisk Mat is often only written in Danish or Norwegian. The people from other Nordic countries who are lacking knowledge of those languages have therefore a difficulty taking part of the information. This problem can easily be solved by also publishing information in English. This would not only help people from other Nordic countries to take part of

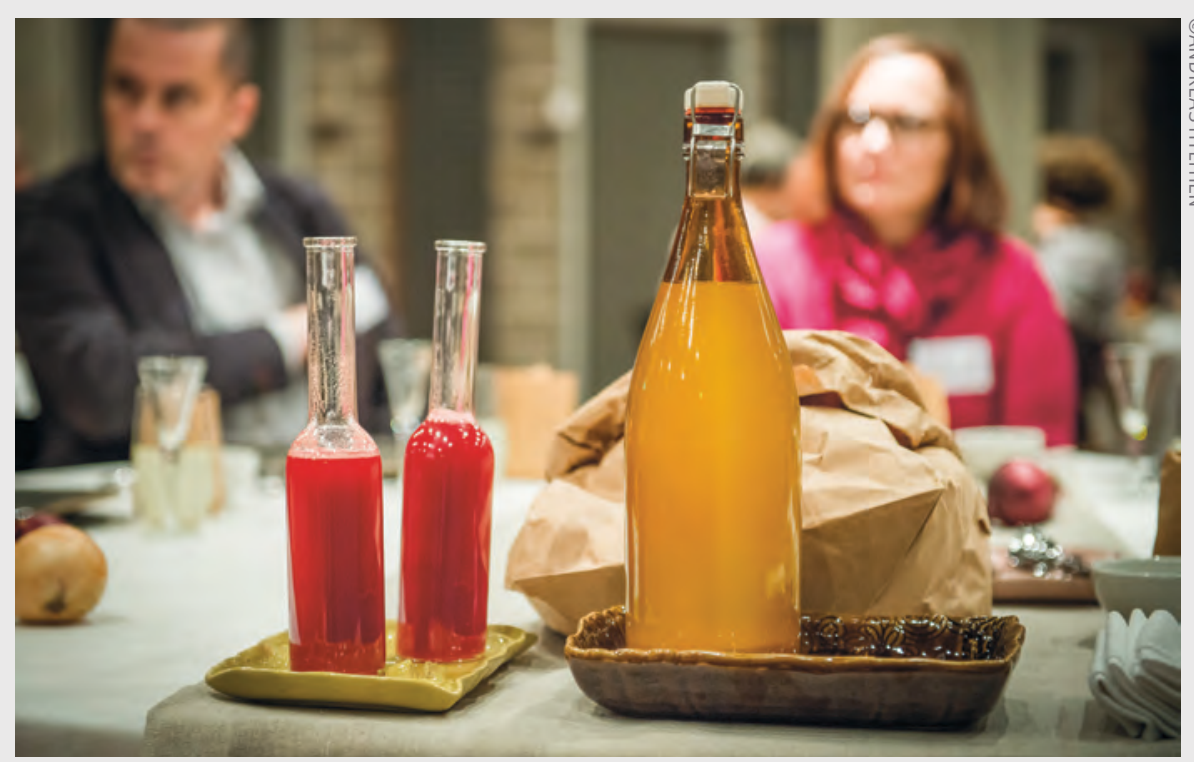




\section{"Together we stand strong"}

the information, but it would also make the information from Ny Nordisk Mat more accessible to people all over the world. Overall, the respondents believe the program Ny Nordisk Mat to be a fruitful collaboration and the majority would gladly see an continuation of the program. Many respondents points out the importance of working together, hence one respondent comments - "Together we stand strong".

\section{INFORMATION ABOUT THE EVALUATION}

\section{BACKGROUND AND PURPOSE}

The Swedish Board of Agriculture, who is the managing authority for the program Ny Nordisk Mat II, and wanted to conduct a midway evaluation of the program. The purpose of the evaluation is to investigate how NNF II has worked, its results, and provide suggestions for improvement and for the next two years.

\section{METHOD}

The first stage of the study was a prestudy to become familiarised with NNF and to better understand how the programs goals, objectives, and activities are structured. This is of importance when developing a questionnaire and to more effectively identify the target group for the study.

A web based questionnaire was sent out to 962 persons that subscribes to the e-mail newsletter. 180 e-mail addresses were inactive and two persons answered that they didn't want to participate. Facebook users, that are members in

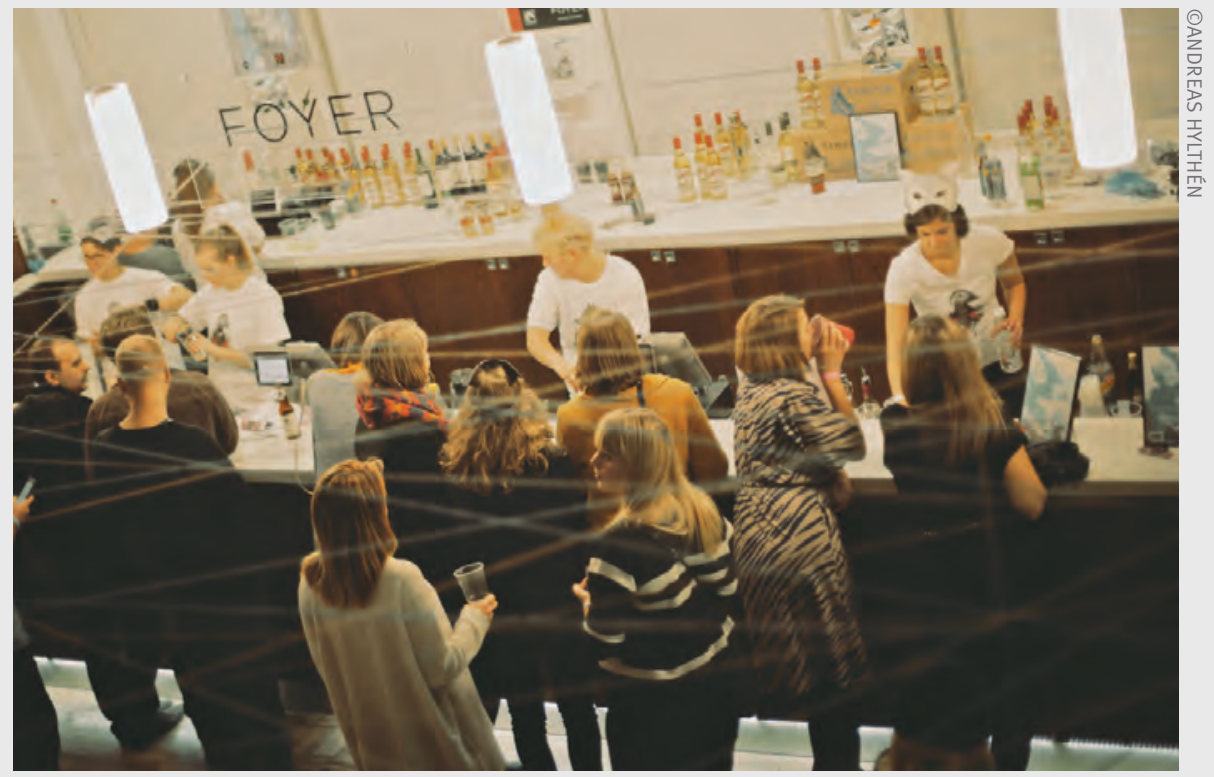

NNF's Facebook group, have also been able to answer the web based questionnaire. In all, we have got 122 web answers and 58 Facebook answers. Two reminders were sent out to the respondents that did not complete the questionnaire in time. The response rate on the telephone conducted part of the survey is $72 \%$ (67 responses). Seven of the numbers on the list given to us from NNF could not be used because of different circumstances (person long-term sick etc.).

\section{THE QUESTIONNAIRE}

The questionnaire consists of the areas: General Questions, Program Goals, The Work related to Ny Nordisk Mat and its Projects, Effects and Usefulness, Information and communication and Overall View and Ideas for Development. The questionnaire is available in Swedish and English.
The respondents have also been given the opportunity to answer open-ended questions about the programs concept, activities, strengths etc. throughout the survey. All comments and replies to the open-ended questions can be found in the appendix.

\section{REALISATION}

The survey was conducted by CMA Research $A B$ during the period December 2012 - January 2013.

For more information, please visit www.cmaresearch.se.

Project manager at CMA: Johanna Svanberg. Responsible for analysis and reporting: Denis Zgela.

Contact person at the Swedish Board of Agriculture: Magnus Gröntoft. 


\section{MANIFESTO FOR THE NEW NORDIC CUISINE}

From 2004

As Nordic chefs we find that the time has now come for us to create a New Nordic Kitchen, which in virtue of its good taste and special character compares favourable with the standard of the greatest kitchens of the world.

The aims of New Nordic Cuisine are:

1. To express the purity, freshness, simplicity and ethics we wish to associate with our region.

2. To reflect the changing of the seasons in the meals we make.

3. To base our cooking on ingredients and produce whose characteristics are particularly excellent in our climates, landscapes and waters.

4. To combine the demand for good taste with modern knowledge of health and well-being.

5. To promote Nordic products and the variety of Nordic producers - and to spread the word about their underlying cultures.
6 To promote animal welfare and a sound production process in our seas, on our farmland and in the wild.

7. To develop potentially new applications of traditional Nordic food products.

8. To combine the best in Nordic cookery and culinary traditions with impulses from abroad.

9. To combine local self-sufficiency with regional sharing of high-quality products.

10. To join forces with consumer representatives, other cooking craftsmen, agriculture, the fishing, food, retail and wholesale industries, researchers, teachers, politicians and authorities on this project for the benefit and advantage of everyone in the Nordic countries.

Hans Välimäki, Finland • Leif Sørensen, Færøerne • Mathias Dahlgren, Sverige • Roger Malmin, Norge René Redzepi, Danmark • Rune Collin, Grønland • Erwin Lauterbach, Danmark • Eyvind Hellstrøm, Norge Fredrik Sigurdsson, Island • Gunndur Fossdal, Færøerne • Hákan Örvarsson, Island • Michael Björklund, Åland 


\section{ÅRHUS DECLARATION ON NEW NORDIC FOOD}

A political declaration from NORDIC COUNCIL OF MINISTERS, 2005

The Ministers for Fisheries, Agriculture, Forestry, and Food discussed the possibilities for developing a joint initiative on Nordic food and food culture - "New Nordic Food" - at their meeting on 30 June 2005 in Århus.

"New Nordic Food" shall offer the consumer a better quality of life through tasty and healthy food based on Nordic ingredients from the sea and land.

Nordic food and Nordic food culture have been under strong pressure for a long time from other food cultures and world cuisines, and also from the way that society is developing. A lack of identity and knowledge has also had an influence.

"New Nordic Food" is an initiative to promote the use of the diverse Nordic ingredients in the development of a new Nordic cuisine. A Nordic food cultural identity shall be created, characterised by the qualities to be found in our region, of purity, simplicity, security and ethics.

“New Nordic Food" shall promote Nordic food prepared from pure and healthy ingredients, so that Nordic food and food culture can create opportunities in the future, and put the Nordic Region clearly on the gastronomic world map. "New Nordic Food" shall be a forward-looking answer to increased international competition in the global food market.

"New Nordic Food" shall promote the market and understanding for the individual countries' traditional food. "New Nordic Food" shall also promote Nordic awareness for Nordic food and increase the common identity, which can lead to mutual inspiration and food cultural development between the Nordic countries.

"New Nordic Food" shall help to brand the Nordic Region internationally, as a centre for ingredients produced under the special Nordic natural conditions and build on ingredients that are particularly outstanding in the Nordic climates, landscapes and waters.

\section{"New Nordic Food" shall contribute to} developing a diverse selection of Nordic ingredients and food from agriculture and fisheries, and also provide people with a diet for health and vitality. It is desirable to develop new ways of using traditional Nordic foods and combine the need for good taste with today's knowledge of health and wellness. In addition, it is desirable to promote and develop knowledge of the potential that exists in Nordic gene resources which are the foundation of the raw materials.

The diverse Nordic rural districts are the basis for local production of a number of valuable ingredients that can be included in "New Nordic Food" and thus contribute to supporting the development of coastal and rural areas. This initiative shall

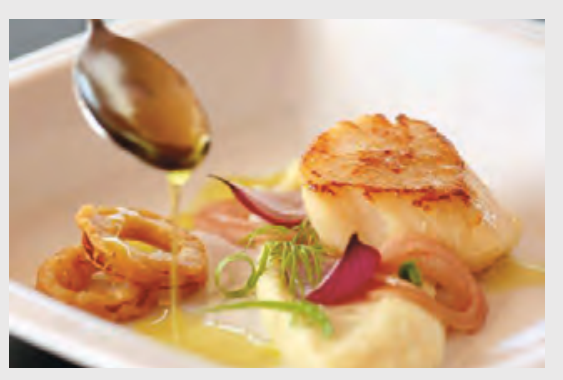

contribute to positive development of coastal and rural areas focusing on sustainable food and food culture, including the development of increased value creation in regional and local products.

The Council of Ministers funded the Nordic Cuisine Symposium held in November 2004, where, amongst other things, a manifesto for understanding the Nordic cuisine was drawn up. The Nordic Kitchen Manifesto's 10 points shall, as far as possible, be part of an understanding and visibility of Nordic food and the food culture.

The Council of Ministers encourages the Nordic member countries, the Nordic food producers and relevant players to promote initiatives for Nordic food, and to give the best possible framework conditions for the development of a diversity of ingredients and foods produced with respect for nature, the environment and consideration for animal health and welfare, as well as the development of Nordic gastronomy characterised by good taste, purity, simplicity, safety and ethics in production.

The Council of Ministers decides to launch future work in "New Nordic Food" that shall promote Nordic awareness of Nordic food and increase the common identity and quality of life as well as brand the Nordic Region internationally.

The Council of Ministers urges also other Councils of Ministers and policy areas under the Nordic Council of Ministers to participate in future work on Nordic food and food culture. 


\section{MEMBERS IN \\ THE STEERING GROUP}

DANMARK

FINLAND

ARøERNE

ISLAND

NORGE

NORGE

SVERIGE

ÅLAND

CHAIRMAN

NMR PROGRAMME MANAGER

NMR OBSERVER
Mads Fischer-Møller (Karen Lorenzen)

Fødevarepolitisk kontor,

Fødevareministeriet

Slotsholmsgade 12, 1216 København K

\section{Kirsi Viljanen (Marja Innanen)}

Jord- och skogsbruksministeriet

PB 30. FI-00023 STATSRÅDET, Helsinki

\section{Anni-Mari Syväniemi}

Centralförbundet för lantbruksproducenter och skogsägare

Simonkatu 6, 00100 Helsinki

Oyvindur av Skarði, Rådgivare

Ministry of Trade and Industry

Tinganes

F0-110 Tórshavn

Amalie Jessen (Peter Løvstrøm)

Departementet for Fiskeri, Fangst og Landbrug,

Postboks 1601. 3900 Nuuk

\section{Kristinn Hugason}

Ministry of Industries and Innovation

Skulagata 4, 150 Reykjavik

\section{Elisabeth Wilmann}

Fiskeri- og kystdepartementet

Grubbegt. 1, Postboks 8118 Dep, 0032 Oslo

Inger Solberg, Direktør

Innovasjon Norge

Pb. 448 Sentrum, Akersgata 13, 0104 Oslo

Linda Nöremark (Jens Heed, Christina Nordin)

Landsbygdsdepartementet

Fredsgatan 8, 10333 Stockholm

\section{Lena Brenner,}

Ålands landsbygdscentrum

AX-22150 Jomala, Åland

Magnus Gröntoft, sekr. i New Nordic Food

Jordbruksverket, 58186 Linköping

\section{Mads Wolff,}

Nordic Council of Ministers

Ved Stranden 18, 1061 Köpenhamn K $m f f m @ f v m . d k$

kirsi.viljanen@mmm.fi

Anni-Mari.Syvaniemi@mtk.fi

oyvindur@vmr.fo

AMALIE@nanoq.gl

Kristinn.hugason@anr.is

Elisabeth.wilmann@fkd.dep.no

Inger.Solberg@innovasjonnorge.no

linda.noremark@regeringskansliet.se

lena.brenner@landsbygd.ax

magnus.grontoft@jordbruksverket.se 


\section{MEMBERS IN \\ THE WORKING GROUP}

\begin{tabular}{|c|c|c|}
\hline DANMARK & $\begin{array}{l}\text { Emil Blauert } \\
\text { Madkulturen } \\
\text { Maglegårdsvej } 12 \\
4000 \text { Roskilde }\end{array}$ & emil@madkulturen.dk \\
\hline FINLAND & $\begin{array}{l}\text { Petri Koskela } \\
\text { Jord- och skogsbruksministeriet } \\
\text { PB 30, } 00023 \text { STATSRÅDET }\end{array}$ & petri.koskela@mmm.fi \\
\hline FÆRØERNE & $\begin{array}{l}\text { Gutti Winther } \\
\text { Undir Ryggi 13, } 100 \text { Tórshavn. } \\
\text { Faroe Islands }\end{array}$ & gutti_winther@hotmail.com \\
\hline ISLAND & $\begin{array}{l}\text { Sigrún Elsa Smáradóttir } \\
\text { Matis, Vínlandsleið 12, } 113 \text { Reykjavík }\end{array}$ & sigrun@matis.is \\
\hline $\begin{array}{l}\text { NORGE } \\
\text { ORDFÖRANDE }\end{array}$ & $\begin{array}{l}\text { Einar Risvik } \\
\text { Nofima } \\
\text { Osloveien 1, } 1430 \text { Ås }\end{array}$ & einar.risvik@matforsk.no \\
\hline SVERIGE & $\begin{array}{l}\text { Johanna Dahlin } \\
\text { Jordbruksdepartementet } \\
\text { Fredsgatan 8, } 10333 \text { Stockholm }\end{array}$ & johanna.dahlin@regeringskansliet.se \\
\hline $\begin{array}{l}\text { NMR } \\
\text { PROJECT MANAGER }\end{array}$ & $\begin{array}{l}\text { Magnus Gröntoft } \\
\text { Jordbruksverket } \\
58186 \text { Linköping }\end{array}$ & magnus.grontoft@jordbruksverket.se \\
\hline $\begin{array}{l}\text { NICE } \\
\text { OBSERVER }\end{array}$ & $\begin{array}{l}\text { Simen Strand Jørgensen } \\
\text { Stensberggt. 25, N-0170 Oslo }\end{array}$ & K.Vikebak@nordicinnovation.org \\
\hline $\begin{array}{l}\text { NORDENS HUS, } \\
\text { ISLAND }\end{array}$ & $\begin{array}{l}\text { Mads Holm } \\
\text { Sturlugötu 5, } 101 \text { Reykjavík, Island }\end{array}$ & madsholm@nordice.is \\
\hline
\end{tabular}




\section{ECONOMY}

During the program period 2010-2014 the main areas has been financed with the following approximate amount of money, transferred to DKK. Besides the Nordic Council of Ministers, the Swedish Foreign Ministry has made substantially contribution to the financing.

Many of the events has either been done in partnership with other organisations, or sponsored, but this is not included.

COMMUNICATION (CONF, SEMINARS, WEB, NEWSLETTERS, PRINTING, ETC.)

EVALUATION

FOOD AND CHILDREN

FOOD AND CREATIVE BUSINESS

FOOD AND CULTURE

FOOD FOR MANY

NORDEN AS A GASTRONOMIC REGION

NORDIC FOOD DIPLOMACY

NORDIC MASTER (HIGHER EDUCATION)

PROGRAM MANAGEMENT (PROJ.LEADER, ADM., STEERING- \& WORKING GROUP)

SEAWEED

SMALL AND MEDIUM SIZES ENTERPRISES

SUM.
4100000,00

60000,00

1800000,00

2200000,00

150000,00

900000,00

1500000,00

1700000,00

70000,00

4700000,00

350000,00

1000000,00

18530000,00 